School of Finance

University of St.Gallen

STYLIZED FACTS AND DYNAMIC MODELING OF HIGHFReQUency Data on Precious Metals

MASSIMILIANO CAPORIN

ANGELO RANALDO

GABRIEL G. VELO

WORKING PAPERS ON FinANCE No. 2013/18

SWISS INSTITUTE OF BANKING AND FINANCE (S/BF - HSG)

MAY 2013 


\title{
Stylized facts and dynamic modeling of high-frequency data on precious metals
}

\author{
Massimiliano Caporin* Angelo Ranaldo ${ }^{\dagger} \quad$ Gabriel G. Velo ${ }^{\ddagger}$ \\ May 8, 2013
}

\begin{abstract}
Taking advantage of a trades-and-quotes database, the main stylized facts and dynamic properties of a time series related to spot precious metals, that is, gold, silver, palladium, and platinum, are documented. The behavior of spot prices, returns, volume, and selected liquidity measures is analyzed. A clear evidence of periodic patterns matching the trading hours of the most active markets, London, Zurich, New York, as well as Asian markets, is found. The time series of spot returns have thus properties similar to those of traditional financial assets with fat tails, asymmetry, periodic behaviors in the conditional variances, and volatility clustering. The empirical analyzes show, as expected, that gold is the most liquid and less volatile asset, whereas palladium and platinum are traded less.
\end{abstract}

Keywords: precious metals, high-frequency data, liquidity measurement, intradaily periodicity.

JEL Classifications: C58, C22, C52, G10.

\footnotetext{
*Department of Economics and Management Marco Fanno, University of Padova; corresponding author: Via del Santo 22, Padova, Italy, Tel: +39 049/8274258. Fax: +39 049/8274211. Email: massimiliano. caporin@unipd.it.

${ }^{\dagger}$ University of St. Gallen, Swiss Institute of Banking and Finance, Rosenbergstrasse 52, St.Gallen, Switerland, angelo.ranaldo@unisg.ch.

${ }_{\ddagger}^{\ddagger}$ Department of Economics and Management Marco Fanno, University of Padova, Via del Santo 22, Padova, Italy,gabriel.velo@unipd.it.
} 


\section{Introduction}

In the last twenty years there has been a growing interest in high-frequency data. Access to these data sources leads to the development of studies and empirical research in several directions. From an economic point of view, research has focused on agent's behavior and market microstructure (price formation, asymmetric information, news and announcement impact). Within a statistical or quantitative framework, different authors have studied the features or stylized facts of high-frequency time series (prices, returns, volumes, liquidity, duration) and proposed appropriate modeling strategies. In the quantitative investment field, the empirical research leads to the development of quantitative trading rules. Finally, within a risk management perspective, we place the studies dealing with the development of daily variance estimators by means of high-frequency returns. ${ }^{1}$ Interest in high-frequency data began with the pioneering work on data collected by Olsen Associates (see Dacorogna et al., 2001), which focused on currencies and were then extended to other asset classes. With the development of IT tools, the high-frequency finance literature also gained access to book data, with further developments from both the theoretical and empirical points of view (see Parlour and Seppi, 2008).

However, only a few authors have discussed the properties of high-frequency data on precious metals. Cai et al. (2001) focus on 5-minute gold future returns. They study the periodicity in absolute returns and link its movements to macroeconomic announcements. Fleming et al. (2003) make use of realized volatility on several assets and determine the economic value of volatility timing. Their study includes 5-minute returns of gold futures contracts. Baillie et al. (2007) analyze the dynamic behavior of several daily and 5-minute commodity futures prices, including the gold future. Bannouh et al. (2009) work on corange computation (an estimator of the integrated covariance) with a trade dataset that includes the gold future. Finally, Khalifa et al. (2011) focus on volatility measurement and forecasting of several commodity future prices, including gold and silver. All of the aforementioned studies have a common element: They work on New York futures data. Moreover, to the best of our knowledge, gold has piqued the greatest amount of interest, whereas silver has only attracted limited attention. We support this by the larger amount of interest in gold, compared with other precious metals, and the perception of gold as a safe-haven investment.

Our work belongs to the strand of literature focusing on high-frequency data on precious metals. We differ from previous studies in many respects because of our unique database. First, we have access to high-frequency data about four different precious metals: gold, silver, palladium, and platinum. Second, our data are related to spot prices and not futures contracts. Therefore, the time-series behaviors might be different as a consequence of the different uses associated with spot and future contracts. To our knowledge, there is no literature on palladium, and platinum high-frequency data. Third, we have access to a brokerage house database that operates on a 24-hours basis. As a result, the movement we observe in high-frequency time series can be linked to the activity in different precious metals markets, including New York but also the European markets (London and Zurich) and the Asian markets. This is of relevant interest because previous

\footnotetext{
${ }^{1}$ Several references to the previous topics can be found in O'Hara (1997), Bauwens and Giot (2001), Dacorogna et al. (2001), Hasbrouck (2007), Engle and Russell (2009), Hautsch (2011), Schmidt (2011), Ye (2011), and Abergel et al. (2012), among others.
} 
works only focused on a specific market. Fourth, we differ from previous works because of our access to a trade-and-quotes dataset. From the trade side, we have trade prices, associated volumes, and order side (allowing us to precisely distinguish seller-initiated from buyer-initiated orders). On the quote side of the database, we have access to the limited order book up to ten levels, with prices and volumes, which makes feasible the evaluation of liquidity and market depth. Finally, the time frequency of the database is extremely high, with book updates reaching a 100-millisecond frequency. Because of the novelty of our database, the pure statistical analysis of high-frequency spot data on precious metals is per se interesting and relevant.

In this work, we focus on the stylized facts and dynamic properties of the precious metals data. We start from the most traditional time series, prices, and returns, and then focus on the volatility, preliminary measured from squared returns and then filtered with periodic components and GARCH-type models. We move later to volume time series and to two specific liquidity measures, the order flow, and the percentage quoted spread. These two quantities provide a first look at the information one might extract from a trade-and-quotes database on precious metals. The analyses reported here are, by construction, preliminary to further economic applications at both the univariate and multivariate level. Later studies will take advantage of the findings in the current paper. There are several areas in which our results might be useful: (1) in trading, because the dynamic properties we identify and the models we propose might be used to produce forecasts of prices and volumes, with potential extensions that include trade duration and liquidity as further covariates; (2) in risk management, as we provide some evidence on the volatility behavior and on its modeling, (3) in event studies, where the dynamic behavior of prices, returns, volume and liquidity might be correlated to scheduled and/or unanticipated announcements, and (4) in studies dealing with safe-haven effects, in which precious metals may represent refuge assets.

The time-series analyzed here are characterized by the presence of a periodic behavior in their levels and/or in the second-order moment. Such a finding is expected as we consider intradaily data. However, the periodic movement is associated with the trading activity of the main markets active in precious metals trading, which can be identified, for instance, with peaks in the volatility of the returns time series. This result has relevant affinities to the periodic behavior observed by Dacorogna et al. (1993) on the foreign exchange market. For each of the analyzed series, we suggest the use of a dynamic model for capturing the serial dependence in the mean and/or in the variance. The proposed specifications seem appropriate in the whitening of the analyzed time series and allow the development of research based on time-series forecasting.

This paper proceeds as follows: Section 2 describes the dataset and the variables of interest; Section 3 focuses on the stylized facts of prices, returns, volumes, and liquidity time series; Section 4 deals with dynamic models; and Section 5 concludes. 


\section{Database description, data handling, and the ana- lyzed quantities}

The database used in this study has been provided by ICAP through its EBS platform. EBS is the leading interdealer trading platform for currencies, and data provided by EBS have been already used in academic research (see, for instance, Berger et al., 2008 and Mancini et al., 2012). The database we access is equivalent to that adopted in Mancini et al. (2012) and includes more than fifty currencies and four precious metals. For all assets made available, the trades and quotes refer to spot prices. In this work we focus on the precious metals: gold (identified by the ticker XAU), silver (XAG), palladium (XPD), and platinum (XPT). We consider spot prices against the U.S. dollar and refer to one ounce (for instance, gold quotes are U.S. dollar per one gold ounce). The data we analyze span the period beginning with December 27, 2008 to November 30, 2010. The dataset includes the recorded trades coupled with the information on the active part of the contract, the traded volume, and the trade price. The presence of the maker and taker sides opens the door to the construction of the order flow. Notably, as observed by Mancini et al. (2012), trade direction data are known and do not need to be inferred by means of rules such as done by Lee and Ready (1991). Besides the trade data, the database includes the binding tradable bid and ask quotes, together with the related volume. In this case, the information is provided for the book up to the tenth level. However, here we present analyses based on the trade data and on the best bid and ask quotes. Moreover, we discuss the dynamic features of the data, comparing our findings to those of previous studies.

In the EBS database, data are recorded at a very high frequency (let us call them nanofrequency data, or NF data ${ }^{2}$ ). From December 27, 2008 to the end of August 2009, the observation frequency is 250 milliseconds; from the first of September 2009 to the end of the sample, the observation frequency increases to 100 milliseconds. ${ }^{3}$ As a result, new information is recorded by the system every 100/250 milliseconds if at least one of the following events takes place: an order is executed and/or a new quote is entered/deleted and/or a new volume is entered into the system at a quote already present in the system. The last case produces a new flash of the book because each flash includes the number of quotes in the market for each side/price together with the available volume. Table (1) reports the total number of trades (buyer/seller initiated) and quotes (by market side) by precious metals that are included in the database. We note that gold is the metal with the highest activity, both in terms of trades and quotes. Silver has less than one-third of the quotes of gold and is followed by platinum and then palladium. The last has less than a twentieth of gold quotes. Excluding gold, with about 185 thousand trades, the other precious metals have a similar number of trades.

Data are recorded on a GMT time scale, on a 24-hour basis, 7 days a week. As a result, there are quotes and trades executed from buyers/sellers located in different geographical areas. To the best of our knowledge, this study provides for the first time an analysis on precious metal trades jointly covering the most active world markets. Compared with the

\footnotetext{
${ }^{2}$ We thank Michael McAleer for suggesting the use of this name for our dataset.

${ }^{3}$ The 100-millisecond frequency begins August 28, 2009, but a few days in July 2009, likely the testing period, use the 100-millisecond frequency. Moreover, both frequencies (100 and 250 milliseconds) are present on July 21, 2009, and August 28, 2009. This finding does not affect our results because we aggregate data at lower frequencies.
} 


\begin{tabular}{ccccc}
\hline & XAU & XAG & XPD & XPT \\
Quotes bid & 184.254 .422 & 51.970 .220 & 8.649 .896 & 22.487 .653 \\
Quotes offer & 169.512 .628 & 48.992 .734 & 7.908 .232 & 23.365 .209 \\
Quotes total & 353.767 .050 & 100.962 .954 & 16.558 .128 & 45.852 .862 \\
Trades total & 184.929 & 27.638 & 21.428 & 27.357 \\
Outside trade Sunday & 385 & 8 & 54 & 38 \\
Outside trade Friday & 32 & 7 & 17 & 40 \\
Outside trade Saturday & 2 & 0 & 1 & 0 \\
Total outside trade & 419 & 15 & 72 & 78 \\
Traded volume (in 1000 oz) & 233.610 & 1.173 .425 & 165.580 & 170.140 \\
& & & & \\
\hline
\end{tabular}

Table 1: Number of quotes and trades

previous studies of Barkoulas et al. (1997), Baillie et al. (2007), and Khalifa et al. (2011), our analysis includes trading activity originating from Asian markets as well as the complete activity of European-based traders. Previous studies have focused on U.S.-based data, including local market activities, where the trades originated from both European and North American markets when trading hours overlapped. Therefore, the daily time coverage of our database is a distinctive feature of our contribution.

In the following analyses, we limit the trading period to five full days, ranging from 10 p.m. Sunday to 10 p.m. Friday, and we delete all trades and quotes outside this range. As shown in Table (1), the information excluded from the database is really of minor relevance. As expected, in absolute terms, the deleted information is higher for gold compared with the remaining metals. The procedure we adopt is similar to that employed for the analysis of currency data (see Andersen et al., 2003 and Berger et al., 2008, among others).

The database reports the precious metals prices expressed in U.S. Dollars per ounce, while the volume is expressed in multiples of the minimum tradable amount (MTA), which is fixed as follows: 1,000 ounces for Gold; 25,000 ounces for silver; and 500 ounces for palladium and platinum. As a consequence, physical volume time series of executed trades might be sensibly different across precious metals, both for the different trading activity, and for the different sizes of the MTA. In fact, as shown in Table (1), the traded volume is the highest for silver (more than 1.1 billion of traded ounces) and lower for gold, platinum, and palladium. Moreover, we observe that the trade size is the highest for silver (about 42.5 MTA per executed trade) and the lowest for gold (less than 1.3 MTA per trade). Platinum and palladium generally have a trade size larger than gold, 6.2 and 7.7 MTA per trade, respectively.

\subsection{The variables of interest}

From the whole database, we extract the relevant NF data, which are analyzed and aggregated in different ways, depending on the quantities of interest. We first recover prices and volume from the recorded trades. Within a given time interval, the price is defined as the price of the last trade recorded in the interval. If no trades are present, we replicate the previous interval price. Returns are then defined using the transaction prices. Volume is equal to the sum of the amount exchanged in the trades recorded within a 
given time interval, regardless of the trade side (buyer/seller initiated). If a given time interval does not include trades, the volume is equal to zero. In the following, we denote the daily time index by $t$, the intradaily period by $i=1,2, \ldots N$ with $N$ denoting the number of intradaily periods in day $t$. Intradaily periods have length equal to $1 / N$ days, or $1440 / N$ minutes. Furthermore, we indicate the end of period $i$ of day $t$ as $(i, t)$, and we use the following notation. The intradaily price sequence is denoted by $p_{i, t}$, while the intradaily volume time series is given as $v_{i, t}$; the intradaily log-returns are defined as $r_{i, t}=\log \left(p_{i, t}\right)-\log \left(p_{i-1, t}\right), \quad i=2,3, \ldots N$, and $r_{1, t}=\log \left(p_{1, t}\right)-\log \left(p_{N, t-1}\right) .{ }^{4}$

Finally, we filter quote data from outliers, most likely associated to errors in matching the asset identifier and the price. ${ }^{5}$ We choose a simple approach, excluding all quotes with a value $20 \%$ higher (for buyer initiated) or lower (for seller initiated) than the average trade price of the day.

The financial economics and econometrics literature includes several liquidity measures (see the survey by Gabrielsen et al., 2011). In this study, we focus on specific quantities that are exploiting part of the informative content of the database. We restrict our attention to the order flow, $O F_{i, t}$, and to the percentage quoted spread, $Q S_{i, t}$, defined as follows.

- Order flow: Let $h$ denote the execution time of an order, and denote by $x_{h}$ the trade direction of the order recorded at time $h$; the trade direction is equal to -1 for seller-initiated trades and +1 for buyer-initiated trades; the order flow for interval $i$ of day $t$ is equal to $O F_{i, t}=\sum_{(i-1, t)<j \leq(i, t)} x_{h}$; by definition, the order flow assumes only integer values and can be either positive or negative. ${ }^{6}$

- Percentage quoted spread: Let $A_{i, t}$ and $B_{i, t}$ denote the best ask and bid Prices available in the book at the end of period $i$ at day $t$; we define the midquote as $M_{i, t}=0.5\left(A_{i, t}+B_{i, t}\right)$ and the percentage quoted spread as $Q S_{i, t}=\frac{A_{i, t}-B_{i, t}}{M_{i, t}}$.

The percentage quoted spread we consider is a standardized quantity allowing a direct comparison across precious metals because it is not dependent on the price of the MTA.

We study time series of the previously defined quantities at different frequencies. We analyze returns and volumes at the 5- and 60-minutes frequencies, where the first case is only considered for gold and silver, due to the higher number of trades recorded for these two metals. We inspect liquidity measures at the 15- and 60-minutes frequencies. When the frequency is set at 60 minutes, the dataset contains 11,880 observations. The number increases to 47,520 when considering the 15-minutes frequency and to 142,560 at the 5-minute frequency. We do not consider higher frequencies because of the large number of zeros that would be observed in the time series of interest (see the following

\footnotetext{
${ }^{4}$ When computing the first return of the week on Sunday evening, we compute the returns with respect to the last price observed on Friday evening. In addition, we have only removed a few bank holidays (New Year's Day [2009 and 2010], Good Friday [2009 and 2010], and Christmas Day [2009]). Two days are not included in the database because of missing data: They are May 17, 2010, and May 18, 2010 (a Monday and a Tuesday).

${ }^{5}$ See, for example, Brownlees and Gallo (2006) for high-frequency data-cleaning techniques.

${ }^{6}$ Note that different orders (at different prices) might be recorded at the same time; these must all be considered in the construction of the order flow.
} 
section for further details).

\section{Stylized facts of precious metals price, return, vol- ume, and liquidity}

In this section, we focus on those features that characterize the time series of returns, volume, and liquidity of our four precious metals. In particular, we evaluate the serial correlation properties of the first- and second-order moments, the distribution, and the existence of periodic patterns.

\subsection{Prices and returns}

The prices of precious metals follow an upward-sloping behavior in the analyzed sample (see Figure (1)). This might depend on the so-called safe-haven effect, that is, the outflow from risky financial assets toward the precious metals, which are perceived as safer investments during periods of high uncertainty. We first analyze the series to determine their integration properties. ADF tests confirm that the log-prices follow a Random Walk model and suggest focusing on returns time series. ${ }^{7}$

Returns time series have patterns similar to those of equity returns and are characterized by volatility clustering, as well as the presence of extreme movements (see Figure (1)). The descriptive analysis, reported in Table (2), suggests that gold returns are less volatile than other precious metals, at both the 5 - and 60 -minutes frequencies. This finding is also matched with an inverse relation in average returns, the lowest being that of gold. We support that by the larger interest for gold compared with silver, platinum, and palladium, which might lead to higher efficiency for this precious metal. In turn, this leads to smaller risk and lower returns. The kurtosis is similar across metals at the hourly frequency, whereas at the 5-minute level, gold has a much smaller kurtosis than silver. Nevertheless, as we discuss in the following paragraph, this might be influenced by the large amount of zeros in the silver time series. Finally, we observe that the skewness is negative for silver, palladium, and platinum at the 60-minute frequency, a behavior similar to that observed in equities. However, gold returns have positive skewness. Considering the range analyzed in this paper, 2009 and 2010, the trend of price time series, and the considerable interest in gold, this result is unsurprising. It suggests that, in the considered period, trades on gold led to a consistent increase in the price of gold over time. When focusing on the returns ACF, we have statistically significant positive correlations for the first lag at the 5-minute level, whereas at the 60-minutes frequency, the first ACF becomes negative but is still statistically significant. The presence of negative correlation is expected on high-frequency data and might have different explanations: bid-ask bounce (Bollerslev and Bomowitz, 1993), order imbalance (Flood, 1994), and/or trade behavior (Engle and Russell, 2009, among others). Such serial correlation has to be taken into account when developing models for the returns time series.

Regarding the trade activity, the proportion of zeros in a given interval of time can be seen as a measure of market liquidity (or illiquidity). For example, Bekaert et al.

\footnotetext{
${ }^{7} \mathrm{ADF}$ tests are available upon request.
} 


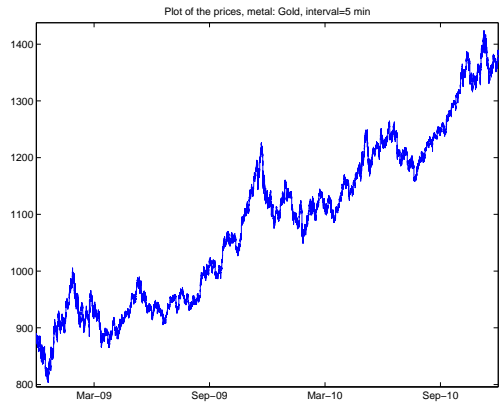

(a) XAU

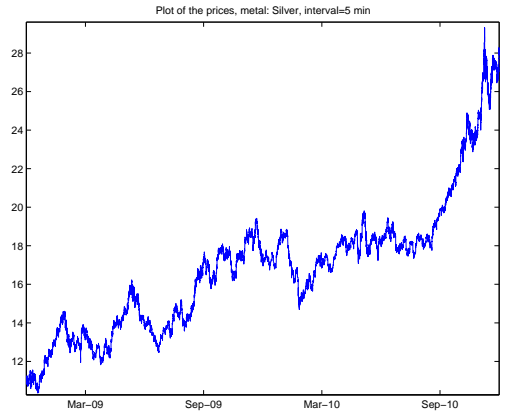

(c) XAG

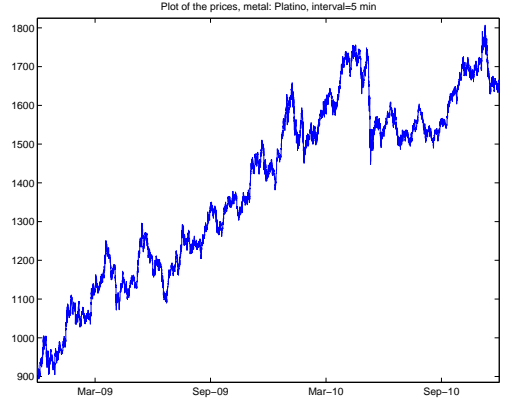

(e) XPT

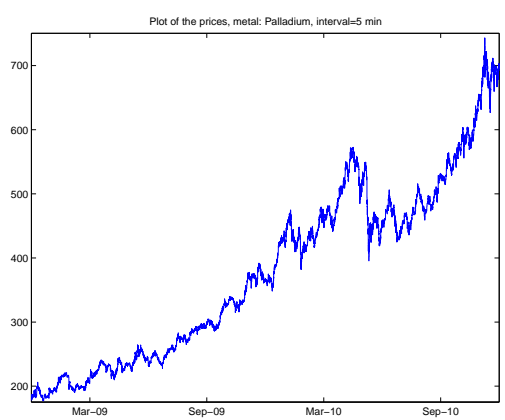

(g) XPD

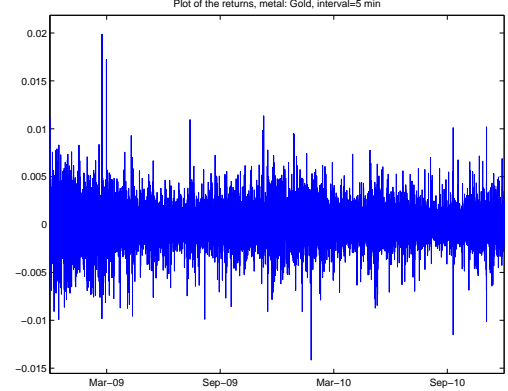

(b) XAU

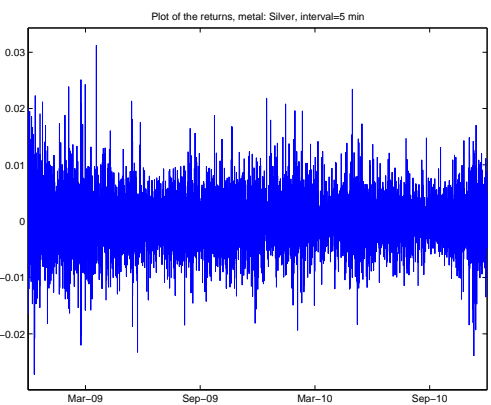

(d) XAG

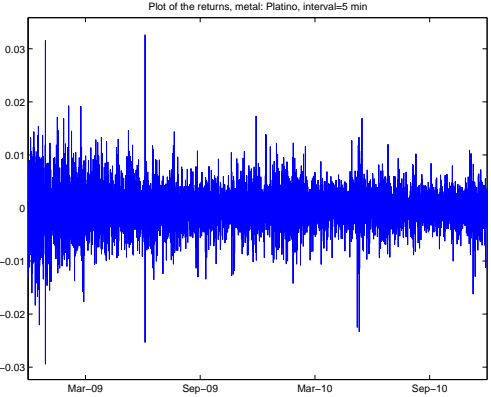

(f) XPT

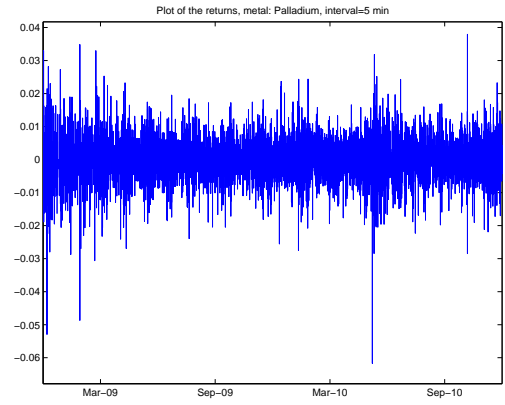

(h) XPD

Figure 1: Prices and return plot 


\begin{tabular}{|c|c|c|c|c|c|c|c|c|c|c|c|c|}
\hline \multirow[b]{3}{*}{ Frequency } & \multicolumn{6}{|c|}{ Return } & \multicolumn{6}{|c|}{ Volume } \\
\hline & $\mathrm{XAU}$ & XAU & XAG & $\mathrm{XAG}$ & XPD & XPT & $\mathrm{XAU}$ & XAU & XAG & XAG & XPD & XPT \\
\hline & 5 & 60 & 5 & 60 & 60 & 60 & 5 & 60 & 5 & 60 & 60 & 60 \\
\hline Mean & 0.0003 & 0.0038 & 0.0006 & 0.0079 & 0.0115 & 0.0049 & 1.6387 & 19.664 & 8.2311 & 98.773 & 13.937 & 14.321 \\
\hline Median & 0.0000 & 0.0000 & 0.0000 & 0.0000 & 0.0000 & 0.0000 & 0.0000 & 12 & 0.0000 & 25 & 0.0000 & 5 \\
\hline Std & 0.0763 & 0.2582 & 0.1240 & 0.4499 & 0.5205 & 0.3369 & 3.5198 & 25.574 & 30.515 & 173.15 & 30.221 & 24.502 \\
\hline Kurtosis & 30.09 & 15.643 & 62.863 & 15.361 & 17.266 & 10.577 & 51.952 & 18.375 & 100.90 & 22.274 & 41.431 & 30.443 \\
\hline Skewness & 0.1031 & 0.3347 & 0.5407 & -0.059 & -0.569 & -0.305 & 5.2819 & 3.0949 & 7.3061 & 3.5571 & 4.9074 & 3.9287 \\
\hline $5 \%$ quant. & -0.104 & -0.385 & -0.039 & -0.701 & -0.795 & -0.540 & 0.0000 & 0.0000 & 0.0000 & 0.0000 & 0.0000 & 0.0000 \\
\hline $50 \%$ quant. & 0.0000 & 0.0000 & 0.0000 & 0.0000 & 0.0000 & 0.0000 & 0.0000 & 12 & 0.0000 & 25 & 0.0000 & 5 \\
\hline $95 \%$ quant. & 0.1070 & 0.3841 & 0.0545 & 0.7305 & 0.8564 & 0.5458 & 8 & 68 & 50 & 450 & 65 & 60 \\
\hline n. of 0 & 83592 & 1772 & 126534 & 5513 & 7063 & 5572 & 79842 & 1580 & 125250 & 5268 & 6354 & 5087 \\
\hline
\end{tabular}

Table 2: Descriptive analysis: Returns and Volume across metals

(2007) examine the impact of liquidity, proxied by the proportion of zero daily firm returns averaged over the month in emerging equity markets, on expected returns. Table (2) highlights that the number of zero returns is sensibly high. The percentage of zeros on hourly data is close to $45 \%$ for silver and platinum, peaks at $60 \%$ for palladium, and is minimum, about 15\%, for gold. We report 5-minute descriptive statistics for gold and silver, the two most traded metals, showing that the number of zeros increases to $60 \%$ for gold and $90 \%$ for silver. The existence of such a large number of zeros makes the analyzes on those time series challenging. In fact, on the one side, the zeros could make the identification of dynamic properties more difficult, but on the other side, the occurrence of zeros during the day, and their potential concentration during specific time ranges, is informative. As reported in Figure (2), zeros are generally present with a very high-frequency during specific hours of the day, in particular at the 60 -minute frequency. ${ }^{8}$ Following previous works, this means that those intervals are the most illiquid times during the 24-hour trading day. As we expected, they coincide with the closure of the main markets. This finding might suggest the possible presence of a periodic pattern in the return means, which is, however, not present. ${ }^{9}$

Precious metals returns provide relevant information on the evolution of the conditional variances. The analysis of squared returns shows evidence of heteroskedasticty, with a clear periodic behavior (see the upper panel of Figure (3) for the gold time series). The pattern is more regular in the gold and silver cases compared to palladium and platinum. This is, however, an expected result and is due to the large number of zeros present in the last two time series. Similar patterns can be identified at the 5-minute frequency for gold and silver. Notably, the oscillations of the ACF have a period of one day (24 hours). Confirmation of the periodic evolution of the intradaily variance is given in Figure (4), where we report, for the gold series, the hourly average squared return, computed as $\bar{r}_{i}^{2}=\frac{1}{T} \sum_{t=1}^{T} r_{i, t}^{2}$. The graph shows evidence, within the day, of three relevant periods, which we can associate with the trading activities in different geographical areas. The first increase in volatility corresponds to the Asian markets' trading activity. The average squared returns then decrease until the opening of European markets. The increase peaks around 10 GMT and then again begins to decrease until 13 GMT. The average returns

${ }^{8}$ Figure (2) refers to the gold. Similar patterns are present for the other metals, with the largest frequency of zeros for palladium and platinum. Graphs are available upon request.

${ }^{9}$ Graphical analyses supporting this claim are available upon request. 


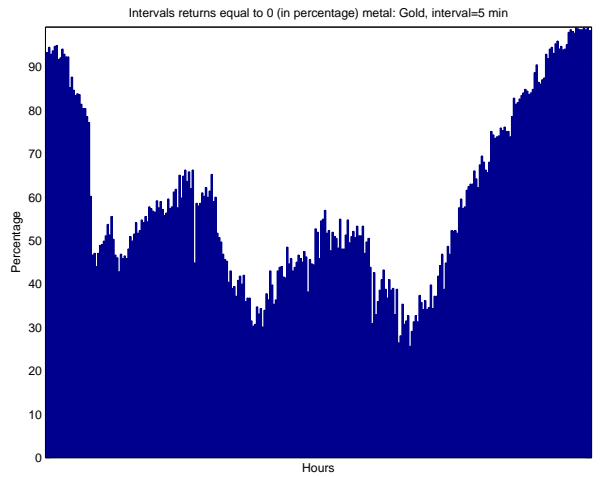

(a) $5 \mathrm{~min}$

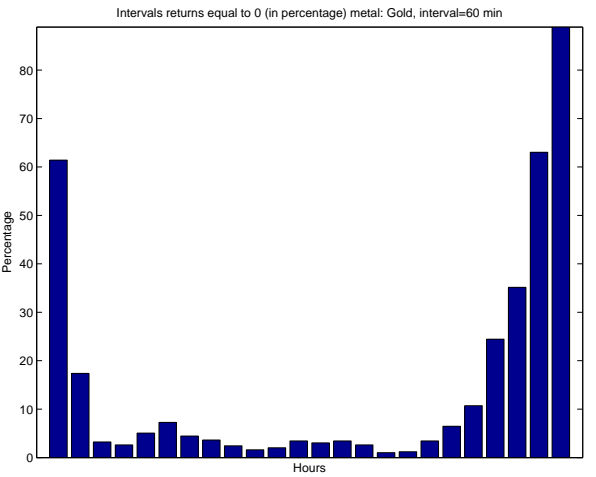

(b) $60 \mathrm{~min}$

Figure 2: Occurrence of zeros during the trading day (5 min and hourly series) - XAU

sharply increase when American markets open and peak when American markets are active and European markets are closing, around 16 GMT. The same behavior is observed in the other three metals.

The periodic behavior of the intradaily volatility might be estimated and filtered out from the returns time series following different approaches. ${ }^{10}$ Among the possible methods, we mention those of Andersen and Bollerslev (1997a) and Boudt et al. (2011). The first approach assumes that returns follow a multiplicative model

$$
r_{i, t}=s_{i, t} \sigma_{i, t} \eta_{i, t},
$$

where $s_{i, t}$ is a periodic deterministic component, $\sigma_{i, t}$ is a GARCH-type variance, and $\eta_{i, t}$ is a standardized innovation with unit variance. The periodic term $s_{i, t}$ is estimated by means of a parametric regression model. The work of Boudt et al. (2011), despite using the same multiplicative model for the return, differs from the parametric approach of Andersen and Bollerslev (1997a) in two elements: First, $\sigma_{i, t}$ is an average volatility factor kept constant in a local window around $r_{i, t}$, and second, the deterministic component $s_{i, t}$ is estimated by means of a nonparametric approach. The estimation of the periodic component $s_{i, t}$ in Andersen and Bollerlev (1997a) considers a regression on harmonics of the log-transformed return series (in deviations from their unconditional mean). However, the large number of zeros present in the precious metal returns makes the method inappropriate for the analyzes of returns. Nevertheless, we consider a variant of the Andersen and Bollerslev (1997a) approach when dealing with volumes.

Boudt et al. (2011) base the estimation of the periodic component in the intraday volatility on the standardized high-frequency return $\left(\bar{r}_{i, t}\right)$, where the standardization factor is given by the square root of the normalized realized bipower variation of BarndorffNielsen and Sheppard (2004). By construction, $\bar{r}_{i, t}$ is distributed with mean zero and variance equal to the squared periodicity factor. Boudt et al. (2011) propose to estimate the periodic component using a nonparametric estimator of the scale of the standardized returns $\bar{r}_{i, t}$. They suggest three possible estimators: (1) the nonparametric periodicity

\footnotetext{
${ }^{10}$ The same procedures to estimate periodic deterministic components have been implemented in different areas. For example, Caporin and Preś (2012) model and forecast wind speed intensity and Caporin and Preś (2011) forecast temperature indices density.
} 

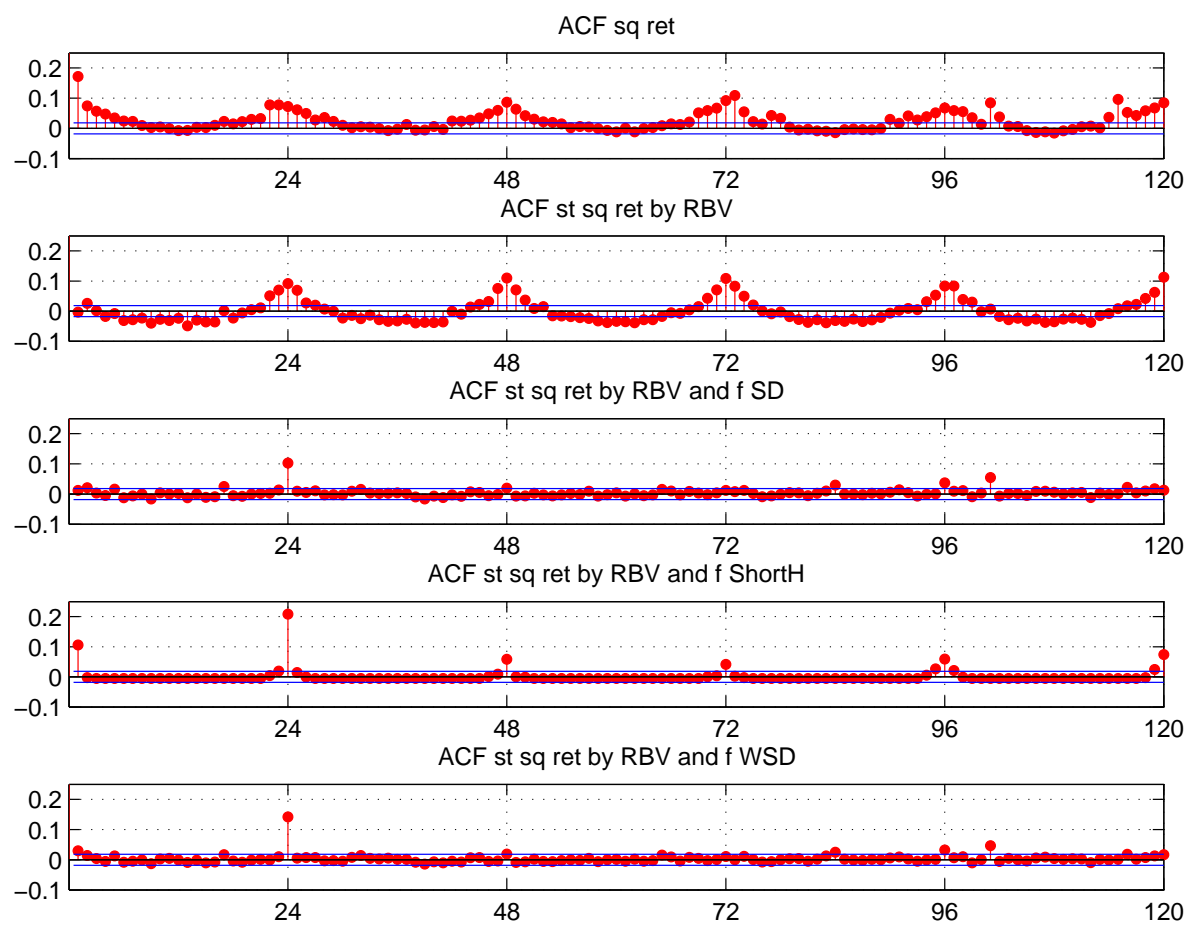

Figure 3: ACF of the squared standardized returns - XAU

estimator $S D$ presented by Taylor and Xu (1997), which is based on the standard deviation of returns belonging to a local window, (2) the Short $H$ estimator for the periodicity factor, based on the Shortest Half scale estimator (see Boudt et al., 2011, for details), and (3) the Weighted Standard Deviation estimator, WSD, of Boudt et al. (2011). Note that the second and third estimators are also robust to the presence of price jumps. Given the nonparametric estimators of the periodic component, and similar to the approach of Andersen and Bollerslev (1997a), it is possible to recover the standardized return series.

Figure (4) displays the estimated periodic component for the hourly return series of gold with the three nonparametric methods presented by Boudt et al. (2011). The plot presents a behavior similar to the average squared returns. However, the ACF of the squared returns standardized series $\left(r_{i, t} / s_{i, t}\right)$ (see Figure $(3)$ ), show evidence of some residual periodic behavior. This finding is not influenced by the estimator adopted to capture the periodic behavior of squared returns. As a consequence, the nonparametric methods of Boudt et al. (2011) are not able to completely capture the periodic evolution characterizing the volatility of precious metals returns. This result suggests the possible presence of a stochastic behavior in the periodic component, which might be captured within an appropriate time-series framework. In the following section, we propose a parametric model that captures both the periodic evolution and the serial correlation of squared returns.

\subsection{Volume}

The volume time series are characterized by a percentage of zeros comparable to the returns time series. Note that volume and returns do not necessarily have the same oc- 


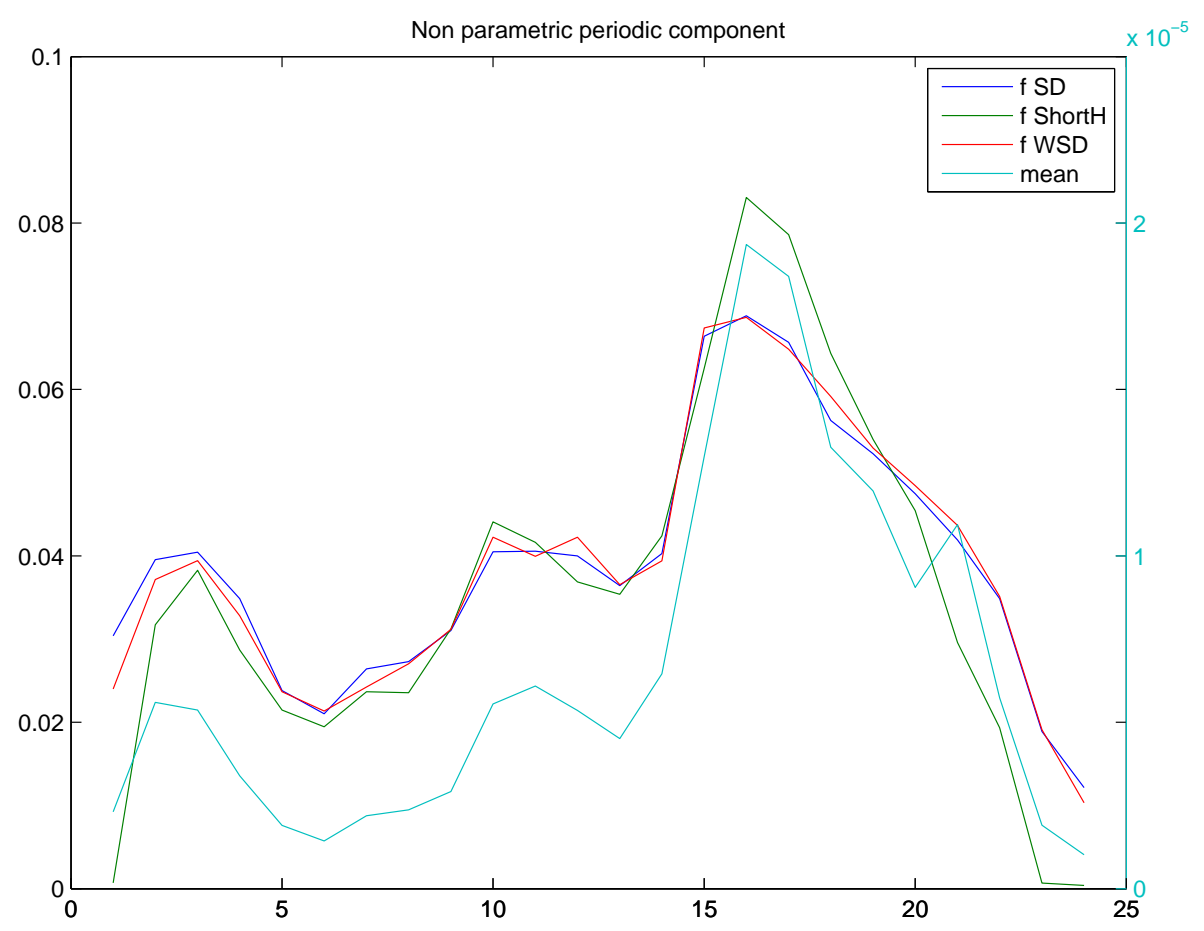

Figure 4: Estimated periodic component, parametric and non parametric approaches $\mathrm{XAU}$

currence of zeros as trades could be executed at the same price over consecutive intradaily periods. Table (2) presents descriptive analysis of the volume data, measured in numbers of MTA. We observe that the average volume is the highest for silver, at both the 5and 60-minute frequencies. Moreover, when we recast the MTAs in ounces, we highlight that gold has the lowest average volume at the 60-minute frequency. This is further confirmed by the volume quantiles (see Table (2)). The volume time series show evidence of a strong periodic pattern: The correlograms are characterized by a cyclical behavior, and the intradaily volume averages, $\bar{v}_{i}=\frac{1}{T} \sum_{t=1}^{T} v_{i, t}$, are higher during the opening hours of the most active precious metals markets. The increases in the volume level has a timing comparable to the increase in squared returns observed in Figure (4).

Similarly to the volatility, the periodic behavior of volume time series might be deterministic, stochastic, or a mixture of both deterministic and stochastic elements. Among the different approaches that are available to filter the periodic component from volume time series, we mention the use of seasonal adjustment methods, which can be based on moving averages or regression approaches and might be either multiplicative or additive. Multiplicative approaches are inappropriate given the large number of zeros, but additive methods might be more suitable. As a first analysis of volume, we propose the use of regression methods based on harmonics. We assume that the volume mean is given as follows (the time index evolves at an intradaily frequency):

$$
v_{t}=\alpha+\sum_{i=1}^{p} \delta_{i} t^{i}+\sum_{j=1}^{q}\left(\gamma_{j} \cos \left(\frac{2 \pi j t}{24}\right)+\phi_{j} \sin \left(\frac{2 \pi j t}{24}\right)\right)+\zeta_{t} .
$$

The periodic mean component is composed by a constant, a polynomial trend, and a 


\begin{tabular}{|c|c|c|c|c|c|c|c|c|c|c|c|c|}
\hline \multirow[b]{3}{*}{ Frequency } & \multicolumn{6}{|c|}{ Order Flow } & \multicolumn{6}{|c|}{ Quoted Spread } \\
\hline & $\mathrm{XAU}$ & XAU & XAG & XAG & XPD & XPT & XAU & $\mathrm{XAU}$ & XAG & XAG & XPD & XPT \\
\hline & 15 & 60 & 15 & 60 & 60 & 60 & 15 & 60 & 15 & 60 & 60 & 60 \\
\hline Mean & -0.174 & -0.699 & 0.0007 & 0.0030 & 0.1084 & 0.1733 & 0.0013 & 0.0012 & 0.0035 & 0.0034 & 0.0098 & 0.0052 \\
\hline Median & 0.0000 & 0.0000 & 0.0000 & 0.0000 & 0.0000 & 0.0000 & 0.0005 & 0.0006 & 0.0024 & 0.0025 & 0.0073 & 0.0038 \\
\hline Std & 3.7337 & 9.0484 & 1.0721 & 2.3514 & 2.2681 & 2.5741 & 0.0049 & 0.0042 & 0.0045 & 0.0039 & 0.0080 & 0.0055 \\
\hline Kurtosis & 22.350 & 15.720 & 57.206 & 18.481 & 20.964 & 21.106 & 1084.5 & 1553.0 & 245.13 & 85.934 & 29.615 & 115.47 \\
\hline Skewness & -0.342 & -0.547 & -1.048 & -0.093 & -0.369 & 0.7425 & 26.257 & 30.551 & 10.422 & 7.0002 & 3.8557 & 7.75 \\
\hline $5 \%$ quant. & -6 & -14 & -1 & -4 & -3 & -3 & 0.0003 & 0.0003 & 0.0010 & 0.0010 & 0.0036 & 0.0016 \\
\hline $50 \%$ quant. & 0 & 0 & 0 & 0 & 0 & 0 & 0.0005 & 0.0006 & 0.0024 & 0.0025 & 0.0073 & 0.0038 \\
\hline $95 \%$ quant. & 5 & 12 & 1 & 4 & 3 & 4 & 0.0040 & 0.0035 & 0.0089 & 0.0083 & 0.0242 & 0.0126 \\
\hline n. of 0 & 18424 & 2305 & 35787 & 5937 & 6852 & 5737 & 0.0000 & 0.0000 & 0.0000 & 0.0000 & 0.0000 & 0.0000 \\
\hline
\end{tabular}

Table 3: Descriptive analysis: OF and QS across metals

combination of harmonics that capture the intradaily periodic behavior. The use of harmonics makes the estimation of periodic components similar to that adopted by Andersen and Bollerslev (1997a) for the volatility. We estimate the parameters with ordinary least squares (OLS) using robust standard errors due to the possible presence of serial correlation and heteroskedasticity in the innovations. We note that the regression provides an expected hourly volume replicating the periodic behavior, but residuals are still characterized by a strong periodic evolution. Moreover, the slow decay of both the volume $\mathrm{ACF}$ and the volume residuals ACF might suggest the presence of long memory. ${ }^{11}$ In the next section, we consider time-series models that capture both the periodic intradaily dynamics and the behavior of the volume.

\subsection{Liquidity: Order flow and percentage quoted spread}

Moving to the liquidity measures, we first point out a relevant difference between order flow (OF) and percentage quoted spread (PQS): OF has a number of zeros comparable to those observed for returns and volume (see Table (3)), while the PQS time series does not have zeros. This is a consequence of the different NF data used to evaluate the two time series. In fact, OF comes from trade data, whereas PQS depends on book-level data. OF time series of gold shows evidence of much larger variability, compared with the other precious metals. This is a consequence of gold attracting the largest number of trades. Notably, the OF is, on average, negative for gold and positive for silver, platinum, and palladium.

The OF time series are negatively skewed (with the exception of platinum) and highly leptokurtic (due to the overconcentration around the mean; see the quantiles reported in Table (3). The PQS time series have similar unconditional behavior at the 15- and 60-minute frequencies (see Table (3)). This result is a by-product of the methodology adopted to compute these quantities, which are determined as intradaily periods averages. As expected, the spreads are on average smaller for gold and higher for platinum and palladium. The dispersion is minimum for silver and maximum for palladium. The

\footnotetext{
${ }^{11}$ The ACF of the residuals and the estimated periodic component for the gold series are available in the appendix.
} 
PQS series show evidence of positive asymmetry and of extremely long upper tails (see the quantiles reported in Table (3)): For Gold at the 15-minute frequency, the average spread between best bid and ask quotes is around 13 basis points, whereas the upper $99 \%$ quantile of PQS reaches the 150 basis points; large values are observed for palladium, where the average spread is close to 100 basis points but peaks at more than 425 basis points at the $99 \%$ quantile. Such large values of the PQS depend on the activity in the EBS platform, which further depends on the timing of the day. In fact, PQS time series have a clear intradaily pattern, with the largest values observed between the closing of American markets and the opening of Asian markets. This pattern is observed in the average hourly PQS of gold, $\overline{Q S} S_{i}=\frac{1}{T} \sum_{t=1}^{T} Q S_{i, t}$, and the ACF of the PQS time series. ${ }^{12}$

The OF time series do not show peculiar periodic behaviors in their mean, even if there is a clear evidence of serial correlation. As a further descriptive analysis, we also evaluate the serial correlation and periodic behavior of the squared order flow, which can be considered a proxy of volatility. In fact, an increase in the order flow, regardless of the sign, shows evidence of an increase in trading activity in the market in one specific direction (either an increase in seller- or buyer-initiated trades). The squared OF has intradaily patterns similar to the squared returns, with a clear increase during the opening hours of the most active precious metals markets.

The estimation of the periodic behavior of OF and PQS might follow the same approaches outlined for the returns volatility and the volume. When those approaches are applied to liquidity measures, the outcome suggests a presence of a periodic behavior largely, but not completely, captured by a deterministic approach. We thus apply in the following models whose aim is to estimate both the deterministic and the stochastic behavior of the series.

\section{Dynamic modeling of precious metals time series}

The previous section shows that precious metals time series are characterized by periodic behaviors. Those patterns are generally captured a priori, before the implementation of dynamic models of the ARMA and GARCH families, which are used to describe the dynamic evolution of high-frequency time series. ${ }^{13}$ However, the use of alternative methodologies for filtering periodic patterns leads to standardized series still demonstrating periodic components. Therefore, the use of two-stage estimation methods might not be appropriate for precious metals time series and calls for time-series models capturing both the nonperiodic dynamic and the periodic behavior. The literature has proposed several models starting with the use of Seasonal ARMA models, with an appropriate selection of the period, up to the models with periodic long memory in the mean (Gray et al., 1988, and Woodward et al., 1998). Moreover, Bollerslev and Ghysels (1996), Guegan (2000), and Bordignon et al. (2007, 2009) propose GARCH-type models with periodic coefficients and periodic long memory. Nevertheless, the periodic behavior and the nonperiodic dynamic can be captured resorting to models in which the ARMA- and

\footnotetext{
${ }^{12}$ Similar patterns are present for silver, palladium, and platinum. Figures are included in the appendix.

${ }^{13}$ Two-step approaches are computationally simple but imply a loss of efficiency compared with models where periodic patterns are estimated together with the parameters driving the series dynamic.
} 


\begin{tabular}{|c|c|c|c|c|c|c|c|c|c|c|c|}
\hline $\begin{array}{c}\mu \\
-1.4 e-09 \\
(2.2 e-05)\end{array}$ & $\begin{array}{c}\phi_{1} \\
-0.038^{\mathbf{b}} \\
(0.019)\end{array}$ & $\begin{array}{c}\omega \\
-0.241 \\
(0.383)\end{array}$ & $\begin{array}{c}\theta_{1} \\
0.123^{\mathbf{a}} \\
(0.025)\end{array}$ & $\begin{array}{c}\theta_{2} \\
0.138^{\mathbf{b}} \\
(0.055)\end{array}$ & $\begin{array}{c}\theta_{3} \\
0.078 \\
(0.053)\end{array}$ & $\begin{array}{c}\theta_{6} \\
-0.009 \\
(0.022)\end{array}$ & $\begin{array}{c}\theta_{12} \\
-0.016^{\mathbf{c}} \\
(0.008)\end{array}$ & $\begin{array}{c}\theta_{24} \\
0.154^{\mathrm{a}} \\
(0.042)\end{array}$ & $\begin{array}{c}\beta_{1} \\
0.007 \\
(0.034)\end{array}$ & $\begin{array}{c}\beta_{2} \\
-0.012^{\mathrm{c}} \\
(0.007)\end{array}$ & $\begin{array}{c}\beta_{3} \\
0.233^{\mathrm{a}} \\
(0.058)\end{array}$ \\
\hline $\begin{array}{c}\beta_{6} \\
0.190 \\
(0.126)\end{array}$ & $\begin{array}{c}\beta_{12} \\
0.166^{\mathbf{a}} \\
(0.051)\end{array}$ & $\begin{array}{c}\beta_{24} \\
0.390^{\mathrm{a}} \\
(0.091)\end{array}$ & $\begin{array}{c}\gamma_{1} \\
-0.516^{\mathbf{a}} \\
(0.130)\end{array}$ & $\begin{array}{c}\phi_{1} \\
-0.372^{\mathbf{a}} \\
(0.087)\end{array}$ & $\begin{array}{c}\gamma_{2} \\
-0.123 \\
(0.105)\end{array}$ & $\begin{array}{c}\phi_{2} \\
0.253^{\mathbf{a}} \\
(0.049)\end{array}$ & $\begin{array}{c}\gamma_{3} \\
-0.177^{\mathbf{b}} \\
(0.090)\end{array}$ & $\begin{array}{c}\phi_{3} \\
0.350^{\mathbf{a}} \\
(0.048)\end{array}$ & $\begin{array}{c}\gamma_{4} \\
-0.199^{\mathrm{a}} \\
(0.054)\end{array}$ & $\begin{array}{c}\phi_{4} \\
-0.014 \\
(0.024)\end{array}$ & $\begin{array}{c}\gamma_{5} \\
-0.251^{\mathbf{a}} \\
(0.046)\end{array}$ \\
\hline $\begin{array}{c}\phi_{5} \\
0.140^{\mathbf{a}} \\
(0.039)\end{array}$ & & & & & & & & & & & $\begin{array}{c}L L F \\
56787.14\end{array}$ \\
\hline $\begin{array}{c}\mu \\
-1.4 e-09 \\
(2.2 e-05)\end{array}$ & $\begin{array}{c}\phi_{1} \\
-0.038^{\mathbf{b}} \\
(0.019)\end{array}$ & $\begin{array}{c}\omega \\
-0.107 \\
(0.067)\end{array}$ & $\begin{array}{c}\theta_{1} \\
0.139^{\mathbf{a}} \\
(0.034)\end{array}$ & $\begin{array}{c}\theta_{2} \\
-\end{array}$ & $\begin{array}{c}\theta_{3} \\
0.097^{\mathbf{c}} \\
(0.056)\end{array}$ & $\begin{array}{c}\theta_{6} \\
-0.107^{\mathbf{b}} \\
(0.045)\end{array}$ & $\begin{array}{c}\theta_{12} \\
0.054 \\
(0.121)\end{array}$ & $\begin{array}{c}\theta_{24} \\
0.051 \\
(0.193)\end{array}$ & $\begin{array}{c}\beta_{1} \\
0.625^{\mathrm{a}} \\
(0.061)\end{array}$ & $\begin{array}{c}\beta_{2} \\
-\end{array}$ & $\begin{array}{c}\beta_{3} \\
-0.243^{\mathrm{b}} \\
(0.099)\end{array}$ \\
\hline $\begin{array}{c}\beta_{6} \\
0.658^{\mathrm{a}} \\
(0.232)\end{array}$ & $\begin{array}{c}\beta_{12} \\
-0.779^{\mathbf{c}} \\
(0.416)\end{array}$ & $\begin{array}{c}\beta_{24} \\
0.728 \\
(0.526)\end{array}$ & $\begin{array}{c}\gamma_{1} \\
-0.071^{\mathbf{b}} \\
(0.034)\end{array}$ & $\begin{array}{c}\phi_{1} \\
-0.138^{\mathbf{c}} \\
(0.079)\end{array}$ & $\begin{array}{c}\gamma_{2} \\
-0.048^{\mathbf{a}} \\
(0.014)\end{array}$ & $\begin{array}{c}\phi_{2} \\
0.350^{\mathrm{a}} \\
(0.049)\end{array}$ & $\begin{array}{c}\gamma_{3} \\
-0.040 \\
(0.029)\end{array}$ & $\begin{array}{c}\phi_{3} \\
0.292^{\mathrm{a}} \\
(0.033)\end{array}$ & $\begin{array}{c}\gamma_{4} \\
-0.257^{\mathrm{a}} \\
(0.051)\end{array}$ & $\begin{array}{c}\phi_{4} \\
0.150^{\mathbf{a}} \\
(0.036)\end{array}$ & $\begin{array}{c}\gamma_{5} \\
-0.073 \\
(0.048)\end{array}$ \\
\hline $\begin{array}{c}\phi_{5} \\
0.257^{\mathrm{a}} \\
(0.036)\end{array}$ & & & & & & & & & & & $\begin{array}{c}L L F \\
56745.73\end{array}$ \\
\hline
\end{tabular}

Note: Estimation results for the return series for the precious metals: Gold (XAU). Egarch (top panel) and Egarch-HAR (bottom panel) models. Period 27th of December 2008 to the 30th of November 2010. Hourly series, 11880 observations. $L L F$ is the Log-likelihood function. Standard errors in bracket. "a", "b" and "c" indicate significance at the $1 \%, 5 \%$ and $10 \%$.

Table 4: Estimation Return Egarch and Egarch-Har models with harmonics - XAU

GARCH-type equations are given as a combination of both deterministic and stochastic components. In fact, those approaches allow for the presence of both a deterministic and a stochastic periodic behavior of a given time series. We thus specify models that fulfill this purpose.

\subsection{Return}

For the returns, we specify an $\operatorname{EGARCHX}(\mathrm{P}, \mathrm{O}, \mathrm{Q})$ with periodic explanatory variables. The EGARCH model couples flexibility with computational simplifications; in fact, by resorting to exponential specifications, we avoid the introduction of parameter restrictions that lead to conditional variance positivity. To simplify the notation, we assume that the time index evolves at an intradaily step. The proposed model has the following structure:

$$
\begin{aligned}
r_{t}=\mu & +\sum_{j=i}^{p} \phi_{j} r_{t-j}+\sigma_{t} \varepsilon_{t} \\
\ln \left(\sigma_{t}^{2}\right)=\omega & +\sum_{j=1}^{Q} \beta_{j} \ln \left(\sigma_{t-j}^{2}\right)+\sum_{j=1}^{O} \alpha_{j} \varepsilon_{t-j}+\sum_{j=1}^{P} \theta_{j}\left|\varepsilon_{t-j}\right|+ \\
& +\sum_{j=1}^{q}\left(\gamma_{j} \cos \left(\frac{2 \pi j t}{24}\right)+\phi_{j} \sin \left(\frac{2 \pi j t}{24}\right)\right) .
\end{aligned}
$$




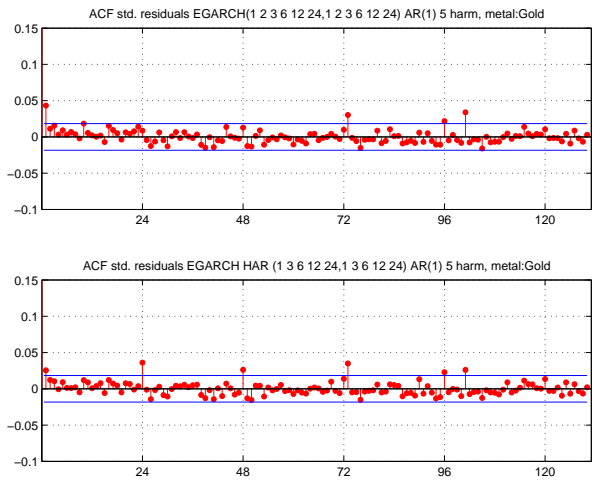

(a) XAU

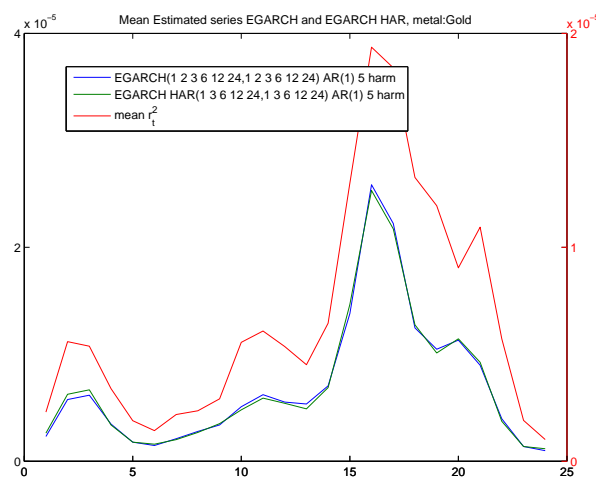

(b) XAU

Figure 5: ACF standardized squared residuals Return and mean estimated series - XAU

The model includes an autoregressive component that captures the limited serial correlation in the mean. The variance dynamic depends on a standard EGARCH structure, with orders governing the autoregressive behavior of the log-conditional variances (or$\operatorname{der} Q$ ), as well as the impact of shocks size and sign (orders $P$ and $O$, respectively). Moreover, the introduction of $q$ harmonics captures the deterministic evolution of logconditional variances. We also stress that the model orders $Q, P$, and $O$ can be increased beyond the common practice of restricting them to one. In fact, the orders set equal to the number of intradaily intervals per day, can detect Seasonal GARCH-type behaviors.

Several authors have also pointed out the presence of long memory in high-frequency returns volatility (see Andersen and Bollersleve, 1997b, 1998, and Bordignon et al., 2007, 2009, among others). Long-range dependence might be captured by resorting to long memory EGARCH specifications, as in Bollerslev and Mikkelsen (1996). However, the introduction of long memory in the conditional variance equation increases the model's complexity. We thus prefer to specify the variance dynamic following a HAR-type structure (Corsi (2009)).

We suggest the estimation of the following EGARCHX-HAR(P,O,Q) model. This specification approximates the long-memory behavior reproducing the volatility persistence terms of the HAR model of Corsi (2009). Whereas in the HAR model the autoregressive dynamic is associated with the target period of different market operators (daily, weekly, and monthly), in our specification the volatility evolves according to terms related to daily and intradaily periods: the day, the half-day, etc. Depending on the frequency of the time series, we include sums of past volatilities or shocks over different horizons; for hourly data we consider periods equal to the day, 24 hours, the half-day, 12 hours, and to 6 and 3 hours. The EGARCHX-HAR(P,O,Q) is characterised by the following equation: 


$$
\begin{aligned}
\ln \left(\sigma_{t}^{2}\right)=\omega & +\sum_{j=1,3,6,12,24} \frac{\beta_{j}}{j}\left(\ln \left(\sigma_{t-j}^{2}\right)+\ldots+\ln \left(\sigma_{t-1}^{2}\right)\right)+ \\
& +\sum_{j=1,3,6,12,24} \frac{\alpha_{j}}{j}\left(\varepsilon_{t-1}+\ldots+\varepsilon_{t-j}\right)+\sum_{j=1,3,6,12,24} \frac{\theta_{j}}{j}\left(\left|\varepsilon_{t-1}\right|+\ldots+\left|\varepsilon_{t-j}\right|\right)+ \\
& +\sum_{j=1}^{q}\left(\gamma_{j} \cos \left(\frac{2 \pi j t}{24}\right)+\phi_{j} \sin \left(\frac{2 \pi j t}{24}\right)\right) .
\end{aligned}
$$

In the analysis of the precious metals returns, we consider different combinations of the EGARCHX and EGARCHX-HAR model orders, as well as different number of harmonics. We augment the model by the introduction of an $\mathrm{AR}(1)$ term, which is needed to capture the limited serial correlation observed on mean returns. Table (4) reports the best specifications for the gold series. They include five harmonics and lags up to order 24 (the day when focusing on hourly time series). Notably, the shock's sign was irrelevant (the EGARCHX order $O$ was then set to zero). In both the EGARCHX and EGARCHX-HAR specifications, the lag 24 and the five harmonics parameters are statistically significant.

The left panel of Figure (5) presents ACF of the standardized squared returns $\left(\left(r_{t} / \hat{\sigma}_{t}\right)^{2}\right)$ for the $\operatorname{EGARCHX}(\mathrm{P}, \mathrm{O}, \mathrm{Q})$ and for the $\operatorname{EGARCHX} \operatorname{HAR}(\mathrm{P}, \mathrm{O}, \mathrm{Q})$ models. The seasonally adjusted residual series show evidence of serial correlation for both specifications. In particular, the first lag in the EGARCHX specification is significant, and a daily periodic residual remains in the correlation in the EGARCHX-HAR case. The serial correlation in the ACF of the EGARCHX standardized residuals might signal the existence of mild long-memory behavior which is not appropriately taken into account by the model. The EGARCHX-HAR model captures the potential long-range dependence of the volatility, but it is not able to completely remove the periodic component. Similar results are obtained for the other precious metals.

\subsection{Volume}

As pointed out in the previous section, the volume time series shows evidence supporting the presence of a stochastic periodic behavior, coupled with the possible presence of longrange dependence. ${ }^{14}$ To capture such a feature, we consider a multifactor GARMA model that allows for long-memory behavior which might be associated with specific periodic frequencies.

Following Woodward et. al (1998), the multifactor GARMA model is defined by

$$
\Phi(L) \prod_{j=0}^{h}\left(1-2 \cos \left(w_{j}\right) L+L^{2}\right)^{d_{j}}\left(y_{t}-\mu\right)=\Theta(L) \epsilon_{t},
$$

where $h$ is an integer, $\epsilon_{t}$ is a white noise with variance $\sigma_{\epsilon}^{2}, \mu$ is the mean of the process, $\omega_{j}$ (with $j=0, \ldots, h$ ) are the frequencies at which the long-memory behavior occurs, $d_{j}$ (with $j=0, \ldots, h$ ) are the long-memory parameters associated to each frequency, and $\Phi(L)$

\footnotetext{
${ }^{14}$ Bollerlsev and Jubinski (1999) and Lobato and Velasco (2000), among others, document long memory in stock-market trading volume.
} 


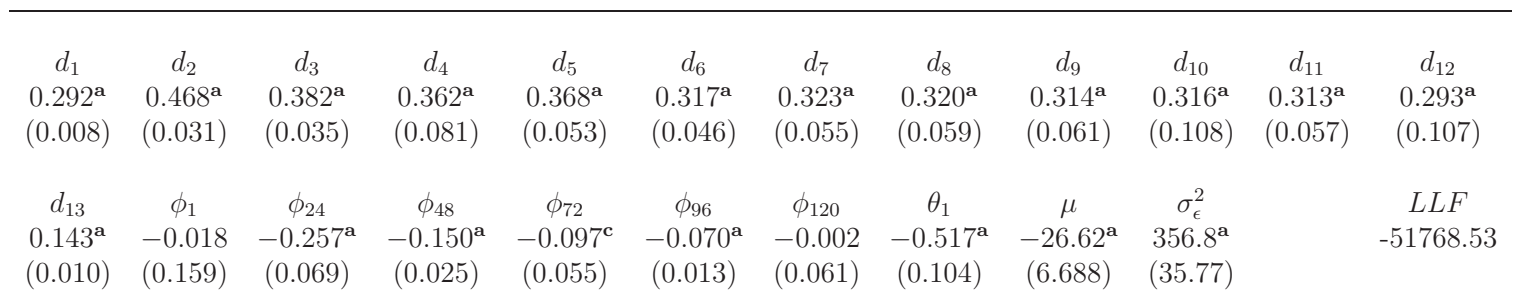

Note: Estimation results for the volume series for the precious metals: Gold (XAU). GARMA models. Period 27th of December 2008 to the 30th of November 2010. Hourly series, 11880 observations. LLF is the Log-likelihood function. Standard errors in bracket. "a", "b" and "c" indicate significance at the 1\%, 5\% and $10 \%$.

Table 5: Estimation Volume GARMA model - XAU

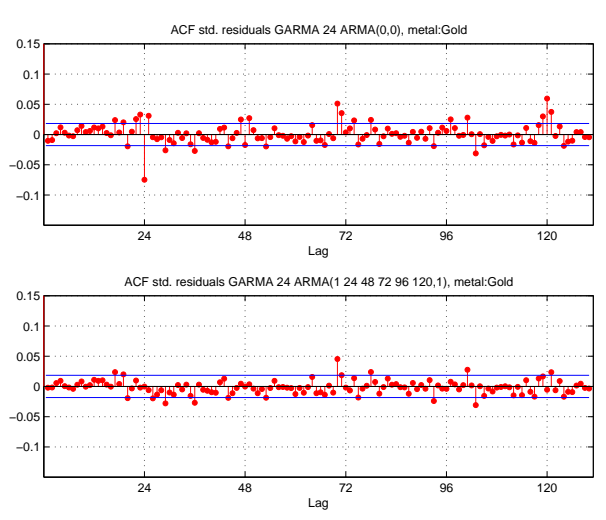

(a) XAU

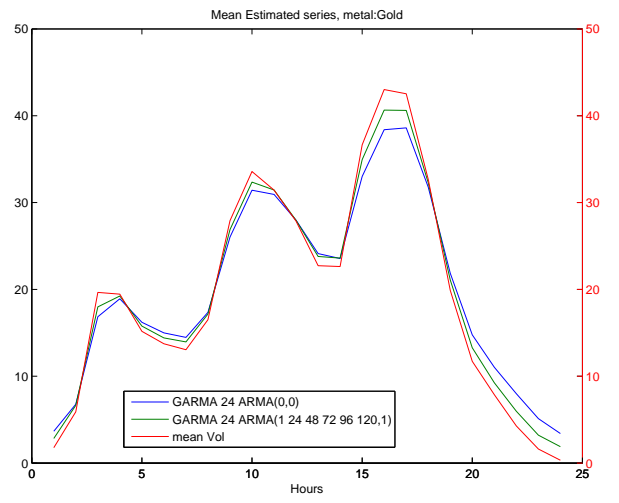

(b) XAU

Figure 6: ACF standardized squared residuals Volume and mean estimated series - XAU

and $\Theta(L)$ are the short-memory autoregressive and moving average polynomials with roots satisfying the usual stationarity and invertibility conditions. Stationarity of the GARMA model is achieved if the memory coefficients assume values below 0.5 for $1 \leq j \leq h-1$ and below 0.25 for $j=0$ and $j=h$ (see Woodward et al., 1998). The most relevant element of the multifactor GARMA model is the so-called Gegenbauer polynomial, given by

$$
P(L)=\prod_{j=0}^{h}\left(1-2 \cos \left(w_{j}\right) L+L^{2}\right)^{d_{j}},
$$

which may be considered as a generalized long-memory filter for the long-memory periodic behavior at $h+1$ frequencies. The $\omega_{j}$ 's are the driving frequencies of a cyclical pattern of length $S$, where $\omega_{j}=(2 \pi j / S), h+1=[S / 2]+1$, and [.] refers to the integer part. Previous studies have shown that the GARMA model is able to replicate the periodic patterns similar to those observed in the volume time series (see Bordignon et al., 2007 and 2009). To estimate the $(h+1)$-factor GARMA model in $(5)$, we implement an autoregressive approximation technique. Following Chung (1996), it is in fact possible to recover an $\mathrm{MA}(\infty)$ or $\mathrm{AR}(\infty)$ expansion of the model, and thus to estimate the model parameters through a quasi-maximum likelihood (QML) approach.

As previously observed, the autocorrelation function oscillates and decays slowly to- 


\begin{tabular}{ccccccccccccc}
\hline$d$ & $\phi_{1}$ & $\phi_{24}$ & $\phi_{48}$ & $\phi_{72}$ & $\phi_{96}$ & $\phi_{120}$ & $\theta_{1}$ & $\mu$ & $\gamma_{1}$ & $\phi_{1}$ & $\gamma_{2}$ \\
$0.076^{\mathbf{a}}$ & $-0.072^{\mathbf{a}}$ & $0.090^{\mathbf{a}}$ & $0.036^{\mathbf{a}}$ & $0.049^{\mathbf{a}}$ & $0.070^{\mathbf{a}}$ & $0.292^{\mathbf{a}}$ & $0.227^{\mathbf{a}}$ & $-0.134^{\mathbf{a}}$ & $-0.120^{\mathbf{a}}$ & 0.014 & $-0.101^{\mathbf{a}}$ \\
$(0.010)$ & $(0.022)$ & $(0.008)$ & $(0.008)$ & $(0.008)$ & $(0.008)$ & $(0.008)$ & $(0.022)$ & $(0.014)$ & $(0.011)$ & $(0.011)$ & $(0.011)$ \\
& & & & & & & & & & \\
$\phi_{2}$ & $\gamma_{3}$ & $\phi_{3}$ & $\gamma_{4}$ & $\phi_{4}$ & $\gamma_{5}$ & $\phi_{5}$ & $\sigma_{\epsilon}^{2}$ & & & \\
-0.002 & $-0.085^{\mathbf{a}}$ & -0.005 & $-0.071^{\mathbf{a}}$ & -0.009 & $-0.057^{\mathbf{a}}$ & -0.011 & $0.128^{\mathbf{a}}$ & & -4674.295 \\
$(0.011)$ & $(0.010)$ & $(0.010)$ & $(0.010)$ & $(0.010)$ & $(0.010)$ & $(0.010)$ & $(0.001)$ & &
\end{tabular}

Note: Estimation results for the $Q S * 100$ series for the precious metals: Gold (XAU). ARFIMA models. Period 27th of December 2008 to the 30th of November 2010. Hourly series, 11880 observations. LLF is the Log-likelihood function. Standard errors in bracket. "a", "b" and "c" indicate significance at the 1\%, 5\% and $10 \%$.

Table 6: Estimation $Q S * 100$ ARFIMA with harmonics - XAU

ward zero, suggesting a stochastic cyclical or periodic behavior coupled with long memory. From the previous section, we know that the periodic behavior has a length of 24 hours (on an hourly time series), leading to $S=24$. In turn, such a value implies the presence of thirteen factors that capture the long-memory and cyclical behavior $(h=12$ in the GARMA model of equation (5)). Table (5) reports the estimation results for the volume time series of gold. The memory parameters are statistically significant at all frequencies. However, we note that the memory coefficients associated with the zero frequency leads to a nonstationary component (the memory parameter is marginally larger than 0.25 ). We observe the same result in two other metals. The introduction of autoregressive and moving average components result in an improvement of the fit of the model compared with a pure long-memory specification; the short-memory coefficients are all statistically significant. We observe that the lags we introduce in the AR polynomial mimic the lags associated with the length of the periodic oscillation and its multiples. Such a result might suggest the presence of a weekly (five days) periodic pattern. Nevertheless, the estimation with $S=120$ (one-week cyclical behavior) provides inferior fit to the data.

The left panel of Figure (6) reports the ACF of the GARMA model residuals for the two different specifications for the short-memory component of the GARMA model. Notably, when considering the larger specification, few values of the correlograms are statistically significant. Moreover, the right panel of Figure (6) includes a comparison of the average hourly volume and of the average hourly fitted volume. The two quantities are close, further supporting the ability of the GARMA model in replicating the behavior of the volume time series.

Finally, unreported ACF of the squared residuals show the presence of a periodic pattern. Introducing a GARCH or EGARCH equation with periodic explanatory variables in the models for the mean allows for considering the presence of a periodic component in the volatility of the volume.

\subsection{Order flow and percentage quoted spread}

The PQS and OF time series have behaviors similar to the volume and returns, respectively. In fact, the PQS has a relevant periodic pattern in the mean, whereas the OF mean values show little evidence of serial correlation. On the contrary, the absolute or squared 
values of $\mathrm{OF}$ are characterized by a strong periodic behavior. Moreover, deterministic periodic filters are not effective in removing the periodic behavior of the liquidity time series. Given these findings, the liquidity measures' dynamic features might be captured using the approaches we consider for the volume and returns cases, that is the GARMA and EGARCH specifications. As an alternative methodology, we consider the ARFIMA and Seasonal ARFIMA (SARFIMA) models extended with the inclusion of periodic explanatory mean variables. We estimate these two models on the PQS mean and on the squared OF values. The SARFIMA is a special case of the multifactor GARMA model. Similar to the most general model, it provides periodic behavior coupled with long memory. The SARFIMA model is given as follows:

$$
\Phi(L)\left(1-L^{S}\right)^{d}\left(y_{t}-\mu-\sum_{j=1}^{q}\left(\gamma_{j} \cos \left(\frac{2 \pi j t}{24}\right)+\phi_{j} \sin \left(\frac{2 \pi j t}{24}\right)\right)\right)=\Theta(L) \epsilon_{t},
$$

where $\epsilon_{t}$ is a white noise with variance $\sigma_{\epsilon}^{2}$. The autoregressive and moving average polynomials $\Phi(L)$ and $\Theta(L)$ satisfy the usual restrictions for stationarity and invertibility, whereas the memory parameter $d$ gives a stationary model if its value is below 0.5 . The seasonal long-memory behavior influences the observed variable $y_{t}$ in deviation from its unconditional mean $\mu$ and from a deterministic periodic behavior captured by the $q$ harmonics. The relation between SARFIMA and GARMA is given by the following decomposition of the seasonal long-memory filter

$$
\left(1-L^{S}\right)=\left(1-2 \cos \left(\omega_{0}\right) L+L^{2}\right)^{\frac{1}{2}}\left[\prod_{j=1}^{S-1}\left(1-2 \cos \left(\omega_{j}\right) L+L^{2}\right)\right]\left(1-2 \cos \left(\omega_{s}\right) L+L^{2}\right)^{\frac{1}{2}}
$$

where $\omega_{0}=1$ and $\omega_{s}=-1$. The previous decomposition takes into account the roots of the polynomial $\left(1-L^{S}\right)$, which are associated with frequencies in $0-\pi$. In particular, the frequencies are $0, \pi$ (if $S$ is even), and a set of frequencies depending on the value of $S$, each associated with a pair of roots of the polynomial. Notably, such a decomposition corresponds to a product of Gegenbauer polynomials. If we introduce long memory and consider $\left(1-L^{S}\right)^{d}$, the exponent of each Gegenbauer polynomial in (8) is either equal to $d$ or to $d / 2$ (this happen for frequencies $\omega_{0}$ and $\omega_{1}$ ). As a consequence, the SARFIMA model is a special case of the multifactor GARMA under a restriction on the memory coefficient, and if the frequencies over which the GARMA model is specified are exactly the same set of frequencies associated with the decomposition of the seasonal filter $\left(1-L^{S}\right)$.

In the analysis of the liquidity series, ${ }^{15}$ we consider different specifications for the models. We set three different values for the seasonal length $(S) 1,24$, and 120. With $S=1$, we specify a pure long-memory model for the hourly series, whereas in the case of $S=24$ or 120 , we specify a daily and weekly seasonal integration pattern. To capture the periodic behavior of the series, we consider up to six daily harmonics, and we include a weekly harmonic. Finally, to model the short-memory component, we introduce different autoregressive and moving average specifications, considering lags up to the week.

\footnotetext{
${ }^{15}$ The estimated series are equal to $Q S \times 100$ and $O F^{2} / 100$, respectively.
} 


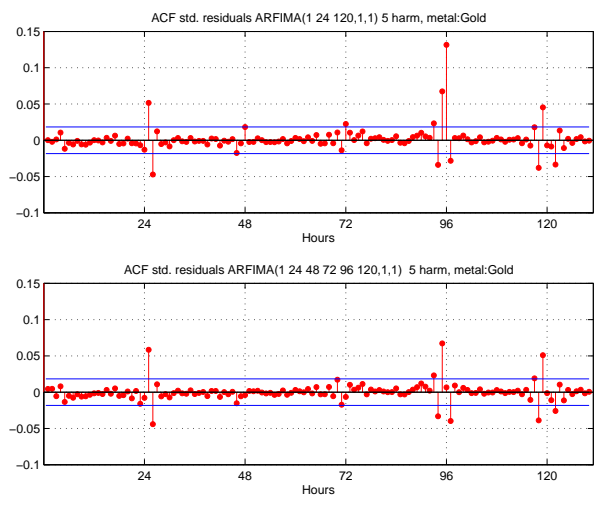

(a) XAU

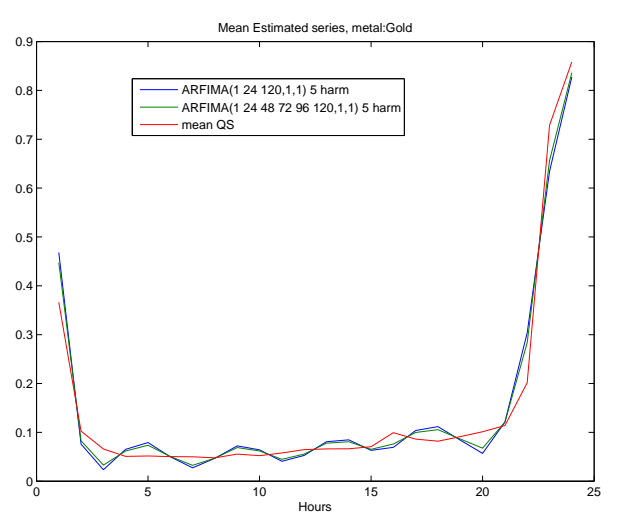

(b) XAU

Figure 7: ACF standardized squared residuals $Q S$ and mean estimated series - XAU

\begin{tabular}{ccccccccccccc}
\hline$d$ & $\phi_{1}$ & $\phi_{24}$ & $\phi_{48}$ & $\phi_{72}$ & $\phi_{96}$ & $\phi_{120}$ & $\theta_{1}$ & $\mu$ & $\gamma_{1}$ & $\phi_{1}$ & $\gamma_{2}$ & \\
$0.046^{\mathbf{a}}$ & $0.294^{\mathbf{a}}$ & $0.029^{\mathbf{a}}$ & $0.027^{\mathbf{a}}$ & $0.021^{\mathbf{b}}$ & $0.020^{\mathbf{b}}$ & $0.048^{\mathbf{a}}$ & $-0.191^{\mathbf{a}}$ & $-0.826^{\mathbf{a}}$ & $0.587^{\mathbf{a}}$ & $0.452^{\mathbf{a}}$ & $0.309^{\mathbf{a}}$ \\
$(0.014)$ & $(0.062)$ & $(0.008)$ & $(0.008)$ & $(0.008)$ & $(0.008)$ & $(0.008)$ & $(0.058)$ & $(0.061)$ & $(0.059)$ & $(0.059)$ & $(0.055)$ \\
& & & & & & & & & & \\
$\phi_{2}$ & $\gamma_{3}$ & $\phi_{3}$ & $\gamma_{4}$ & $\phi_{4}$ & $\gamma_{5}$ & $\phi_{5}$ & $\sigma_{\epsilon}^{2}$ & & & & & \\
$-0.268^{\mathbf{a}}$ & $-0.150^{\mathbf{a}}$ & $-0.245^{\mathbf{a}}$ & $0.093^{\mathbf{c}}$ & $0.237^{\mathbf{a}}$ & 0.017 & -0.013 & $9.220^{\mathbf{a}}$ & & & -30052.31 \\
$(0.055)$ & $(0.051)$ & $(0.051)$ & $(0.048)$ & $(0.048)$ & $(0.045)$ & $(0.045)$ & $(0.119)$ & & &
\end{tabular}

Note: Estimation results for the $O F^{2} / 100$ series for the precious metals: Gold (XAU).ARFIMA models. Period 27th of December 2008 to the 30th of November 2010. Hourly series, 11880 observations. LLF is the Log-likelihood function. Standard errors in bracket. "a", "b" and "c" indicate significance at the 1\%, 5\% and $10 \%$.

Table 7: Estimation $O F^{2} / 100$ ARFIMA with harmonics - XAU

For the QS, Table (6) presents the results of the model that best fits the gold series. Although we try with the ARFIMA and SARFIMA models, we concentrate on the first kind of models $(S=1)$. Estimation results and the ACF of the residuals of SARFIMA models are similar. The long-memory parameter is significant for all the metals, but it is lower for gold than the other three metals. In the first case, it is equal to 0.076 whereas it is near 0.28 for silver and palladium and 0.493 for platinum. The introduction of the autoregressive lags improves the fitting of the model. Note that the lags are all statistically significant. ${ }^{16}$ The analysis of the ACF of the residuals, in the left panel of Figure (7), favors the introduction of short-memory component at the daily and its multiple lags. Moreover, it displays significant correlations associated with particular lags. This fact is more evident in the gold series. We believe they are neither associated with the long-memory component nor with the periodic pattern, which have both been correctly removed. The right panel of Figure (7) presents the mean fitted series, which replicates the periodic component observed in the QS time series.

For the $O F^{2}$, Table (7) displays the estimation result for the gold series. As in the previous case, we consider ARFIMA and Seasonal ARFIMA specifications and we find very similar outcomes. Then we focus on the pure long-memory model $(S=1)$. Esti-

\footnotetext{
${ }^{16}$ A likelihood ratio test between an ARFIMA(1 24487296 120,d,1) and ARFIMA(1 24 120,d,1) specification rejects the restricted model in the four metals at $5 \%$ level.
} 


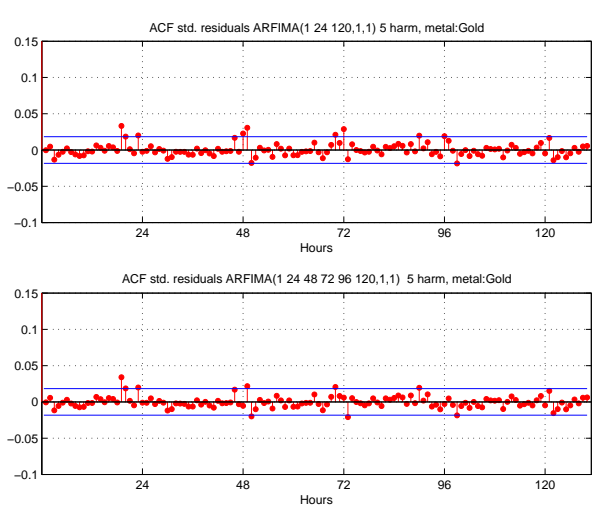

(a) XAU

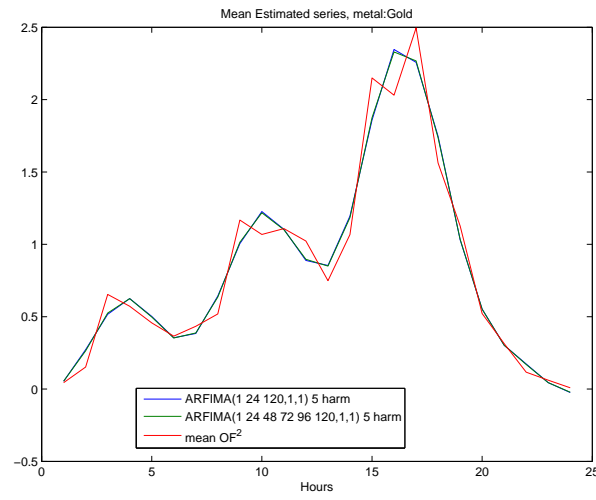

(b) XAU

Figure 8: ACF standardized squared residuals $O F^{2}$ and mean estimated series - XAU

mations of the $d$ range from 0.046 to 0.168 for the different models, and they are always highly significant. Regarding the short-memory specification, the autoregressive lags produce an improvement in the fitting of the model. We consider an ARFIMA(1 24 120,d,1) and an ARFIMA(1 24487296 120,d,1) model. In the case of the gold time series, the full specification presents significant coefficients, and it is preferred to the restricted one when formally testing. ${ }^{17}$ Finally, ACF of the residuals displays a good performance of the models with the mean estimated series reproducing the periodic component present in the $O F^{2}$ series, in Figure (8).

\section{Conclusions}

We provide a first and pioneering description of the stylized facts and dynamic properties of precious metals time series extracted from a novel nanofrequency database that includes trade and quotes data. The most innovative elements are given by the time frequency of the database, up to 100 millisecond. We focus on four precious metals, including palladium and platinum, the use of spot prices rather than commodity future prices of previous studies, and on trading activity recorded around the clock. The analysis shows that the prices, returns, and volume time series have features comparable to those of traditional assets. Moreover, two specific liquidity measures present evidence of peculiar dynamic features. The results reported here shed some light on high-frequency data related to spot precious metal prices, which have never been considered in the literature. Moreover, our study shows a clear evidence of periodic behaviors linked to the activity of the most relevant precious metals markets.

This work represents a preliminary and fundamental research focused on the statistical aspects and data analysis of the precious metals financial variables. Building on our results, future research might be extended in several dimensions, for instance, to better understand the price discovery process and liquidity provision on spot precious metals. Alternatively, multivariate approaches might be considered, focusing on the joint analyses

\footnotetext{
${ }^{17}$ A likelihood ratio test between an ARFIMA(1 24487296 120,d,1) and ARFIMA(1 24 120,d,1) specification rejects the restricted model in the gold and palladium series at $5 \%$ level.
} 
on different precious metals or on models capturing the interdependence between returns, volume, volatility, and liquidity.

\section{References}

[1] Abergel, F., Bouchaud, J., Foucault, T., Lehalle, C., and Rosenbaum, M., 2012, Market Microstructure: Confronting Many Viewpoints, Wiley.

[2] Andersen, T.G., and Bollerslev, T., 1997a, Intraday periodicity and volatility persistence in financial markets, Journal of Empirical Finance 4, 115-158.

[3] Andersen, T.G., and Bollerslev, T., 1997b, Heterogeneous information arrivals and return volatility dynamics: uncovering the long run in high volatility returns. Journal of Finance, 52, 975-1005.

[4] Andersen, T.G., and Bollerslev, T., 1998, Answering the skeptics: Yes, standard volatility models do provide accurate forecasts, International Economic Review, 39, 885-905.

[5] Andersen, T.G., Bollerslev, T., Diebold, F.X., and Vega, C., 2003, Micro effects of macro announcements: real-time price discovery in foreign exchange, American Economic Review, 93, 38-62.

[6] Baillie, R.T., Han, Y., Myers, R.J., and Song, J., 2007, Long-memory models for daily and high-frequency commodity future returns, Journal of Future Markets, 27-7, 643-668.

[7] Bannouh, K., van Dijk, D., and Martens, M., 2009, Range-Based Covariance Estimation Using High-Frequency Data: The Realized Co-Range, Journal of Financial Econometrics, 7-4, 341-372.

[8] Barkoulas, J., Labys, W.C., Onochie, J., 1997, Fractional Dynamics in International Commodity Prices. Journal of Future Markets, 17-2, 161-189.

[9] Barndorff-Nielsen, O.E., and Shephard, N., 2004, Power and bipower variation with stochastic volatility and jumps, Journal of Financial Econometrics, 2, 1-37.

[10] Bauwens, L., and Giot, P., 2001, Econometric modeling of stock market intraday activity, Kluwer, Dordrecht.

[11] Bekaert, G., Harvey, C., and Lundblad, C., 2007, Liquidity and Expected Returns: Lessons from Emerging Markets, Review of Financial Studies, 20-6, 1783-1831.

[12] Berger, D.W., Chaboud, A.P., Chernenko, S.V., Howorka, E., and Wright,J.H., 2008, Order Flow and Exchange Rate Dynamics in Electronic Brokerage System Data, Journal of International Economics, 75, 93-109.

[13] Bollerslev, T., and Domowitz, I., 1993, Trading Patterns and Prices in the Interbank Foreign Exchange Market, Journal of Finance, 48, 1421-43.

[14] Bollerslev, T., and Ghysel, E., 1996, Periodic Autoregressive Conditional Heteroscedasticity, Journal of Business and Economic Statistics, 14, 139-151. 
[15] Bollerlsev, T., and Jubinski, D., 1999, Equity Trading Volume and Volatility: Latent Information Arrivals and Common Long-Run Dependencies, Journal of Business and Economic Statistics, 17-1, 9-21.

[16] Bollerslev, T., and Mikkelsen, H.O., 1996, Modeling and pricing long memory in stock market volatility. Journal of Econometrics, 73, 151-184.

[17] Bordignon, S., Caporin, M., and Lisi, F., 2007, Generalised Long Memory GARCH models for intradaily volatility, Computational Statistics \& Data Analysis, 51-12, 5900-5912.

[18] Bordignon, S., Caporin, M., and Lisi, F., 2009, Periodic Long Memory GARCH models, Econometric Reviews, 28, 60-82.

[19] Boudt, K, Croux, C., and Laurent, S., 2011, Robust estimation of intraweek periodicity in volatility and jump detection, Journal of Empirical Finance, 18, 353-367.

[20] Brownlees, C.T., and Gallo, G.M., 2006, Financial econometric analysis at ultrahigh-frequency: Data handling concerns, Computational Statistics \& Data Analysis, $51-4,2232-2245$.

[21] Cai, J., Cheung, Y., and Song, M.C.S., 2001, What Moves the Gold Market?, Journal of Future Markets, 21-3, 257-278.

[22] Caporin, M., and Preś, J., 2011, Forecasting Temperature Indices Density with Time-Varying Long-Memory Models, Journal of Forecasting.

[23] Caporin, M., and Preś, J., 2012, modeling and forecasting wind speed intensity for weather risk management, Computational Statistics \& Data Analysis, 56 - 11, 3459-3476.

[24] Corsi, F., 2009, A simple approximate long-memory model of realized volatility. Journal of Financial Econometrics, 7, 174-196.

[25] Chung, C., 1996, Estimating a generalized long memory process. Journal of Econometrics, 73, 237-259.

[26] Dacorogna, M.M., Muller U.A., Nagler, R.J., Olsen, R.B., Pictet, O.V., 1993, A geographical model for the daily and weekly seasonal volatility in the foreign exchange market, Journal of International Money and Finance 12, 413-438.

[27] Dacorogna, M.M., Gencay, R., Muller, U.A., Olsen, R., Pictet, O.V., 2001, An introduction to high-frequency finance, Academic Press, London.

[28] Engle, R.F., Russell, J.R., 2009, Analysis of high-frequency Data, Handbook of Financial Econometrics, Eds. Y. Ait-Sahalia and L.P. Hansen, Elsevier, North Holland.

[29] Fleming, J., Kirby, C., and Ostdiek, B., 2003, The economic value of volatility timing using realized volatility, Journal of Financial Economics, 67, 473-509.

[30] Flood, M.D., 1994, Market structure and inefficiency in the foreign exchange market, Journal of International Money and Finance, 13, 131-158. 
[31] Gabrielsen, A., Marzo, M., and Zagaglia, P., 2011, Measuring market liquidity: an introductory survey, MPRA paper 35829, available at http://mpra.ub.unimuenchen.de/35829/

[32] Gray, H.L., Zhang, N., and Woodward, W., 1988, On generalized fractional processes, Journal of Time Series Analysis, 10, 233-257.

[33] Guegan, D., 2000, A new model: the k-factor GIGARCH process, Journal of Signal Processing 4, 265-271.

[34] Hasbrouck, J., 2007, Empirical Market Microstructure: The Institutions, Economics, and Econometrics of Securities Trading, Oxford University Press, USA.

[35] Hautsch, N., 2011, Econometrics of financial high-frequency data, Springer.

[36] Khalifa, A.A.A., Miao, H., and Ramchander, S., 2011, Return distribution and volatility forecasting in metal futures markets: evidence from gold, silver and copper, Journal of Future Markets, 31-1, 55-80.

[37] Lee, C., and Ready, M., 1991, Inferring Trade Direction from Intraday Data, Journal of Finance, 46, 733-746.

[38] Lobato, I., and Velasco, C., 2000, Long Memory in Stock-Marcket Trading Volume, Journal of Business and Economic Statistics, 18-4, 410-427.

[39] Mancini, L., Ranaldo, A., and Wrampelmeyer, J., 2012, Liquidity in the Foreign Exchange Market: Measurement, Commonality, and Risk Premiums, Journal of Finance, forthcoming.

[40] O’Hara, M., 1997, Market Microstructure, Blackwell, London.

[41] Parlour, C.A., and Seppi, D.J., Limit order markets: a survey, Handbook of financial intermediation and banking, Thakor, A.V., and Boot A.W.A. (Eds.), NorthHolland, Elsevier, Amsterdam.

[42] Schmidt, A., 2011, Financial Markets and Trading: An Introduction to Market Microstructure and Trading Strategies, Wiley.

[43] Taylor, S.J., and Xu, X., 1997, The incremental volatility information in one million foreign exchange quotations, Journal of Empirical Finance 4, 317-340.

[44] Woodward, W.A., Cheng, Q.C., and Gray, H., 1998, A k-factor GARMA longmemory model, Journal of Time Series Analysis 19, 485-504.

[45] Ye, G., 2011, high-frequency trading models, Wiley. 
A Web Appendix ${ }^{18}$

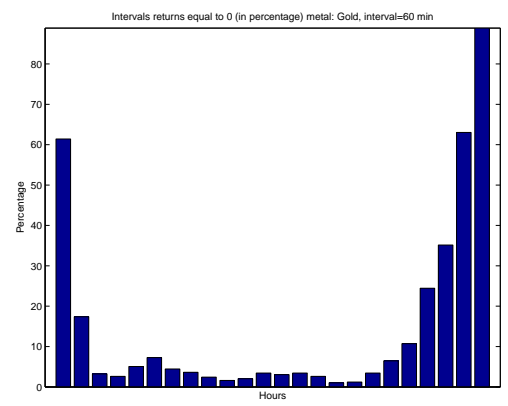

(a) XAU

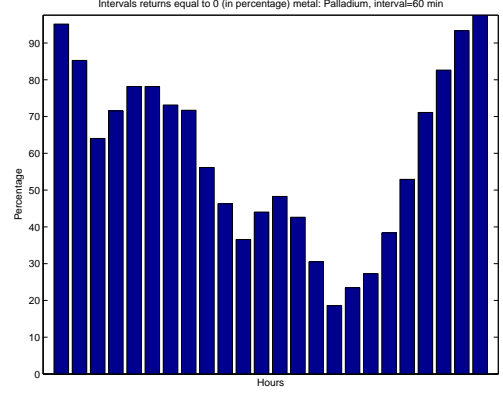

(c) XPD

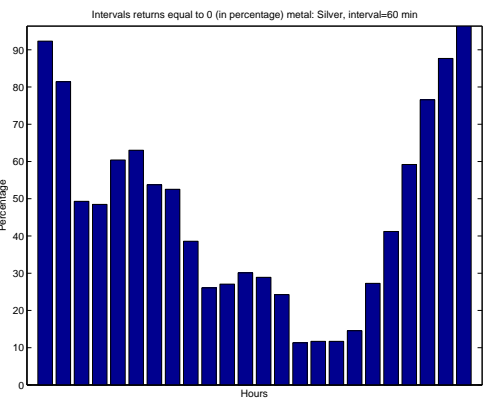

(b) XAG

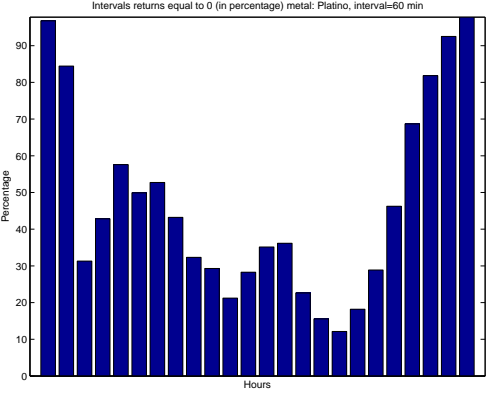

(d) XPT

Figure A.1: Occurrence of zeros during the trading day (hourly series) 


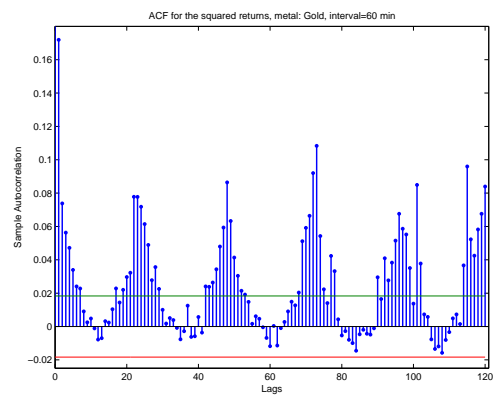

(a) XAU

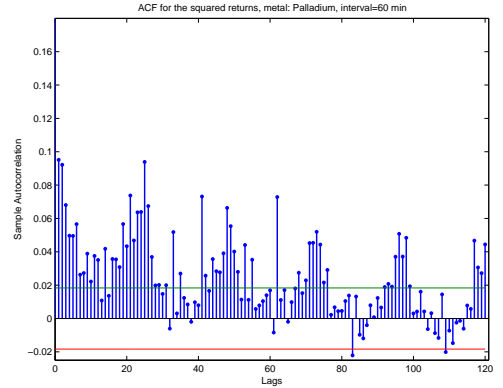

(c) XPD

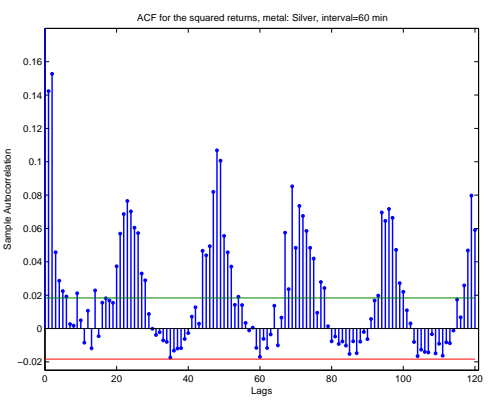

(b) XAG

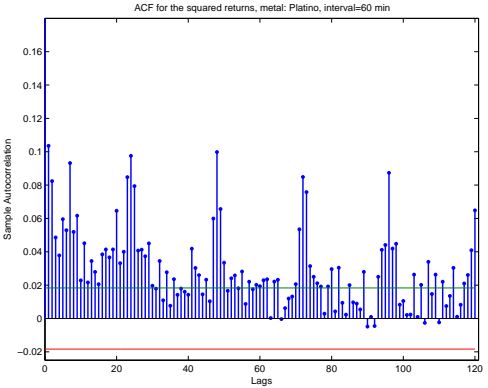

(d) XPT

Figure A.2: ACF squared returns

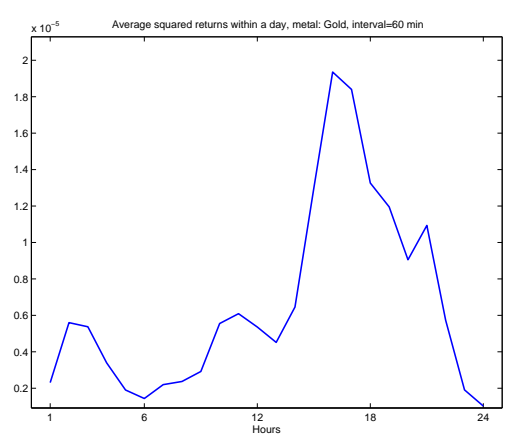

(a) XAU

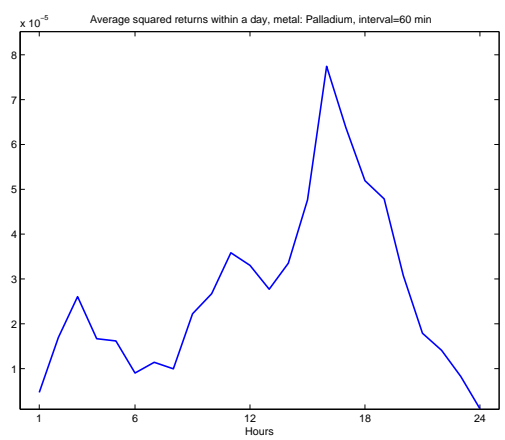

(c) XPD

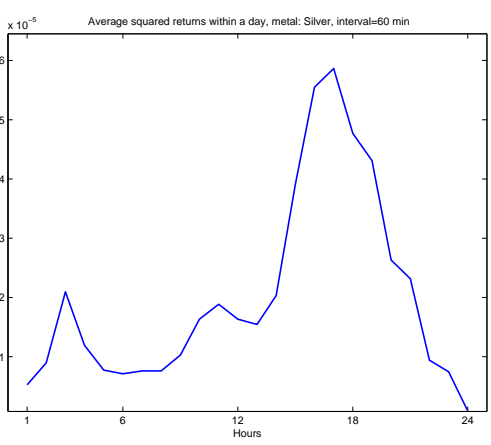

(b) XAG

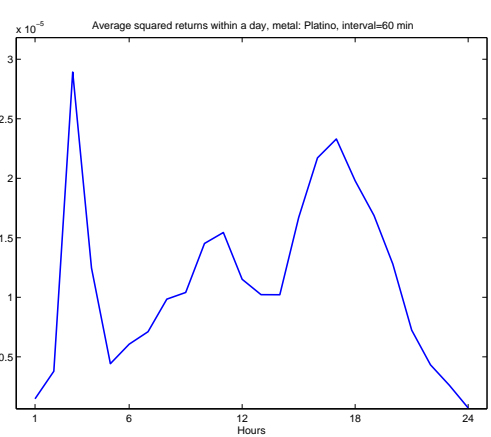

(d) XPT

Figure A.3: Average hourly squared return 


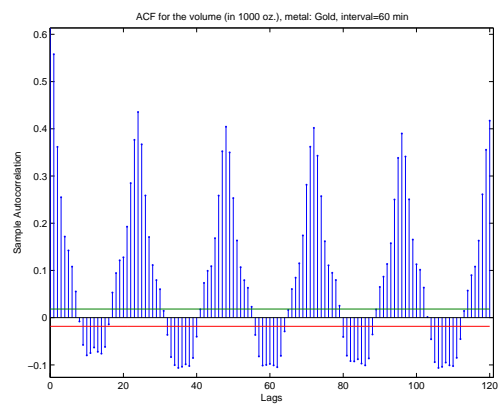

(a) XAU

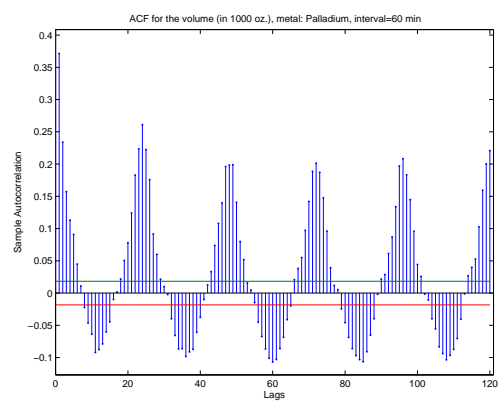

(c) XPD

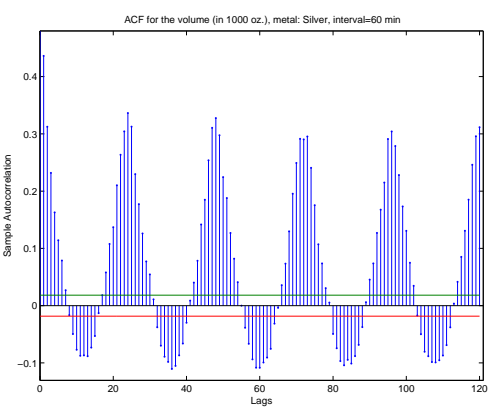

(b) XAG

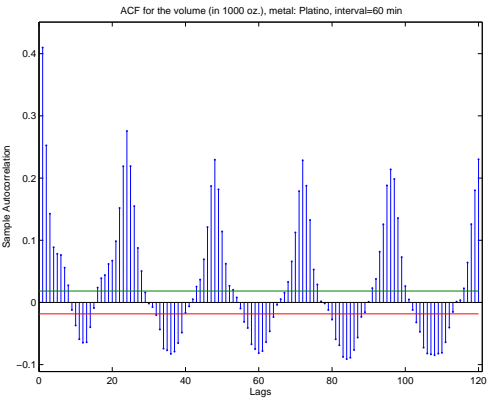

(d) XPT

Figure A.4: ACF volume

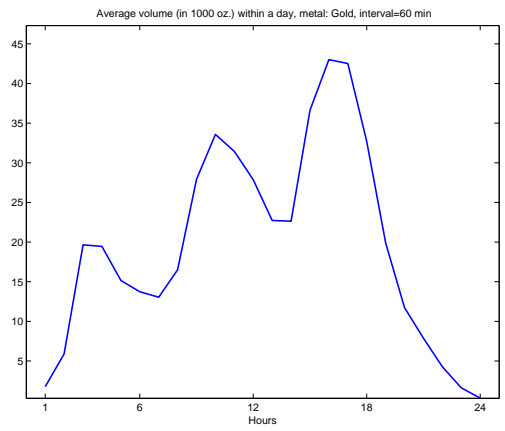

(a) XAU

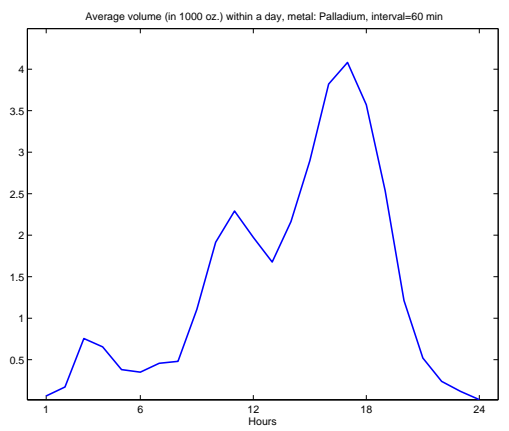

(c) XPD

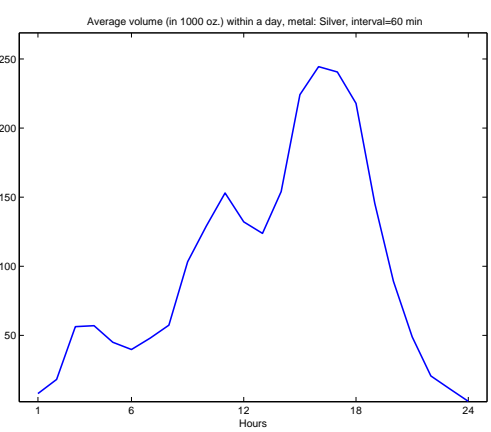

(b) XAG

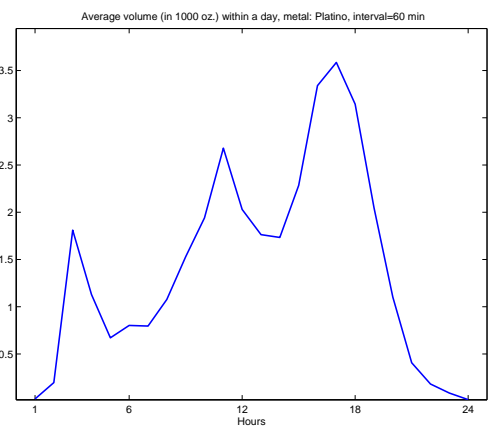

(d) XPT

Figure A.5: Average hourly volume 


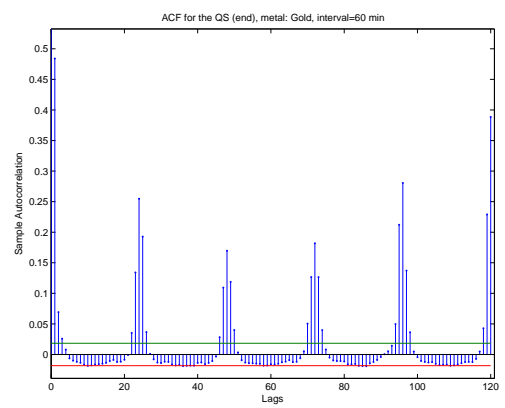

(a) XAU

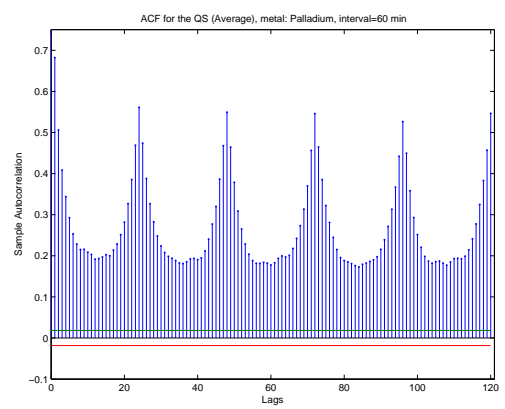

(c) XPD

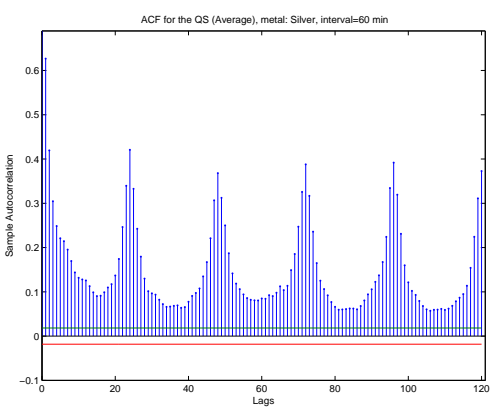

(b) XAG

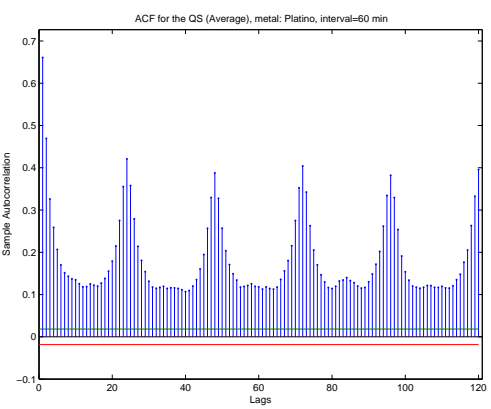

(d) XPT

Figure A.6: ACF PQS

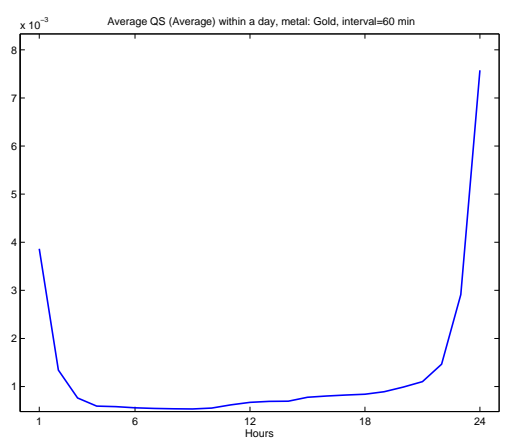

(a) $\mathrm{XAU}$

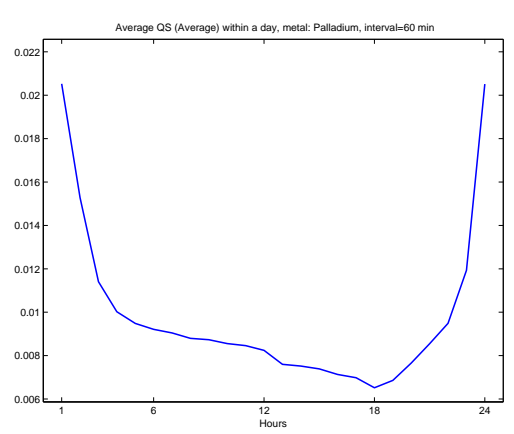

(c) XPD

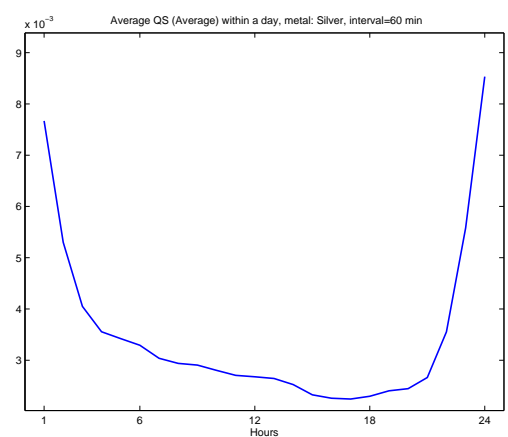

(b) XAG

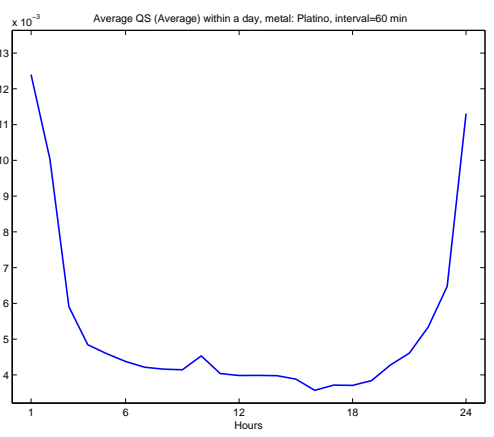

(d) XPT

Figure A.7: Average hourly PQS 


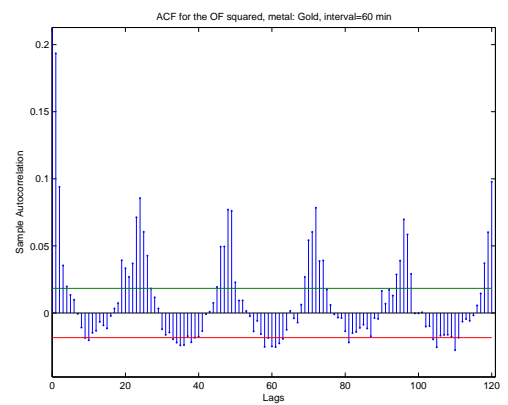

(a) XAU

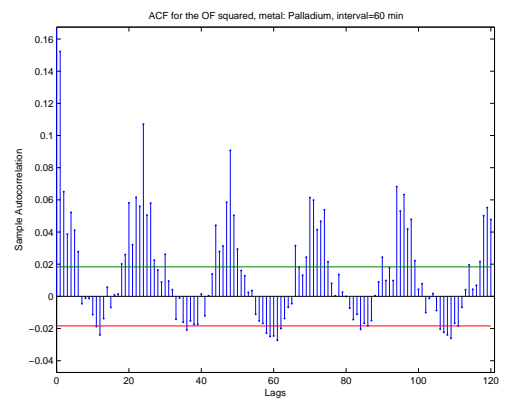

(c) XPD

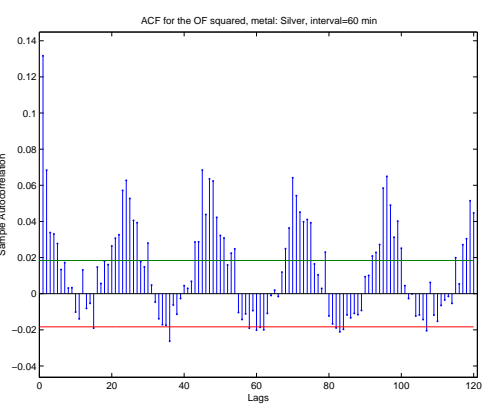

(b) XAG

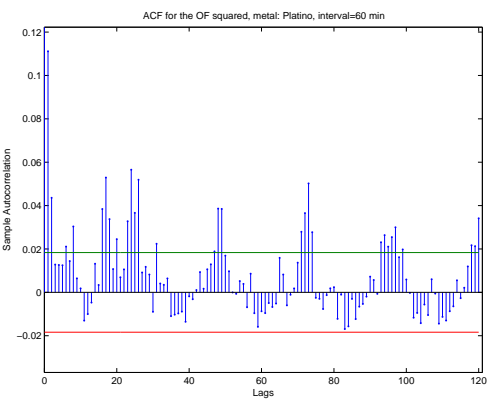

(d) XPT

Figure A.8: ACF OF squared

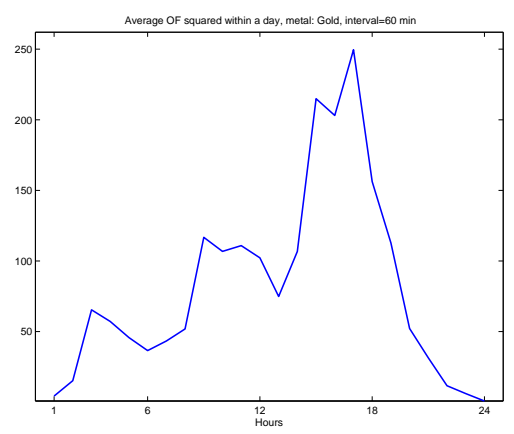

(a) XAU

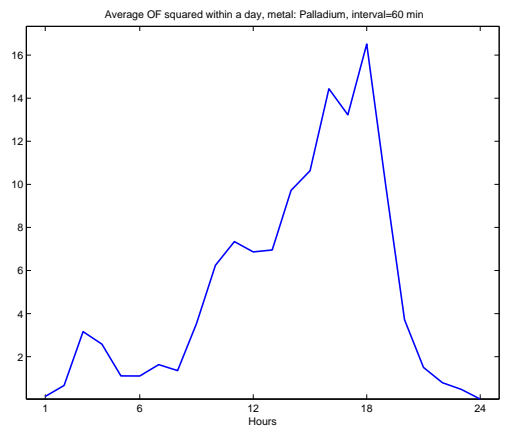

(c) XPD

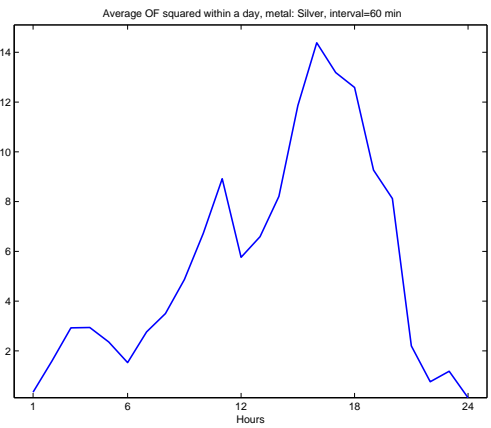

(b) XAG

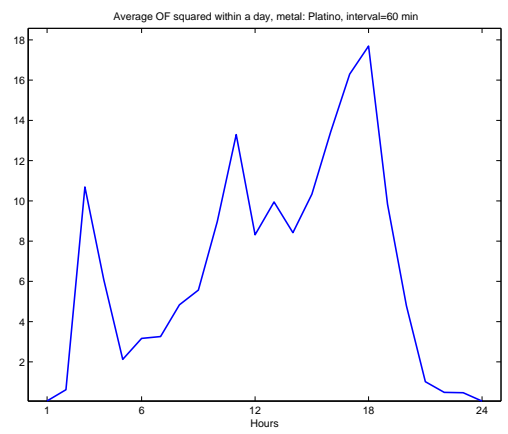

(d) XPT

Figure A.9: Average hourly OF squared 


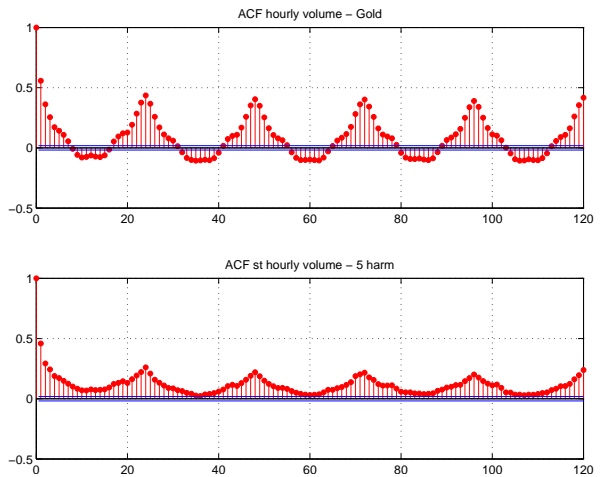

(a) $\mathrm{ACF}$

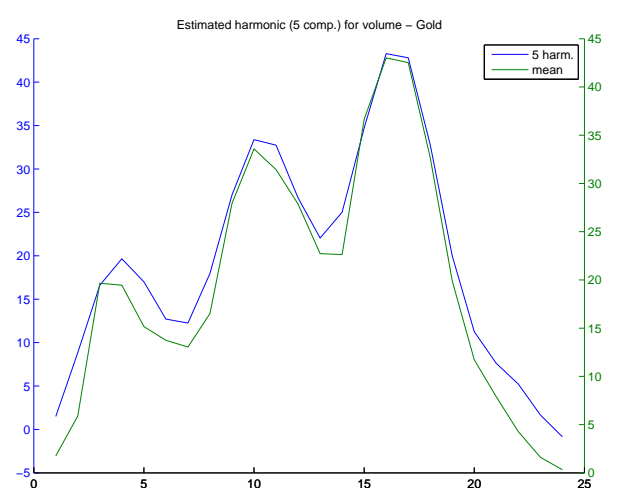

(b) Estimated harmonic

Figure A.10: ACF of the volume and ACF of volume residuals after a regression on harmonics (left panel) and estimated periodic component (right panel)

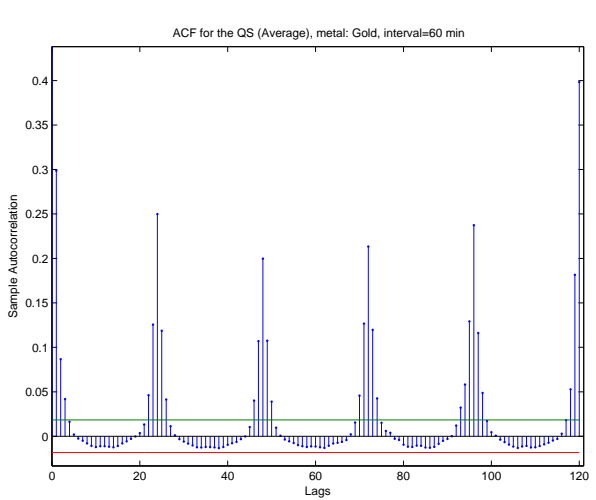

(a) ACF QS

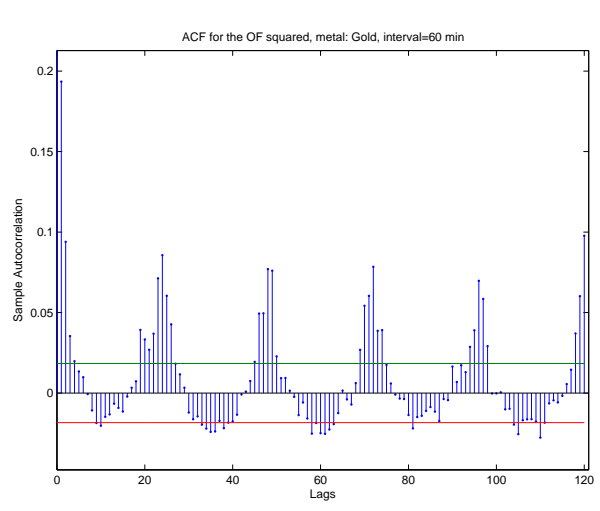

(c) ACF OF

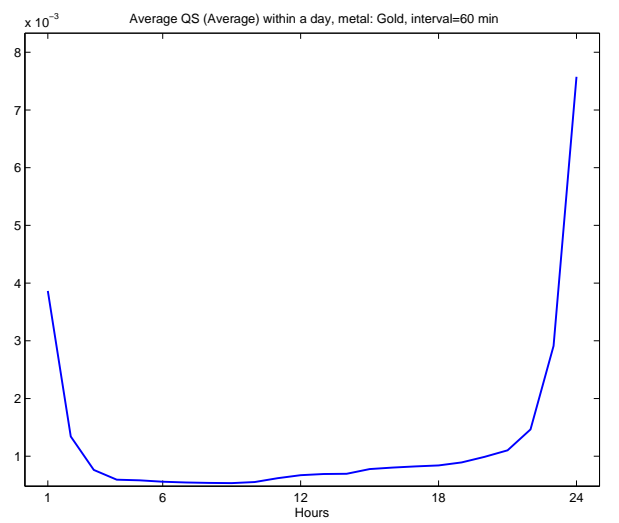

(b) Average QS

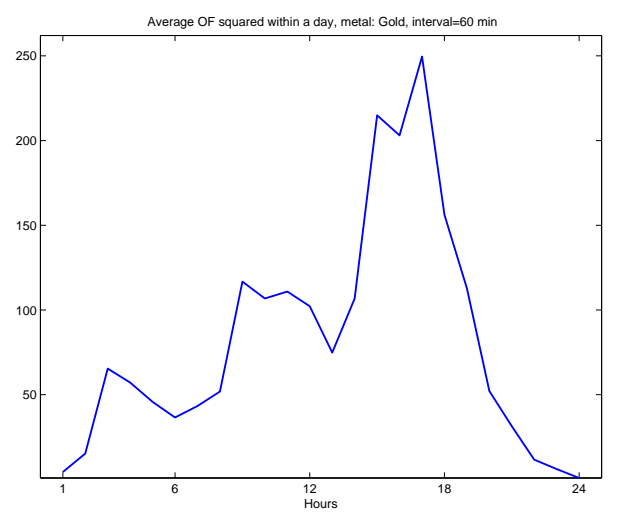

(d) Avegare OF

Figure A.11: ACF and average hourly QS and OF squared - XAU 
Table A.1: Estimation Return Egarch and Egarch-Har models with harmonics

\begin{tabular}{|c|c|c|c|c|c|c|c|c|}
\hline & $\mathrm{XAU}$ & $\mathrm{XAU}$ & XAG & XAG & XPD & XPD & XPT & XPT \\
\hline$\mu$ & $\begin{array}{c}\text { Egarch } \\
-1.4 e-09 \\
(2.2 e-05)\end{array}$ & $\begin{array}{c}\text { Egarch HAR } \\
-1.4 e-09 \\
(2.2 e-05)\end{array}$ & $\begin{array}{c}\text { Egarch } \\
3.00 e-09 \\
(3.9 e-05)\end{array}$ & $\begin{array}{c}\text { Egarch HAR } \\
3.00 e-09 \\
(3.9 e-05)\end{array}$ & $\begin{array}{c}\text { Egarch } \\
4.28 e-10 \\
(4.6 e-05)\end{array}$ & $\begin{array}{c}\text { Egarch HAR } \\
4.28 e-10 \\
(4.6 e-05)\end{array}$ & $\begin{array}{c}\text { Egarch } \\
1.06 e-10 \\
(2.9 e-05)\end{array}$ & $\begin{array}{c}\text { Egarch HAR } \\
1.06 e-10 \\
(2.9 e-05)\end{array}$ \\
\hline$\phi_{1}$ & $\begin{array}{c}-0.038^{\mathbf{b}} \\
(0.019)\end{array}$ & $\begin{array}{c}-0.038^{\mathbf{b}} \\
(0.019)\end{array}$ & $\begin{array}{l}-0.023 \\
(0.015)\end{array}$ & $\begin{array}{l}-0.023 \\
(0.015)\end{array}$ & $\begin{array}{c}-0.044^{\mathrm{a}} \\
(0.013)\end{array}$ & $\begin{array}{c}-0.044^{\mathrm{a}} \\
(0.013)\end{array}$ & $\begin{array}{c}-0.025^{\mathbf{b}} \\
(0.012)\end{array}$ & $\begin{array}{c}-0.025^{\mathrm{b}} \\
(0.012)\end{array}$ \\
\hline$\omega$ & $\begin{array}{l}-0.241 \\
(0.383)\end{array}$ & $\begin{array}{l}-0.107 \\
(0.067)\end{array}$ & $\begin{array}{l}-0.241 \\
(0.262)\end{array}$ & $\begin{array}{l}-0.656 \\
(8.834)\end{array}$ & $\begin{array}{c}-0.053^{\mathbf{c}} \\
(0.030)\end{array}$ & $\begin{array}{l}-0.115 \\
(0.197)\end{array}$ & $\begin{array}{l}-0.018 \\
(0.014)\end{array}$ & $\begin{array}{l}-0.193 \\
(0.274)\end{array}$ \\
\hline$\theta_{1}$ & $\begin{array}{l}0.123^{\mathrm{a}} \\
(0.025)\end{array}$ & $\begin{array}{l}0.139^{\mathrm{a}} \\
(0.034)\end{array}$ & $\begin{array}{l}0.096^{\mathrm{a}} \\
(0.030)\end{array}$ & $\begin{array}{l}-0.143 \\
(1.193)\end{array}$ & $\begin{array}{l}-0.009 \\
(0.007)\end{array}$ & $\begin{array}{l}-0.169 \\
(0.111)\end{array}$ & $\begin{array}{l}-0.006 \\
(0.013)\end{array}$ & $\begin{array}{l}-0.085 \\
(0.089)\end{array}$ \\
\hline$\theta_{2}$ & $\begin{array}{l}0.138^{\mathrm{b}} \\
(0.055)\end{array}$ & - & $\begin{array}{l}0.106^{\mathrm{a}} \\
(0.039)\end{array}$ & - & $\begin{array}{l}0.173^{\mathrm{a}} \\
(0.042)\end{array}$ & - & $\begin{array}{l}0.123^{\mathrm{a}} \\
(0.026)\end{array}$ & - \\
\hline$\theta_{3}$ & $\begin{array}{l}0.078 \\
(0.053)\end{array}$ & $\begin{array}{l}0.097^{\mathrm{c}} \\
(0.056)\end{array}$ & $\begin{array}{l}0.053^{\mathrm{c}} \\
(0.028)\end{array}$ & $\begin{array}{l}0.370 \\
(2.262)\end{array}$ & $\begin{array}{c}-0.083^{\mathbf{b}} \\
(0.038)\end{array}$ & $\begin{array}{c}0.267 \\
(0.526)\end{array}$ & $\begin{array}{l}-0.031 \\
(0.030)\end{array}$ & $\begin{array}{l}0.375^{\mathrm{a}} \\
(0.140)\end{array}$ \\
\hline$\theta_{6}$ & $\begin{array}{l}-0.009 \\
(0.022)\end{array}$ & $\begin{array}{c}-0.107^{\mathbf{b}} \\
(0.045)\end{array}$ & $\begin{array}{l}-0.031 \\
(0.046)\end{array}$ & $\begin{array}{l}0.031 \\
(3.319)\end{array}$ & $\begin{array}{c}0.032 \\
(0.022)\end{array}$ & $\begin{array}{c}0.560 \\
(0.631)\end{array}$ & $\begin{array}{c}-0.085^{\mathbf{b}} \\
(0.033)\end{array}$ & $\begin{array}{l}0.140^{c} \\
(0.084)\end{array}$ \\
\hline$\theta_{12}$ & $\begin{array}{l}-0.016^{\mathbf{c}} \\
(0.008)\end{array}$ & $\begin{array}{c}0.054 \\
(0.121)\end{array}$ & $\begin{array}{l}0.001 \\
(0.008)\end{array}$ & $\begin{array}{c}0.914 \\
(3.858)\end{array}$ & $\begin{array}{c}-0.041^{\mathbf{c}} \\
(0.022)\end{array}$ & $\begin{array}{l}0.466 \\
(0.306)\end{array}$ & $\begin{array}{l}0.043^{\mathrm{a}} \\
(0.008)\end{array}$ & $\begin{array}{l}-0.251 \\
(0.289)\end{array}$ \\
\hline$\theta_{24}$ & $\begin{array}{l}0.154^{a} \\
(0.042)\end{array}$ & $\begin{array}{c}0.051 \\
(0.193)\end{array}$ & $\begin{array}{l}0.108^{a} \\
(0.025)\end{array}$ & $\begin{array}{l}-0.153 \\
(2.019)\end{array}$ & $\begin{array}{c}-0.030^{\mathbf{b}} \\
(0.015)\end{array}$ & $\begin{array}{c}-1.024^{\mathbf{c}} \\
(0.566)\end{array}$ & $\begin{array}{l}-0.022 \\
(0.021)\end{array}$ & $\begin{array}{l}0.126 \\
(0.495)\end{array}$ \\
\hline$\beta_{1}$ & $\begin{array}{l}0.007 \\
(0.034)\end{array}$ & $\begin{array}{l}0.625^{\mathbf{a}} \\
(0.061)\end{array}$ & $\begin{array}{l}0.285^{a} \\
(0.021)\end{array}$ & $\begin{array}{l}-0.644 \\
(6.078)\end{array}$ & $\begin{array}{l}0.911^{\mathrm{a}} \\
(0.056)\end{array}$ & $\begin{array}{l}-0.145 \\
(0.569)\end{array}$ & $\begin{array}{l}1.177^{\mathrm{a}} \\
(0.013)\end{array}$ & $\begin{array}{c}-1.630^{\mathbf{a}} \\
(0.413)\end{array}$ \\
\hline$\beta_{2}$ & $\begin{array}{l}-0.012^{\mathrm{c}} \\
(0.007)\end{array}$ & - & $\begin{array}{c}-0.453^{\mathbf{a}} \\
(0.039)\end{array}$ & - & $\begin{array}{c}-2.5 e-05 \\
(0.006)\end{array}$ & - & $\begin{array}{c}3.9 e-05 \\
(0.012)\end{array}$ & - \\
\hline$\beta_{3}$ & $\begin{array}{l}0.233^{\mathrm{a}} \\
(0.058)\end{array}$ & $\begin{array}{c}-0.243^{\mathbf{b}} \\
(0.099)\end{array}$ & $\begin{array}{l}0.304^{\mathrm{a}} \\
(0.024)\end{array}$ & $\begin{array}{l}-1.050 \\
(8.508)\end{array}$ & $\begin{array}{c}-0.235^{\mathbf{b}} \\
(0.092)\end{array}$ & $\begin{array}{c}-1.752^{\mathbf{b}} \\
(0.845)\end{array}$ & $\begin{array}{c}0.001 \\
(0.011)\end{array}$ & $\begin{array}{l}3.143^{\mathrm{a}} \\
(0.665)\end{array}$ \\
\hline$\beta_{6}$ & $\begin{array}{c}0.190 \\
(0.126)\end{array}$ & $\begin{array}{l}0.658^{a} \\
(0.232)\end{array}$ & $\begin{array}{l}0.153^{a} \\
(0.031)\end{array}$ & $\begin{array}{c}0.577 \\
(8.509)\end{array}$ & $\begin{array}{l}0.336^{\mathbf{a}} \\
(0.046)\end{array}$ & $\begin{array}{l}-0.886 \\
(1.512)\end{array}$ & $\begin{array}{c}-0.296^{\mathbf{a}} \\
(0.055)\end{array}$ & $\begin{array}{l}-0.436 \\
(1.030)\end{array}$ \\
\hline$\beta_{12}$ & $\begin{array}{l}0.166^{\mathrm{a}} \\
(0.051)\end{array}$ & $\begin{array}{c}-0.779^{\mathbf{c}} \\
(0.416)\end{array}$ & $\begin{array}{l}0.200^{\mathrm{b}} \\
(0.080)\end{array}$ & $\begin{array}{l}-3.748 \\
(2.542)\end{array}$ & $\begin{array}{c}0.001 \\
(0.006)\end{array}$ & $\begin{array}{l}5.708^{\mathrm{a}} \\
(2.171)\end{array}$ & $\begin{array}{l}0.120^{\mathbf{b}} \\
(0.053)\end{array}$ & $\begin{array}{c}-1.138^{\mathbf{b}} \\
(0.568)\end{array}$ \\
\hline$\beta_{24}$ & $\begin{array}{l}0.390^{\mathrm{a}} \\
(0.091)\end{array}$ & $\begin{array}{c}0.728 \\
(0.526)\end{array}$ & $\begin{array}{l}0.480^{\mathrm{a}} \\
(0.086)\end{array}$ & $\begin{array}{l}5.784 \\
(24.91)\end{array}$ & $\begin{array}{l}-0.021 \\
(0.014)\end{array}$ & $\begin{array}{l}-1.937 \\
(4.814)\end{array}$ & $\begin{array}{l}-0.005 \\
(0.008)\end{array}$ & $\begin{array}{c}1.038 \\
(1.560)\end{array}$ \\
\hline$\gamma_{1}$ & $\begin{array}{c}-0.516^{\mathbf{a}} \\
(0.130)\end{array}$ & $\begin{array}{c}-0.071^{\mathbf{b}} \\
(0.034)\end{array}$ & $\begin{array}{c}-0.534^{\mathbf{a}} \\
(0.112)\end{array}$ & $\begin{array}{c}0.623 \\
(12.10)\end{array}$ & $\begin{array}{c}-0.483^{\mathrm{a}} \\
(0.051)\end{array}$ & $\begin{array}{c}-4.222^{\mathrm{a}} \\
(0.758)\end{array}$ & $\begin{array}{c}0.011 \\
(0.008)\end{array}$ & $\begin{array}{l}-0.012 \\
(0.017)\end{array}$ \\
\hline$\phi_{1}$ & $\begin{array}{c}-0.372^{\mathrm{a}} \\
(0.087)\end{array}$ & $\begin{array}{c}-0.138^{\mathrm{c}} \\
(0.079)\end{array}$ & $\begin{array}{c}-0.254^{\mathrm{b}} \\
(0.102)\end{array}$ & $\begin{array}{c}-2.957^{\mathbf{b}} \\
(1.208)\end{array}$ & $\begin{array}{l}0.158^{\mathrm{a}} \\
(0.058)\end{array}$ & $\begin{array}{l}-0.187 \\
(0.462)\end{array}$ & $\begin{array}{c}0.001 \\
(0.006)\end{array}$ & $\begin{array}{c}0.087 \\
(0.071)\end{array}$ \\
\hline$\gamma_{2}$ & $\begin{array}{l}-0.123 \\
(0.105)\end{array}$ & $\begin{array}{c}-0.048^{\mathrm{a}} \\
(0.014)\end{array}$ & $\begin{array}{c}-0.240^{\mathrm{a}} \\
(0.090)\end{array}$ & $\begin{array}{l}-1.505 \\
(6.471)\end{array}$ & $\begin{array}{c}-0.181^{\mathrm{a}} \\
(0.046)\end{array}$ & $\begin{array}{c}-1.364^{\mathbf{a}} \\
(0.327)\end{array}$ & $\begin{array}{l}0.448^{\mathrm{a}} \\
(0.053)\end{array}$ & $\begin{array}{l}-0.238 \\
(0.437)\end{array}$ \\
\hline$\phi_{2}$ & $\begin{array}{l}0.253^{\mathrm{a}} \\
(0.049)\end{array}$ & $\begin{array}{l}0.350^{\mathrm{a}} \\
(0.049)\end{array}$ & $\begin{array}{l}0.197^{\mathrm{a}} \\
(0.036)\end{array}$ & $\begin{array}{c}0.239 \\
(5.689)\end{array}$ & $\begin{array}{l}0.255^{\mathrm{a}} \\
(0.059)\end{array}$ & $\begin{array}{l}-0.309 \\
(0.207)\end{array}$ & $\begin{array}{l}0.266^{\mathrm{a}} \\
(0.080)\end{array}$ & $\begin{array}{l}1.185^{\mathrm{a}} \\
(0.274)\end{array}$ \\
\hline$\gamma_{3}$ & $\begin{array}{c}-0.177^{\mathbf{b}} \\
(0.090)\end{array}$ & $\begin{array}{l}-0.040 \\
(0.029)\end{array}$ & $\begin{array}{c}-0.342^{\mathrm{a}} \\
(0.091)\end{array}$ & $\begin{array}{l}-1.155 \\
(10.10)\end{array}$ & $\begin{array}{c}-0.026^{\mathbf{c}} \\
(0.013)\end{array}$ & $\begin{array}{c}-0.698 \\
(0.429)\end{array}$ & $\begin{array}{l}0.254^{\mathrm{a}} \\
(0.085)\end{array}$ & $\begin{array}{l}-0.626 \\
(0.525)\end{array}$ \\
\hline$\phi_{3}$ & $\begin{array}{l}0.350^{\mathrm{a}} \\
(0.048)\end{array}$ & $\begin{array}{l}0.292^{\mathrm{a}} \\
(0.033)\end{array}$ & $\begin{array}{l}0.197^{\mathrm{b}} \\
(0.080)\end{array}$ & $\begin{array}{l}-0.221 \\
(7.866)\end{array}$ & $\begin{array}{l}0.131^{\mathrm{b}} \\
(0.065)\end{array}$ & $\begin{array}{c}0.302 \\
(0.340)\end{array}$ & $\begin{array}{l}0.645^{\mathrm{a}} \\
(0.070)\end{array}$ & $\begin{array}{l}1.199^{\mathrm{a}} \\
(0.323)\end{array}$ \\
\hline$\gamma_{4}$ & $\begin{array}{c}-0.199^{\mathrm{a}} \\
(0.054)\end{array}$ & $\begin{array}{c}-0.257^{\mathrm{a}} \\
(0.051)\end{array}$ & $\begin{array}{c}-0.040^{\mathbf{b}} \\
(0.019)\end{array}$ & $\begin{array}{l}-0.280 \\
(4.217)\end{array}$ & $\begin{array}{c}-0.113^{\mathrm{a}} \\
(0.038)\end{array}$ & $\begin{array}{l}-0.044 \\
(0.119)\end{array}$ & $\begin{array}{c}-0.401^{\mathrm{a}} \\
(0.089)\end{array}$ & $\begin{array}{c}-1.305^{\mathrm{a}} \\
(0.203)\end{array}$ \\
\hline$\phi_{4}$ & $\begin{array}{c}-0.014 \\
(0.024)\end{array}$ & $\begin{array}{l}0.150^{\mathrm{a}} \\
(0.036)\end{array}$ & $\begin{array}{c}-0.057^{\mathrm{a}} \\
(0.013)\end{array}$ & $\begin{array}{l}-0.490 \\
(3.658)\end{array}$ & $\begin{array}{l}0.300^{\mathrm{a}} \\
(0.064)\end{array}$ & $\begin{array}{l}-0.493 \\
(0.318)\end{array}$ & $\begin{array}{l}0.329^{\mathrm{a}} \\
(0.069)\end{array}$ & $\begin{array}{l}-0.295 \\
(0.331)\end{array}$ \\
\hline$\gamma_{5}$ & $\begin{array}{c}-0.251^{\mathrm{a}} \\
(0.046)\end{array}$ & $\begin{array}{l}-0.073 \\
(0.048)\end{array}$ & $\begin{array}{c}-0.108^{\mathbf{c}} \\
(0.063)\end{array}$ & $\begin{array}{l}-0.168 \\
(1.890)\end{array}$ & $\begin{array}{c}-0.174^{\mathbf{b}} \\
(0.084)\end{array}$ & $\begin{array}{l}-0.163 \\
(0.111)\end{array}$ & $\begin{array}{c}-0.323^{\mathbf{a}} \\
(0.083)\end{array}$ & $\begin{array}{c}-0.627^{\mathrm{a}} \\
(0.169)\end{array}$ \\
\hline$\phi_{5}$ & $\begin{array}{l}0.140^{\mathrm{a}} \\
(0.039)\end{array}$ & $\begin{array}{l}0.257^{\mathrm{a}} \\
(0.036)\end{array}$ & $\begin{array}{c}0.043 \\
(0.050)\end{array}$ & $\begin{array}{l}-0.202 \\
(3.097)\end{array}$ & $\begin{array}{l}0.308^{\mathbf{a}} \\
(0.111)\end{array}$ & $\begin{array}{l}-0.044 \\
(0.055)\end{array}$ & $\begin{array}{l}0.107^{\mathrm{a}} \\
(0.031)\end{array}$ & $\begin{array}{c}-0.657^{\mathrm{a}} \\
(0.254)\end{array}$ \\
\hline$L L F$ & 56787.14 & 56745.73 & 50203.66 & 50150.49 & 48111.29 & 48167.20 & 53140.53 & 53155.10 \\
\hline
\end{tabular}

Note: Estimation results for the return series for the precious metals: Gold (XAU), Silver (XAG), Palladium (XPD) and Platinum (XPT). Egarch and Egarch-HAR models. Period 27th of December 2008 to the 30th of November 2010. Hourly series, 11880 observations. LLF is the Log-likelihood function. Standard errors in bracket. "a", "b" and "c" indicate significance at the $1 \%, 5 \%$ and $10 \%$. 

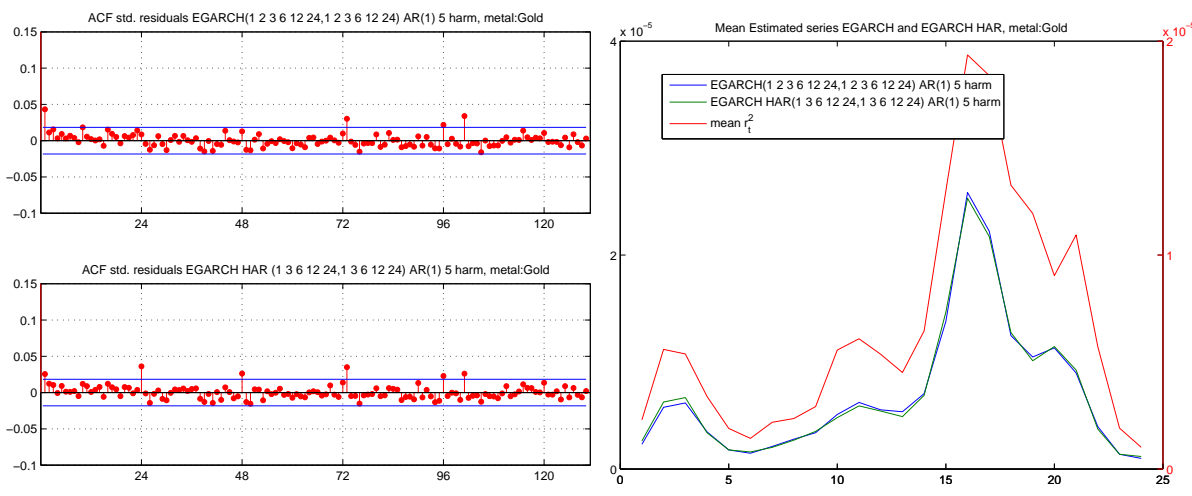

(a) XAU

(b) XAU
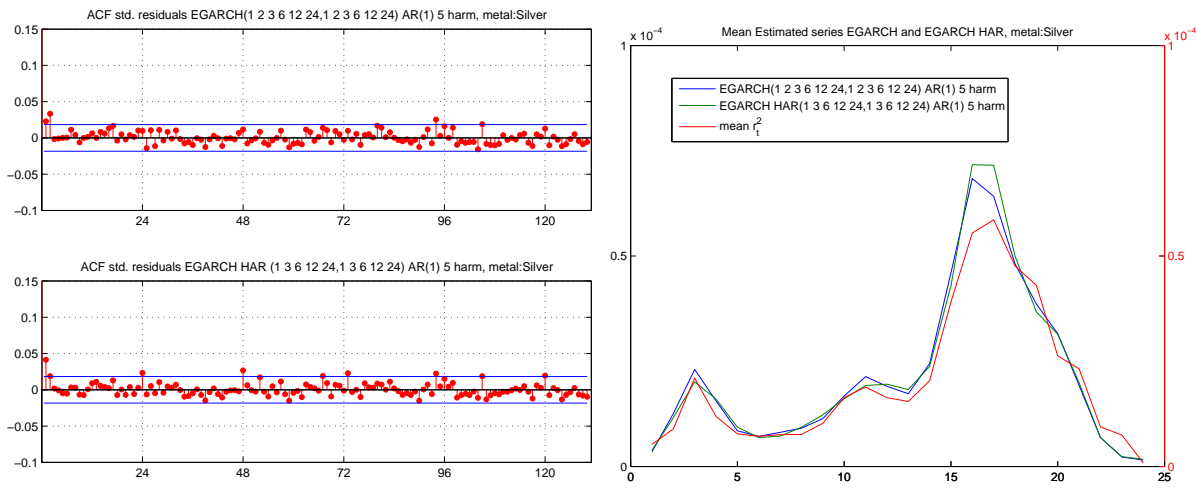

(c) XAG

(d) XAG
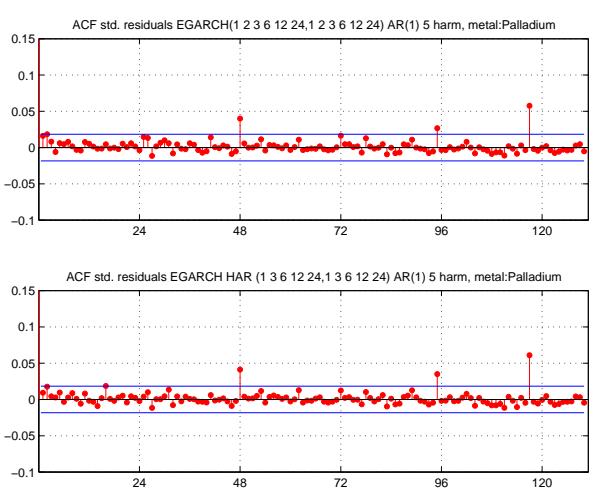

(e) XPD

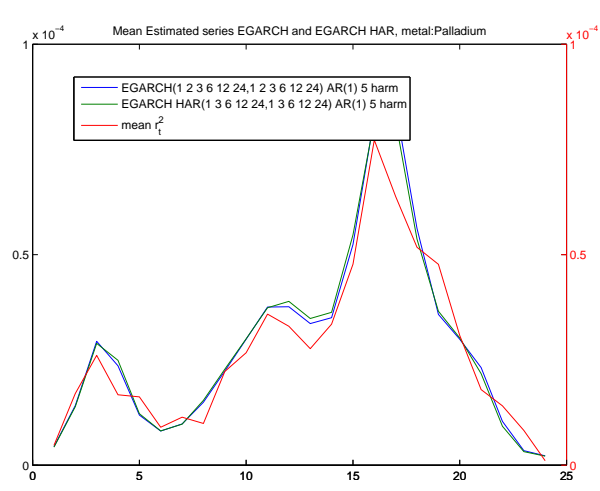

(f) $\mathrm{XPD}$
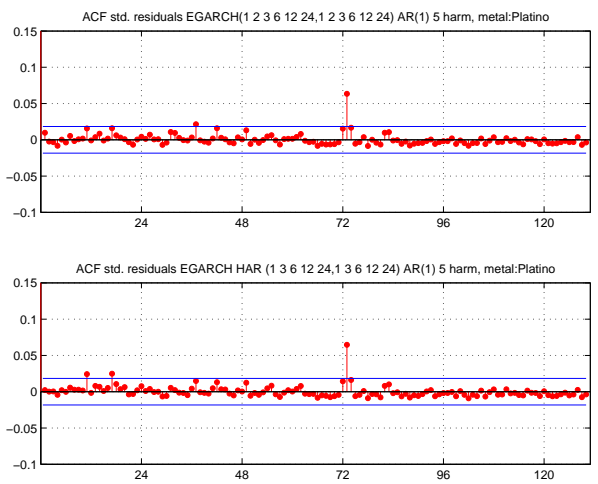

(g) XPT

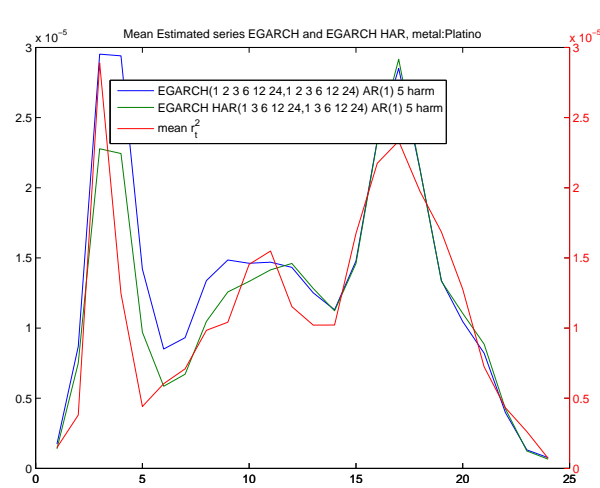

(h) XPT

Figure A.12: ACF standardized squared residuals Return and mean estimated series 
Table A.2: Estimation Volume GARMA model

\begin{tabular}{|c|c|c|c|c|c|c|c|c|}
\hline & $\mathrm{XAU}$ & $\mathrm{XAU}$ & XAG & XAG & XPD & XPD & XPT & XPT \\
\hline \multirow[t]{2}{*}{$d_{1}$} & $0.151^{\mathrm{a}}$ & $0.292^{\mathrm{a}}$ & $0.118^{\mathrm{a}}$ & $0.254^{\mathrm{a}}$ & $0.103^{\mathrm{a}}$ & $0.237^{\mathrm{a}}$ & $0.134^{\mathrm{a}}$ & $0.258^{\mathrm{a}}$ \\
\hline & $(0.022)$ & $(0.008)$ & (0.013) & $(0.014)$ & $(0.006)$ & $(0.010)$ & $(0.017)$ & $(0.008)$ \\
\hline \multirow[t]{2}{*}{$d_{2}$} & $0.257^{\mathrm{a}}$ & $0.468^{a}$ & $0.220^{\mathrm{a}}$ & $0.390^{\mathbf{a}}$ & $0.199^{a}$ & $0.374^{\mathrm{a}}$ & $0.200^{a}$ & $0.359^{a}$ \\
\hline & $(0.015)$ & $(0.031)$ & $(0.006)$ & $(0.014)$ & $(0.010)$ & (0.013) & $(0.016)$ & $(0.008)$ \\
\hline \multirow[t]{2}{*}{$d_{3}$} & $0.176^{\mathrm{a}}$ & $0.382^{\mathrm{a}}$ & $0.131^{\mathrm{a}}$ & $0.263^{\mathrm{a}}$ & $0.112^{\mathrm{a}}$ & $0.270^{\mathrm{a}}$ & $0.123^{\mathrm{a}}$ & $0.269^{\mathrm{a}}$ \\
\hline & $(0.016)$ & $(0.035)$ & $(0.010)$ & $(0.014)$ & (0.009) & (0.008) & $(0.012)$ & (0.009) \\
\hline \multirow[t]{2}{*}{$d_{4}$} & $0.180^{\mathrm{a}}$ & $0.362^{\mathrm{a}}$ & $0.142^{\mathrm{a}}$ & $0.248^{\mathrm{a}}$ & $0.132^{\mathrm{a}}$ & $0.259^{\mathrm{a}}$ & $0.182^{\mathrm{a}}$ & $0.319^{\mathrm{a}}$ \\
\hline & $(0.046)$ & $(0.081)$ & $(0.011)$ & $(0.015)$ & $(0.007)$ & $(0.011)$ & $(0.023)$ & (0.009) \\
\hline \multirow[t]{2}{*}{$d_{5}$} & $0.211^{\mathrm{a}}$ & $0.368^{\mathrm{a}}$ & $0.153^{\mathrm{a}}$ & $0.231^{\mathrm{a}}$ & $0.125^{\mathrm{a}}$ & $0.237^{\mathrm{a}}$ & $0.159^{\mathrm{a}}$ & $0.271^{\mathrm{a}}$ \\
\hline & (0.009) & $(0.053)$ & (0.011) & $(0.014)$ & $(0.013)$ & $(0.011)$ & $(0.013)$ & (0.011) \\
\hline \multirow[t]{2}{*}{$d_{6}$} & $0.153^{\mathrm{a}}$ & $0.317^{\mathrm{a}}$ & $0.131^{\mathrm{a}}$ & $0.196^{\mathrm{a}}$ & $0.142^{\mathrm{a}}$ & $0.243^{a}$ & $0.130^{\mathrm{a}}$ & $0.234^{\mathrm{a}}$ \\
\hline & $(0.038)$ & $(0.046)$ & $(0.011)$ & $(0.016)$ & $(0.010)$ & $(0.017)$ & $(0.021)$ & (0.008) \\
\hline \multirow[t]{2}{*}{$d_{7}$} & $0.179^{\mathrm{a}}$ & $0.323^{\mathrm{a}}$ & $0.137^{a}$ & $0.191^{\mathrm{a}}$ & $0.119^{\mathrm{a}}$ & $0.209^{\mathrm{a}}$ & $0.133^{a}$ & $0.232^{\mathrm{a}}$ \\
\hline & $(0.013)$ & $(0.055)$ & $(0.016)$ & $(0.015)$ & $(0.010)$ & $(0.013)$ & (0.019) & $(0.012)$ \\
\hline \multirow[t]{2}{*}{$d_{8}$} & $0.175^{a}$ & $0.320^{\mathbf{a}}$ & $0.137^{a}$ & $0.189^{a}$ & $0.120^{\mathrm{a}}$ & $0.208^{a}$ & $0.133^{a}$ & $0.221^{\mathrm{a}}$ \\
\hline & $(0.047)$ & (0.059) & $(0.010)$ & $(0.015)$ & $(0.012)$ & $(0.011)$ & $(0.017)$ & $(0.011)$ \\
\hline \multirow[t]{2}{*}{$d_{9}$} & $0.182^{a}$ & $0.314^{a}$ & $0.153^{a}$ & $0.191^{a}$ & $0.116^{\mathbf{a}}$ & $0.197^{a}$ & $0.141^{a}$ & $0.23^{\mathbf{a}}$ \\
\hline & $(0.045)$ & $(0.061)$ & $(0.014)$ & (0.018) & $(0.010)$ & $(0.010)$ & $(0.023)$ & (0.013) \\
\hline \multirow[t]{2}{*}{$d_{10}$} & $0.176^{a}$ & $0.316^{a}$ & $0.140^{a}$ & $0.172^{\mathrm{a}}$ & $0.126^{a}$ & $0.204^{a}$ & $0.143^{a}$ & $0.224^{\mathrm{a}}$ \\
\hline & $(0.040)$ & (0.108) & $(0.010)$ & $(0.017)$ & $(0.012)$ & $(0.015)$ & $(0.012)$ & $(0.010)$ \\
\hline \multirow[t]{2}{*}{$d_{11}$} & $0.181^{a}$ & $0.313^{a}$ & $0.138^{a}$ & $0.164^{a}$ & $0.138^{a}$ & $0.211^{\mathrm{a}}$ & $0.143^{a}$ & $0.228^{\mathbf{a}}$ \\
\hline & (0.023) & $(0.057)$ & $(0.017)$ & $(0.017)$ & $(0.012)$ & $(0.010)$ & $(0.015)$ & $(0.010)$ \\
\hline \multirow[t]{2}{*}{$d_{12}$} & $0.156^{\mathrm{a}}$ & $0.293^{\mathrm{a}}$ & $0.135^{a}$ & $0.152^{a}$ & $0.109^{a}$ & $0.189^{a}$ & $0.132^{a}$ & $0.213^{\mathrm{a}}$ \\
\hline & $(0.018)$ & $(0.107)$ & $(0.018)$ & (0.019) & $(0.014)$ & (0.009) & $(0.025)$ & $(0.014)$ \\
\hline \multirow[t]{2}{*}{$d_{13}$} & $0.077^{\mathrm{c}}$ & $0.143^{a}$ & $0.075^{a}$ & $0.083^{a}$ & $0.063^{a}$ & $0.101^{a}$ & $0.077^{a}$ & $0.116^{\mathrm{a}}$ \\
\hline & $(0.042)$ & $(0.010)$ & $(0.008)$ & $(0.011)$ & $(0.008)$ & (0.008) & (0.009) & $(0.010)$ \\
\hline \multirow[t]{2}{*}{$\phi_{1}$} & - & -0.018 & - & $-0.234^{\mathrm{a}}$ & - & $-0.055^{\mathrm{b}}$ & - & -0.028 \\
\hline & & $(0.159)$ & & $(0.044)$ & & $(0.021)$ & & $(0.026)$ \\
\hline \multirow[t]{2}{*}{$\phi_{24}$} & - & $-0.257^{\mathbf{a}}$ & - & $-0.157^{\mathbf{a}}$ & - & $-0.170^{\mathbf{a}}$ & - & $-0.182^{\mathrm{a}}$ \\
\hline & & $(0.069)$ & & $(0.015)$ & & $(0.009)$ & & $(0.008)$ \\
\hline \multirow[t]{2}{*}{$\phi_{48}$} & - & $-0.150^{\mathrm{a}}$ & - & $-0.068^{\mathbf{a}}$ & - & $-0.132^{\mathbf{a}}$ & - & $-0.103^{a}$ \\
\hline & & $(0.025)$ & & $(0.011)$ & & $(0.009)$ & & $(0.010)$ \\
\hline \multirow[t]{2}{*}{$\phi_{72}$} & - & $-0.097^{\mathbf{c}}$ & - & $-0.083^{a}$ & - & $-0.084^{a}$ & - & $-0.056^{\mathbf{a}}$ \\
\hline & & $(0.055)$ & & $(0.010)$ & & $(0.008)$ & & $(0.009)$ \\
\hline \multirow[t]{2}{*}{$\phi_{96}$} & - & $-0.070^{\mathbf{a}}$ & - & $-0.033^{\mathrm{a}}$ & - & $-0.052^{\mathrm{a}}$ & - & $-0.058^{\mathrm{a}}$ \\
\hline & & (0.013) & & (0.009) & & $\begin{array}{c}(0.007) \\
-0.026^{a}\end{array}$ & & $\begin{array}{l}(0.012) \\
-0.006\end{array}$ \\
\hline$\phi_{120}$ & - & $\begin{array}{l}-0.002 \\
(0.061)\end{array}$ & - & $\begin{array}{l}-0.002 \\
(0.009)\end{array}$ & - & $\begin{array}{c}-0.026^{\mathbf{a}} \\
(0.009)\end{array}$ & - & $\begin{array}{c}-0.006 \\
(0.009)\end{array}$ \\
\hline$\theta_{1}$ & - & $\begin{array}{c}-0.517^{\mathbf{a}} \\
(0.104)\end{array}$ & - & $\begin{array}{c}-0.667^{\mathbf{a}} \\
(0.033)\end{array}$ & - & $\begin{array}{c}-0.587^{\mathrm{a}} \\
(0.037)\end{array}$ & - & $\begin{array}{c}-0.519^{\mathrm{a}} \\
(0.031)\end{array}$ \\
\hline \multirow[t]{2}{*}{$\mu$} & $-22.01^{\mathrm{a}}$ & $-26.62^{\mathrm{a}}$ & $-99.93^{\mathrm{a}}$ & $-99.21^{\mathbf{a}}$ & $-13.31^{\mathrm{a}}$ & $-11.38^{a}$ & $-13.39^{\mathrm{a}}$ & $-10.88^{a}$ \\
\hline & $(1.742)$ & $(6.688)$ & $(6.929)$ & $(12.12)$ & $(1.090)$ & $(0.892)$ & $(1.161)$ & $(0.540)$ \\
\hline \multirow[t]{2}{*}{$\sigma$} & $367.0^{\mathbf{a}}$ & $356.8^{a}$ & $20908^{a}$ & $20274^{a}$ & $706.6^{a}$ & $690.7^{a}$ & $441.3^{a}$ & $433.3^{\mathbf{a}}$ \\
\hline & (20.12) & $(35.77)$ & (361.8) & (292.9) & (8.443) & (8.043) & $(5.404)$ & $(3.859)$ \\
\hline$L L F$ & -51936.01 & -51768.53 & -75947.61 & -75764.66 & -55826.96 & -55691.76 & -53030.35 & -52921.69 \\
\hline
\end{tabular}

Note: Estimation results for the volume series for the precious metals: Gold (XAU), Silver (XAG), Palladium (XPD) and Platinum (XPT). GARMA models. Period 27th of December 2008 to the 30th of November 2010. Hourly series, 11880 observations. $L L F$ is the Log-likelihood function. Standard errors in bracket. "a", "b" and "c" indicate significance at the $1 \%, 5 \%$ and $10 \%$. 


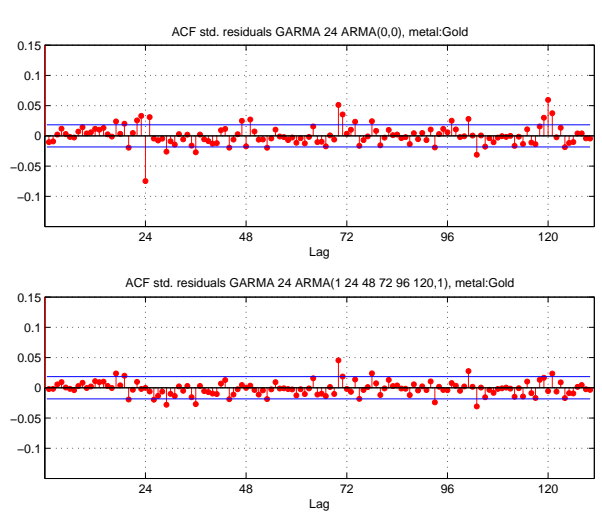

(a) XAU
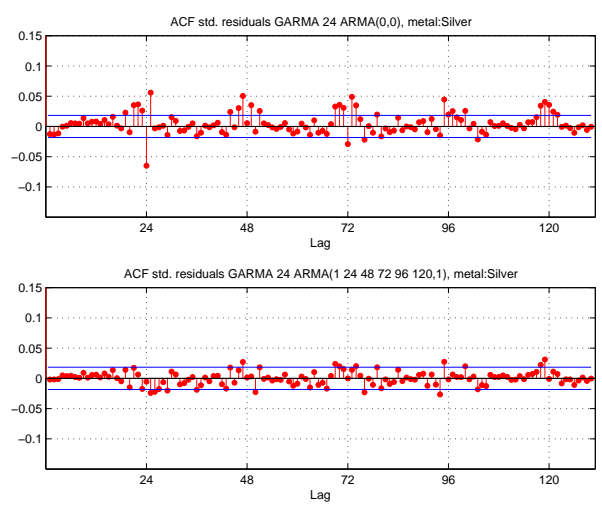

(c) XAG
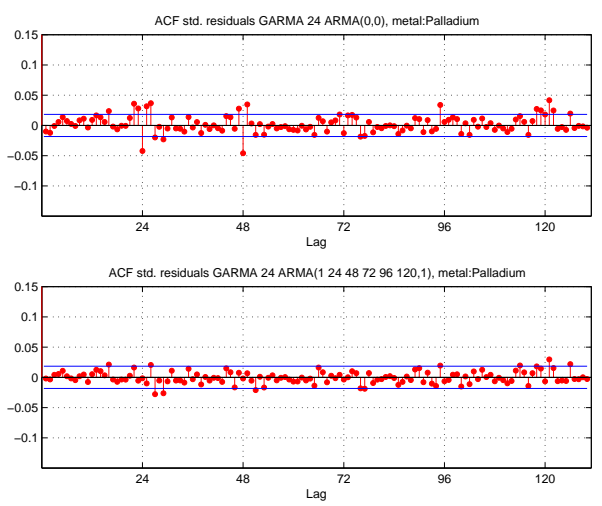

(e) XPD
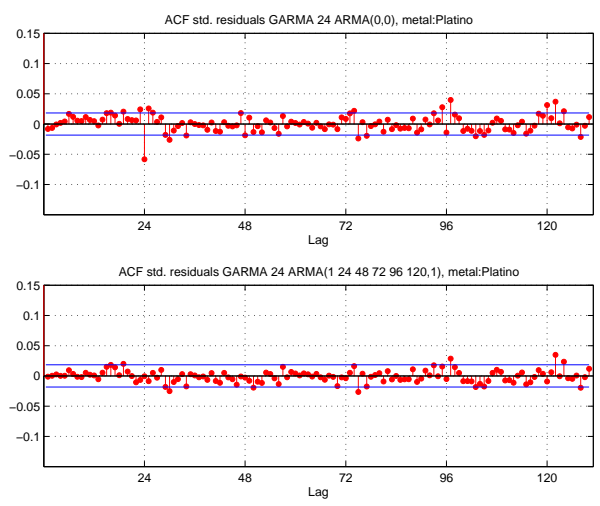

(g) XPT

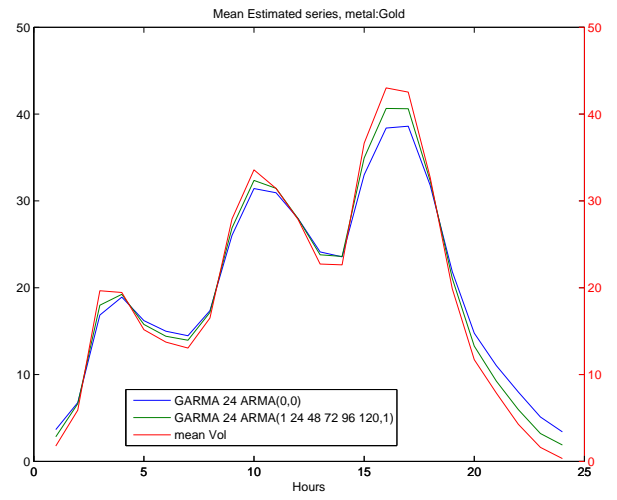

(b) XAU

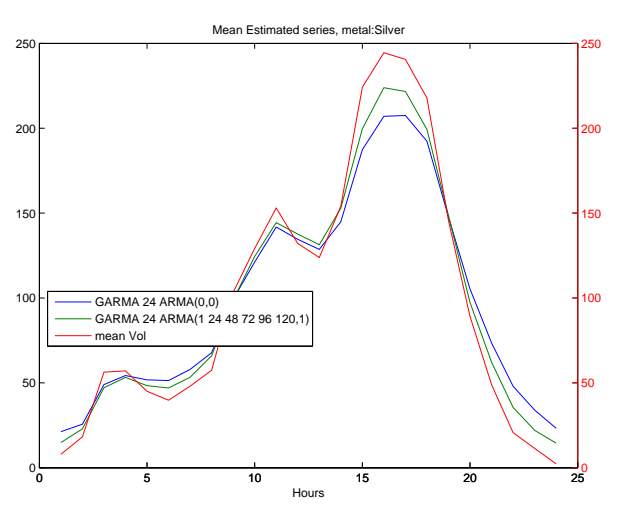

(d) XAG

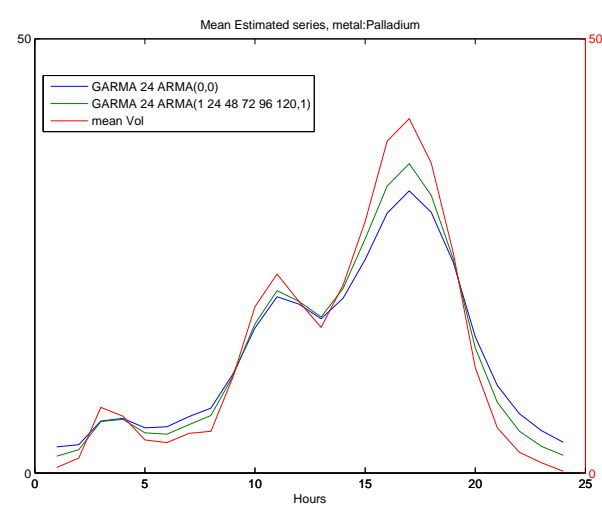

(f) XPD

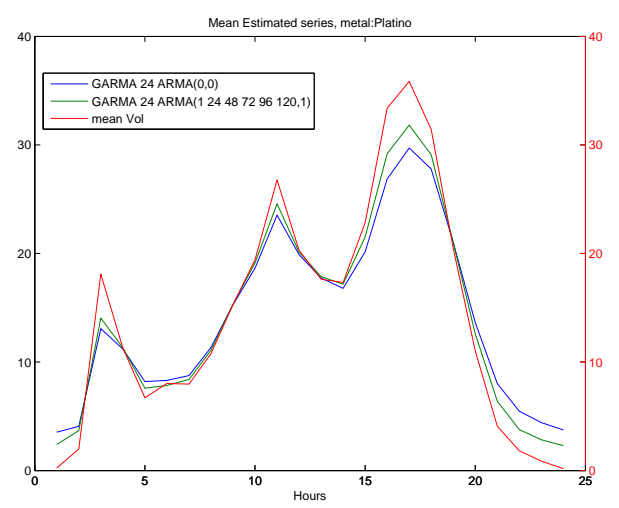

(h) XPT

Figure A.13: ACF standardized squared residuals Volume and mean estimated series 
Table A.3: Estimation $O F^{2} / 100$ ARFIMA with harmonics

\begin{tabular}{|c|c|c|c|c|c|c|c|c|}
\hline & $\mathrm{XAU}$ & $\mathrm{XAU}$ & $\mathrm{XAG}$ & XAG & XPD & $\mathrm{XPD}$ & XPT & $\mathrm{XPT}$ \\
\hline$d$ & $\begin{array}{l}0.051^{\mathrm{a}} \\
(0.014)\end{array}$ & $\begin{array}{l}0.046^{\mathbf{a}} \\
(0.014)\end{array}$ & $\begin{array}{l}0.168^{\mathrm{a}} \\
(0.025)\end{array}$ & $\begin{array}{l}0.163^{\mathbf{a}} \\
(0.025)\end{array}$ & $\begin{array}{l}0.080^{\mathbf{a}} \\
(0.009)\end{array}$ & $\begin{array}{l}0.077^{\mathbf{a}} \\
(0.009)\end{array}$ & $\begin{array}{l}0.070^{\mathbf{a}} \\
(0.009)\end{array}$ & $\begin{array}{l}0.071^{\mathrm{a}} \\
(0.009)\end{array}$ \\
\hline$\phi_{1}$ & $0.294^{\mathrm{a}}$ & $0.294^{\mathrm{a}}$ & $0.734^{\mathrm{a}}$ & $0.724^{\mathrm{a}}$ & $-0.261^{\mathbf{c}}$ & -0.165 & $-0.547^{\mathbf{b}}$ & $-0.616^{\mathbf{a}}$ \\
\hline & $(0.068)$ & $(0.062)$ & $(0.046)$ & $(0.045)$ & $(0.137)$ & $(0.109)$ & $(0.255)$ & $(0.219)$ \\
\hline$\phi_{24}$ & $\begin{array}{l}0.031^{\mathrm{a}} \\
(0.008)\end{array}$ & $\begin{array}{l}0.029^{\mathrm{a}} \\
(0.008)\end{array}$ & $\begin{array}{c}0.008 \\
(0.006)\end{array}$ & $\begin{array}{c}0.007 \\
(0.006)\end{array}$ & $\begin{array}{l}0.055^{\mathrm{a}} \\
(0.009)\end{array}$ & $\begin{array}{l}0.054^{\mathrm{a}} \\
(0.009)\end{array}$ & $\begin{array}{l}0.021^{\mathrm{b}} \\
(0.008)\end{array}$ & $\begin{array}{l}0.020^{\mathbf{b}} \\
(0.008)\end{array}$ \\
\hline$\phi_{48}$ & - & $\begin{array}{l}0.027^{\mathrm{a}} \\
(0.008)\end{array}$ & - & $\begin{array}{c}0.005 \\
(0.006)\end{array}$ & - & $\begin{array}{l}0.038^{\mathbf{a}} \\
(0.009)\end{array}$ & - & $\begin{array}{l}-0.001 \\
(0.007)\end{array}$ \\
\hline$\phi_{72}$ & - & $\begin{array}{l}0.021^{b} \\
(0.008)\end{array}$ & - & $\begin{array}{c}0.002 \\
(0.006)\end{array}$ & - & $\begin{array}{c}-0.015^{\mathbf{c}} \\
(0.009)\end{array}$ & - & $\begin{array}{l}-0.001 \\
(0.007)\end{array}$ \\
\hline$\phi_{96}$ & - & $\begin{array}{l}0.020^{\mathbf{b}} \\
(0.008)\end{array}$ & - & $\begin{array}{l}0.014^{\mathrm{b}} \\
(0.006)\end{array}$ & - & $\begin{array}{l}0.016^{\mathbf{c}} \\
(0.009)\end{array}$ & - & $\begin{array}{l}-0.007 \\
(0.007)\end{array}$ \\
\hline$\phi_{120}$ & $\begin{array}{c}0.051^{\mathrm{a}} \\
(0.008)\end{array}$ & $\begin{array}{l}0.048^{\mathbf{a}} \\
(0.008)\end{array}$ & $\begin{array}{c}0.011^{\mathbf{c}} \\
(0.006)\end{array}$ & $\begin{array}{c}0.010 \\
(0.006)\end{array}$ & $\begin{array}{l}-0.007 \\
(0.009)\end{array}$ & $\begin{array}{l}-0.007 \\
(0.009)\end{array}$ & $\begin{array}{c}0.004 \\
(0.009)\end{array}$ & $\begin{array}{c}0.005 \\
(0.008)\end{array}$ \\
\hline$\theta_{1}$ & $\begin{array}{c}-0.195^{\mathrm{a}} \\
(0.064)\end{array}$ & $\begin{array}{c}-0.191^{\mathrm{a}} \\
(0.058)\end{array}$ & $\begin{array}{c}-0.806^{\mathbf{a}} \\
(0.033)\end{array}$ & $\begin{array}{c}-0.794^{\mathrm{a}} \\
(0.035)\end{array}$ & $\begin{array}{l}0.291^{\mathbf{b}} \\
(0.133)\end{array}$ & $\begin{array}{c}0.198^{c} \\
(0.107)\end{array}$ & $\begin{array}{l}0.558^{\mathbf{b}} \\
(0.245)\end{array}$ & $\begin{array}{c}0.624^{\mathrm{a}} \\
(0.210)\end{array}$ \\
\hline$\mu$ & $\begin{array}{c}-0.827^{a} \\
(0.056)\end{array}$ & $\begin{array}{c}-0.826^{\mathbf{a}} \\
(0.061)\end{array}$ & $\begin{array}{c}-0.056^{\mathbf{a}} \\
(0.007)\end{array}$ & $\begin{array}{c}-0.056^{\mathbf{a}} \\
(0.007)\end{array}$ & $\begin{array}{c}-0.051^{\mathbf{a}} \\
(0.004)\end{array}$ & $\begin{array}{c}-0.051^{\mathrm{a}} \\
(0.004)\end{array}$ & $\begin{array}{c}-0.065^{\mathrm{a}} \\
(0.005)\end{array}$ & $\begin{array}{c}-0.065^{\mathbf{a}} \\
(0.005)\end{array}$ \\
\hline$\gamma_{1}$ & $\begin{array}{l}0.587^{\mathrm{a}} \\
(0.053)\end{array}$ & $\begin{array}{l}0.587^{\mathrm{a}} \\
(0.059)\end{array}$ & $\begin{array}{c}0.035^{\mathrm{a}} \\
(0.003)\end{array}$ & $\begin{array}{l}0.035^{\mathrm{a}} \\
(0.003)\end{array}$ & $\begin{array}{l}0.037^{\mathrm{a}} \\
(0.003)\end{array}$ & $\begin{array}{l}0.037^{\mathrm{a}} \\
(0.003)\end{array}$ & $\begin{array}{l}0.044^{\mathrm{a}} \\
(0.004)\end{array}$ & $\begin{array}{l}0.044^{\mathrm{a}} \\
(0.004)\end{array}$ \\
\hline$\phi_{1}$ & $\begin{array}{l}0.453^{\mathrm{a}} \\
(0.053)\end{array}$ & $\begin{array}{l}0.452^{\mathrm{a}} \\
(0.059)\end{array}$ & $\begin{array}{l}0.038^{\mathbf{a}} \\
(0.003)\end{array}$ & $\begin{array}{l}0.038^{\mathrm{a}} \\
(0.003)\end{array}$ & $\begin{array}{l}0.044^{\mathrm{a}} \\
(0.003)\end{array}$ & $\begin{array}{l}0.044^{\mathrm{a}} \\
(0.003)\end{array}$ & $\begin{array}{l}0.030^{\mathrm{a}} \\
(0.004)\end{array}$ & $\begin{array}{l}0.030^{\mathrm{a}} \\
(0.004)\end{array}$ \\
\hline$\gamma_{2}$ & $\begin{array}{l}0.309^{\mathrm{a}} \\
(0.050)\end{array}$ & $\begin{array}{l}0.309^{\mathrm{a}} \\
(0.055)\end{array}$ & $\begin{array}{l}0.019^{\mathrm{a}} \\
(0.003)\end{array}$ & $\begin{array}{l}0.019^{\mathrm{a}} \\
(0.003)\end{array}$ & $\begin{array}{l}0.018^{\mathbf{a}} \\
(0.003)\end{array}$ & $\begin{array}{c}0.018^{\mathbf{a}} \\
(0.003)\end{array}$ & $\begin{array}{l}0.020^{\mathrm{a}} \\
(0.004)\end{array}$ & $\begin{array}{l}0.020^{\mathbf{a}} \\
(0.004)\end{array}$ \\
\hline$\phi_{2}$ & $\begin{array}{c}-0.268^{\mathbf{a}} \\
(0.050)\end{array}$ & $\begin{array}{c}-0.268^{\mathrm{a}} \\
(0.055)\end{array}$ & $\begin{array}{c}-0.012^{\mathrm{a}} \\
(0.003)\end{array}$ & $\begin{array}{c}-0.012^{\mathrm{a}} \\
(0.003)\end{array}$ & $\begin{array}{c}-0.019^{\mathrm{a}} \\
(0.003)\end{array}$ & $\begin{array}{c}-0.019^{\mathrm{a}} \\
(0.003)\end{array}$ & $\begin{array}{c}-0.019^{\mathrm{a}} \\
(0.004)\end{array}$ & $\begin{array}{c}-0.019^{\mathrm{a}} \\
(0.004)\end{array}$ \\
\hline$\gamma_{3}$ & $\begin{array}{c}-0.151^{\mathrm{a}} \\
(0.047)\end{array}$ & $\begin{array}{c}-0.150^{\mathbf{a}} \\
(0.051)\end{array}$ & $\begin{array}{l}-0.002 \\
(0.003)\end{array}$ & $\begin{array}{l}-0.002 \\
(0.003)\end{array}$ & $\begin{array}{l}-0.002 \\
(0.003)\end{array}$ & $\begin{array}{l}-0.002 \\
(0.003)\end{array}$ & $\begin{array}{l}0.007^{\mathrm{c}} \\
(0.003)\end{array}$ & $\begin{array}{l}0.007^{\mathrm{c}} \\
(0.003)\end{array}$ \\
\hline$\phi_{3}$ & $\begin{array}{c}-0.245^{\mathrm{a}} \\
(0.047)\end{array}$ & $\begin{array}{c}-0.245^{\mathrm{a}} \\
(0.051)\end{array}$ & $\begin{array}{c}-0.016^{\mathbf{a}} \\
(0.003)\end{array}$ & $\begin{array}{c}-0.016^{\mathbf{a}} \\
(0.003)\end{array}$ & $\begin{array}{c}-0.018^{\mathbf{a}} \\
(0.003)\end{array}$ & $\begin{array}{c}-0.018^{\mathbf{a}} \\
(0.003)\end{array}$ & $\begin{array}{c}-0.029^{\mathrm{a}} \\
(0.003)\end{array}$ & $\begin{array}{c}-0.029^{\mathrm{a}} \\
(0.003)\end{array}$ \\
\hline$\gamma_{4}$ & $\begin{array}{l}0.093^{\mathbf{b}} \\
(0.044)\end{array}$ & $\begin{array}{l}0.093^{\mathrm{c}} \\
(0.048)\end{array}$ & $\begin{array}{c}0.002 \\
(0.003)\end{array}$ & $\begin{array}{c}0.002 \\
(0.003)\end{array}$ & $\begin{array}{c}-0.005^{\mathrm{c}} \\
(0.003)\end{array}$ & $\begin{array}{c}-0.005^{\mathbf{c}} \\
(0.003)\end{array}$ & $\begin{array}{l}-0.004 \\
(0.003)\end{array}$ & $\begin{array}{l}-0.004 \\
(0.003)\end{array}$ \\
\hline$\phi_{4}$ & $\begin{array}{l}0.237^{\mathrm{a}} \\
(0.044)\end{array}$ & $\begin{array}{l}0.237^{\mathrm{a}} \\
(0.048)\end{array}$ & $\begin{array}{l}0.007^{\mathrm{b}} \\
(0.003)\end{array}$ & $\begin{array}{l}0.007^{\mathrm{b}} \\
(0.003)\end{array}$ & $\begin{array}{l}0.008^{\mathbf{a}} \\
(0.003)\end{array}$ & $\begin{array}{l}0.008^{\mathbf{a}} \\
(0.003)\end{array}$ & $\begin{array}{l}0.013^{\mathrm{a}} \\
(0.003)\end{array}$ & $\begin{array}{l}0.013^{\mathrm{a}} \\
(0.003)\end{array}$ \\
\hline$\gamma_{5}$ & $\begin{array}{c}0.017 \\
(0.042)\end{array}$ & $\begin{array}{c}0.017 \\
(0.045)\end{array}$ & $\begin{array}{l}-0.001 \\
(0.002)\end{array}$ & $\begin{array}{l}-0.001 \\
(0.002)\end{array}$ & $\begin{array}{l}-0.000 \\
(0.002)\end{array}$ & $\begin{array}{l}-0.000 \\
(0.003)\end{array}$ & $\begin{array}{l}0.006^{\mathbf{c}} \\
(0.003)\end{array}$ & $\begin{array}{l}0.006^{\mathbf{c}} \\
(0.003)\end{array}$ \\
\hline$\phi_{5}$ & $\begin{array}{l}-0.013 \\
(0.042)\end{array}$ & $\begin{array}{l}-0.013 \\
(0.045)\end{array}$ & $\begin{array}{l}-0.003 \\
(0.002)\end{array}$ & $\begin{array}{l}-0.003 \\
(0.002)\end{array}$ & $\begin{array}{l}0.005^{\mathrm{c}} \\
(0.002)\end{array}$ & $\begin{array}{l}0.005^{\mathrm{c}} \\
(0.003)\end{array}$ & $\begin{array}{l}0.011^{\mathrm{a}} \\
(0.003)\end{array}$ & $\begin{array}{l}0.011^{\mathrm{a}} \\
(0.003)\end{array}$ \\
\hline$\sigma$ & $\begin{array}{l}9.238^{\mathbf{a}} \\
(0.118)\end{array}$ & $\begin{array}{l}9.220^{\mathbf{a}} \\
(0.119)\end{array}$ & $\begin{array}{l}0.050^{\mathrm{a}} \\
(0.000)\end{array}$ & $\begin{array}{l}0.050^{\mathrm{a}} \\
(0.000)\end{array}$ & $\begin{array}{l}0.049^{\mathrm{a}} \\
(0.000)\end{array}$ & $\begin{array}{l}0.049^{\mathbf{a}} \\
(0.000)\end{array}$ & $\begin{array}{l}0.085^{\mathrm{a}} \\
(0.001)\end{array}$ & $\begin{array}{l}0.085^{\mathrm{a}} \\
(0.001)\end{array}$ \\
\hline$L L F$ & -30063.71 & -30052.31 & 858.8025 & 861.9133 & 1032.726 & 1044.071 & -2263.594 & -2263.024 \\
\hline
\end{tabular}

Note: Estimation results for the $O F^{2} / 100$ series for the precious metals: Gold (XAU), Silver (XAG), Palladium (XPD) and Platinum (XPT). ARFIMA models.Period 27th of December 2008 to the 30th of November 2010. Hourly series, 11880 observations. $L L F$ is the Log-likelihood function. Standard errors in bracket. "a", "b" and "c" indicate significance at the $1 \%, 5 \%$ and $10 \%$. 

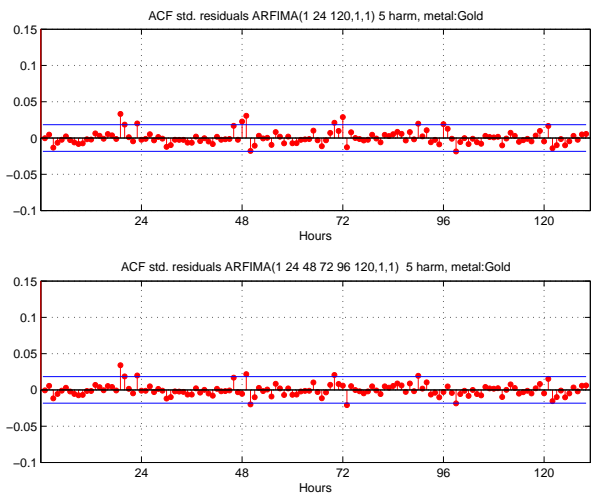

(a) XAU
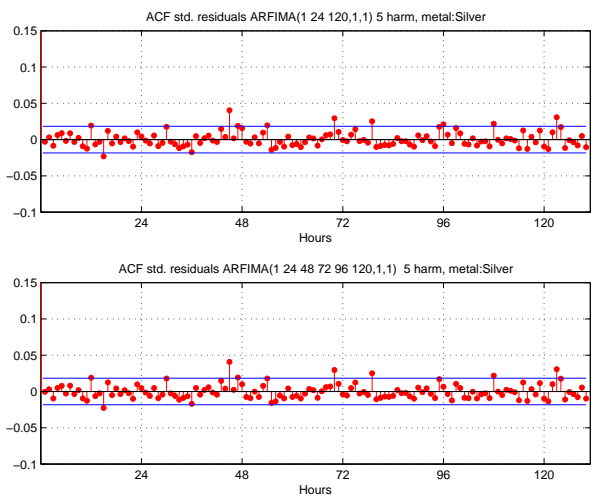

(c) XAG
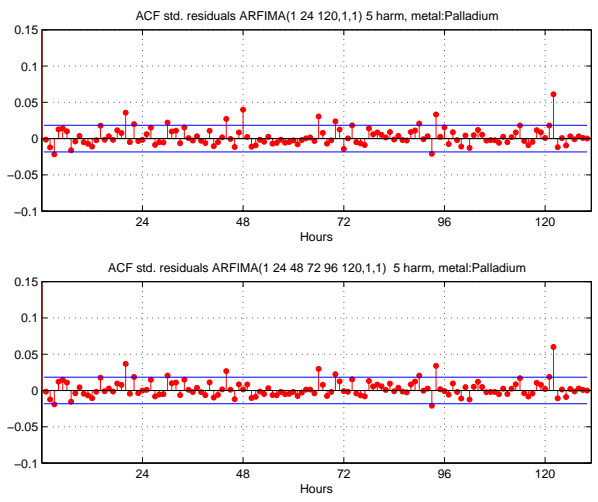

(e) XPD
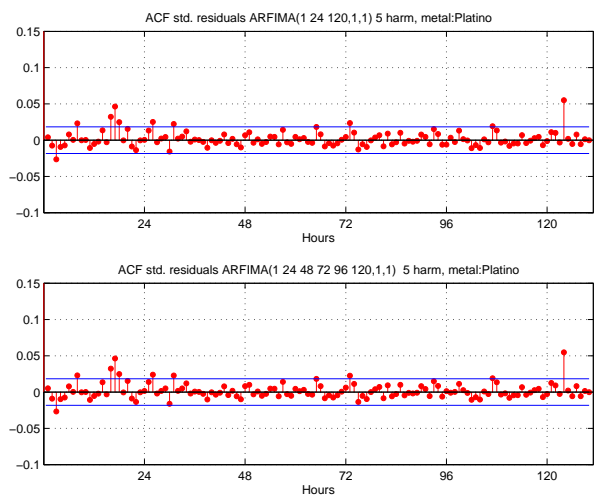

(g) XPT

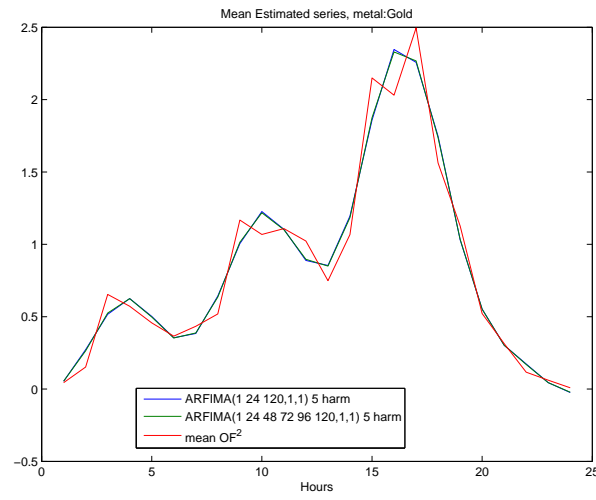

(b) XAU

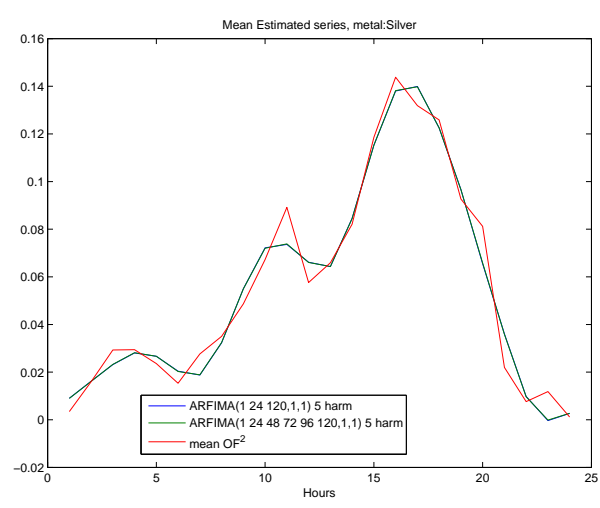

(d) XAG

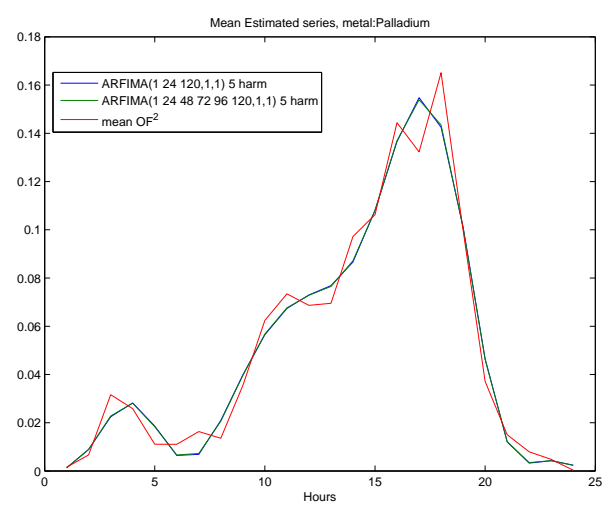

(f) XPD

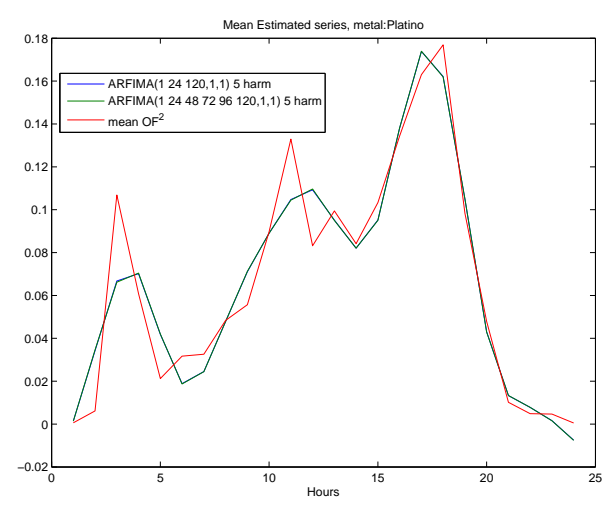

(h) XPT

Figure A.14: ACF standardized squared residuals $O F 2$ and mean estimated series 
Table A.4: Estimation $Q S * 100$ ARFIMA with harmonics

\begin{tabular}{|c|c|c|c|c|c|c|c|c|}
\hline & $\mathrm{XAU}$ & $\mathrm{XAU}$ & XAG & XAG & $\mathrm{XPD}$ & XPD & $\mathrm{XPT}$ & $\mathrm{XPT}$ \\
\hline \multirow[t]{2}{*}{$d_{S}$} & $0.083^{\mathrm{a}}$ & $0.076^{\mathrm{a}}$ & $0.281^{\mathrm{a}}$ & $0.274^{\mathrm{a}}$ & $0.283^{\mathrm{a}}$ & $0.267^{\mathrm{a}}$ & $0.513^{\mathrm{a}}$ & $0.493^{\mathrm{a}}$ \\
\hline & $(0.010)$ & $(0.010)$ & $(0.011)$ & $(0.011)$ & $(0.010)$ & $(0.011)$ & $(0.023)$ & $(0.017)$ \\
\hline \multirow[t]{2}{*}{$\phi_{1}$} & $-0.084^{\mathrm{a}}$ & $-0.072^{\mathrm{a}}$ & 0.033 & $0.056^{\mathrm{c}}$ & -0.031 & 0.006 & 0.079 & $0.080^{\mathrm{c}}$ \\
\hline & $(0.023)$ & $(0.022)$ & $(0.035)$ & $(0.032)$ & $(0.032)$ & $(0.027)$ & $(0.057)$ & $(0.045)$ \\
\hline \multirow[t]{2}{*}{$\phi_{24}$} & $0.104^{\mathrm{a}}$ & $0.090^{\mathrm{a}}$ & $0.153^{\mathrm{a}}$ & $0.130^{\mathrm{a}}$ & $0.163^{\mathrm{a}}$ & $0.120^{\mathrm{a}}$ & $0.123^{\mathrm{a}}$ & $0.106^{\mathrm{a}}$ \\
\hline & $(0.008)$ & $(0.008)$ & (0.009) & (0.009) & $(0.009)$ & $(0.009)$ & $(0.009)$ & $(0.009)$ \\
\hline$\phi_{48}$ & - & $0.036^{\mathbf{a}}$ & - & $0.041^{\mathrm{a}}$ & - & $0.100^{\mathrm{a}}$ & - & $0.070^{\mathrm{a}}$ \\
\hline \multirow[t]{2}{*}{$\phi_{72}$} & - & $0.049^{\mathrm{a}}$ & - & $0.086^{\mathrm{a}}$ & - & $0.102^{\mathrm{a}}$ & - & $0.075^{\mathrm{a}}$ \\
\hline & & $(0.008)$ & & $(0.009)$ & & $(0.009)$ & & $(0.009)$ \\
\hline \multirow[t]{2}{*}{$\phi_{96}$} & - & $0.070^{\mathrm{a}}$ & - & $0.084^{\mathrm{a}}$ & - & $0.077^{a}$ & - & $0.046^{\mathrm{a}}$ \\
\hline & & $(0.008)$ & & (0.009) & & $(0.009)$ & & $(0.009)$ \\
\hline \multirow[t]{2}{*}{$\phi_{120}$} & $0.308^{\mathrm{a}}$ & $0.292^{a}$ & $0.101^{a}$ & $0.076^{\mathrm{a}}$ & $0.168^{a}$ & $0.125^{\mathrm{a}}$ & $0.105^{\mathrm{a}}$ & $0.088^{\mathrm{a}}$ \\
\hline & $(0.008)$ & $(0.008)$ & $(0.009)$ & $(0.009)$ & $(0.009)$ & (0.009) & $(0.009)$ & $(0.009)$ \\
\hline \multirow[t]{2}{*}{$\theta_{1}$} & $0.234^{\mathrm{a}}$ & $0.227^{a}$ & $0.149^{\mathrm{a}}$ & $0.125^{\mathrm{a}}$ & $0.196^{\mathrm{a}}$ & $0.177^{a}$ & -0.071 & -0.053 \\
\hline & $(0.023)$ & $(0.022)$ & $(0.032)$ & $(0.029)$ & $(0.029)$ & $(0.025)$ & $(0.066)$ & $(0.046)$ \\
\hline \multirow[t]{2}{*}{$\mu$} & $-0.132^{a}$ & $-0.134^{\mathrm{a}}$ & $-0.431^{\mathrm{a}}$ & $-0.464^{\mathrm{a}}$ & $-1.172^{\mathrm{a}}$ & $-1.192^{\mathbf{a}}$ & $-4.736^{\mathbf{a}}$ & $-4.891^{\mathrm{a}}$ \\
\hline & $(0.012)$ & $(0.014)$ & $(0.047)$ & $(0.057)$ & $(0.091)$ & $(0.109)$ & $(0.655)$ & $(0.433)$ \\
\hline \multirow[t]{2}{*}{$\gamma_{1}$} & $-0.118^{a}$ & $-0.120^{\mathrm{a}}$ & $-0.152^{\mathrm{a}}$ & $-0.154^{\mathrm{a}}$ & $-0.325^{\mathrm{a}}$ & $-0.324^{\mathrm{a}}$ & $-0.227^{\mathrm{a}}$ & $-0.232^{\mathrm{a}}$ \\
\hline & $(0.009)$ & $(0.011)$ & $(0.008)$ & $(0.010)$ & $(0.016)$ & $(0.022)$ & $(0.012)$ & $(0.016)$ \\
\hline \multirow[t]{2}{*}{$\phi_{1}$} & 0.014 & 0.014 & $-0.060^{\mathbf{a}}$ & $-0.062^{a}$ & $-0.165^{\mathrm{a}}$ & $-0.171^{\mathbf{a}}$ & $-0.064^{\mathrm{a}}$ & $-0.064^{\mathrm{a}}$ \\
\hline & $(0.009)$ & $(0.011)$ & $(0.008)$ & $(0.010)$ & $(0.016)$ & $(0.022)$ & $(0.012)$ & $(0.016)$ \\
\hline \multirow[t]{2}{*}{$\gamma_{2}$} & $-0.100^{\mathbf{a}}$ & $-0.101^{\mathrm{a}}$ & $-0.113^{\mathrm{a}}$ & $-0.114^{\mathrm{a}}$ & $-0.253^{a}$ & $-0.250^{\mathbf{a}}$ & $-0.169^{a}$ & $-0.172^{\mathrm{a}}$ \\
\hline & $(0.008)$ & $(0.011)$ & $(0.006)$ & $(0.008)$ & $(0.013)$ & $(0.018)$ & $(0.009)$ & $(0.011)$ \\
\hline \multirow[t]{2}{*}{$\phi_{2}$} & -0.002 & -0.002 & $-0.030^{\mathbf{a}}$ & $-0.032^{\mathbf{a}}$ & $-0.085^{\mathrm{a}}$ & $-0.085^{a}$ & $-0.063^{a}$ & $-0.065^{\mathrm{a}}$ \\
\hline & $(0.008)$ & $(0.011)$ & $(0.006)$ & $(0.008)$ & $(0.013)$ & $(0.018)$ & $(0.009)$ & $(0.011)$ \\
\hline \multirow[t]{2}{*}{$\gamma_{3}$} & $-0.084^{a}$ & $-0.085^{\mathrm{a}}$ & $-0.076^{\mathbf{a}}$ & $-0.076^{\mathbf{a}}$ & $-0.159^{a}$ & $-0.157^{a}$ & $-0.097^{a}$ & $-0.097^{a}$ \\
\hline & $(0.008)$ & $(0.010)$ & $(0.005)$ & $(0.007)$ & $(0.011)$ & $(0.016)$ & $(0.007)$ & $(0.009)$ \\
\hline \multirow[t]{2}{*}{$\phi_{3}$} & -0.005 & -0.005 & $-0.022^{\mathrm{a}}$ & $-0.023^{\mathrm{a}}$ & $-0.087^{a}$ & $-0.087^{\mathrm{a}}$ & $-0.075^{\mathrm{a}}$ & $-0.076^{\mathrm{a}}$ \\
\hline & $(0.008)$ & $(0.010)$ & $(0.005)$ & $(0.007)$ & $(0.011)$ & $(0.016)$ & $(0.007)$ & $(0.009)$ \\
\hline \multirow[t]{2}{*}{$\gamma_{4}$} & $-0.070^{\mathbf{a}}$ & $-0.071^{\mathbf{a}}$ & $-0.058^{\mathrm{a}}$ & $-0.058^{\mathrm{a}}$ & $-0.096^{\mathbf{a}}$ & $-0.095^{\mathrm{a}}$ & $-0.051^{\mathrm{a}}$ & $-0.051^{\mathrm{a}}$ \\
\hline & $(0.008)$ & $(0.010)$ & $(0.005)$ & $(0.006)$ & $(0.010)$ & $(0.014)$ & $(0.006)$ & $(0.008)$ \\
\hline \multirow[t]{2}{*}{$\phi_{4}$} & -0.009 & -0.009 & $-0.020^{\mathbf{a}}$ & $-0.021^{\mathrm{a}}$ & $-0.080^{\mathrm{a}}$ & $-0.079^{\mathrm{a}}$ & $-0.070^{\mathrm{a}}$ & $-0.071^{a}$ \\
\hline & (0.008) & $(0.010)$ & $(0.005)$ & $(0.006)$ & $(0.010)$ & $(0.014)$ & $(0.006)$ & $(0.008)$ \\
\hline \multirow[t]{2}{*}{$\gamma_{5}$} & $-0.056^{\mathbf{a}}$ & $-0.057^{\mathrm{a}}$ & $-0.039^{\mathrm{a}}$ & $-0.039^{\mathrm{a}}$ & $-0.061^{\mathbf{a}}$ & $-0.059^{\mathrm{a}}$ & $-0.030^{\mathbf{a}}$ & $-0.029^{\mathbf{a}}$ \\
\hline & $(0.008)$ & $(0.010)$ & $(0.004)$ & $(0.006)$ & $(0.009)$ & $(0.013)$ & $(0.005)$ & $(0.007)$ \\
\hline \multirow[t]{2}{*}{$\phi_{5}$} & -0.010 & -0.011 & $-0.013^{\mathrm{a}}$ & $-0.014^{\mathrm{b}}$ & $-0.083^{\mathrm{a}}$ & $-0.083^{\mathrm{a}}$ & $-0.060^{a}$ & $-0.060^{\mathrm{a}}$ \\
\hline & $(0.008)$ & $(0.010)$ & $(0.004)$ & $(0.006)$ & $(0.009)$ & $(0.013)$ & $(0.005)$ & $(0.007)$ \\
\hline \multirow[t]{2}{*}{$\sigma$} & $0.130^{\mathrm{a}}$ & $0.128^{\mathrm{a}}$ & $0.075^{\mathrm{a}}$ & $0.074^{\mathrm{a}}$ & $0.253^{\mathrm{a}}$ & $0.245^{\mathrm{a}}$ & $0.140^{\mathrm{a}}$ & $0.138^{\mathrm{a}}$ \\
\hline & $(0.001)$ & $(0.001)$ & $(0.000)$ & $(0.000)$ & $(0.003)$ & $(0.003)$ & $(0.001)$ & $(0.001)$ \\
\hline$L L F$ & -4742.710 & -4674.295 & -1520.893 & -1400.621 & -8712.461 & -8508.625 & -5210.185 & -5122.007 \\
\hline
\end{tabular}

Note: Estimation results for the $Q S * 100$ series for the precious metals: Gold (XAU), Silver (XAG), Palladium (XPD) and Platinum (XPT). ARFIMA models. Period 27th of December 2008 to the 30th of November 2010. Hourly series, 11880 observations. $L L F$ is the Log-likelihood function. Standard errors in bracket. "a", "b" and "c" indicate significance at the $1 \%, 5 \%$ and $10 \%$. 


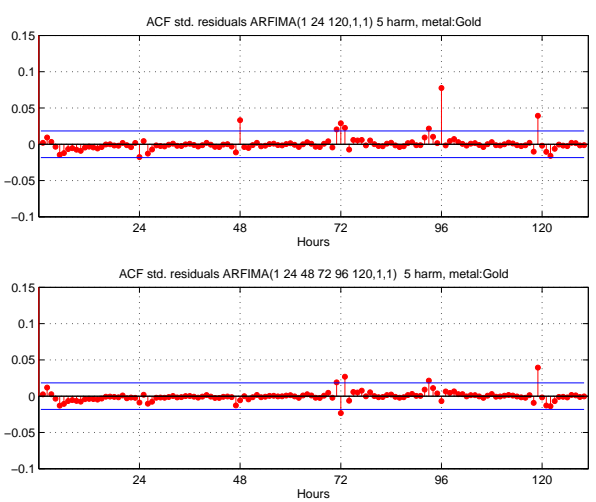

(a) XAU
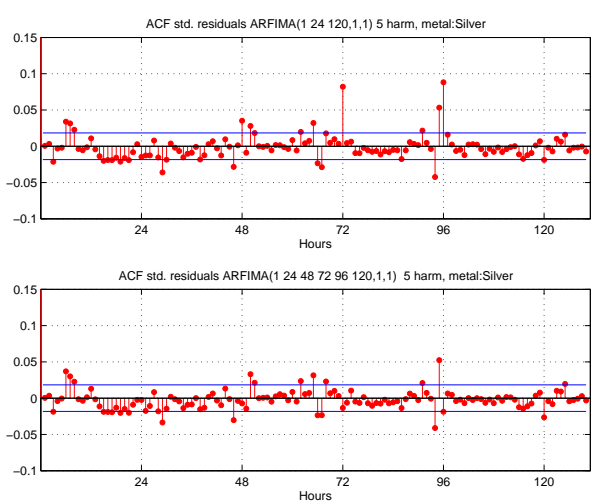

(c) XAG
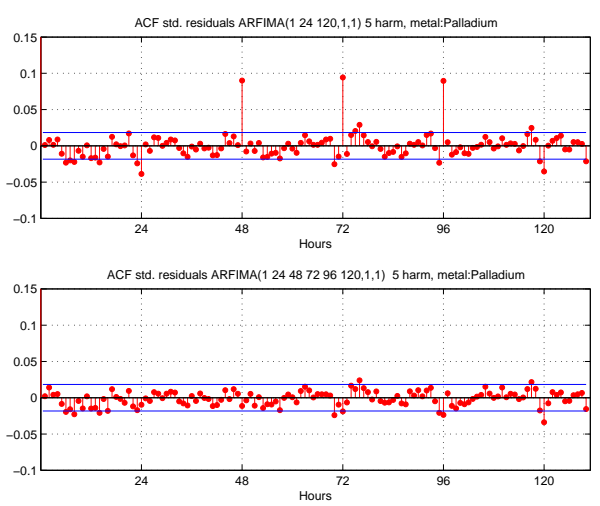

(e) XPD
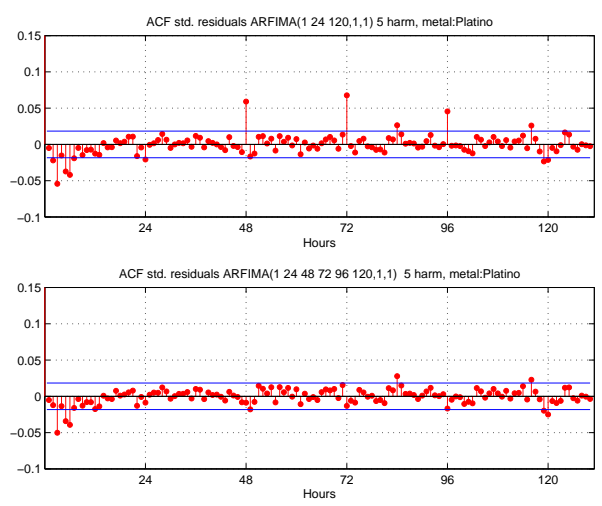

(g) XPT

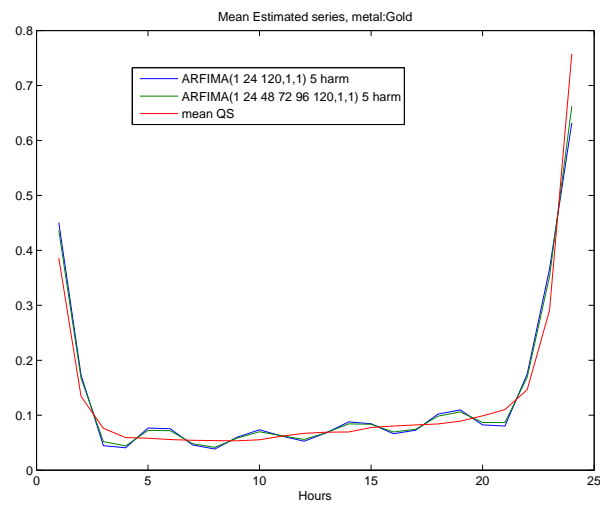

(b) XAU

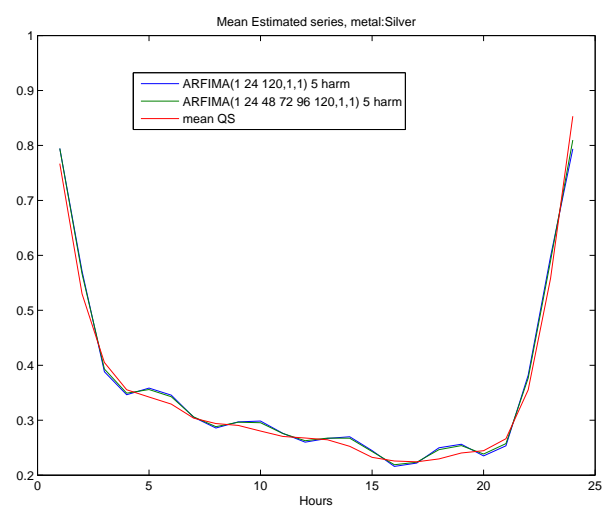

(d) XAG

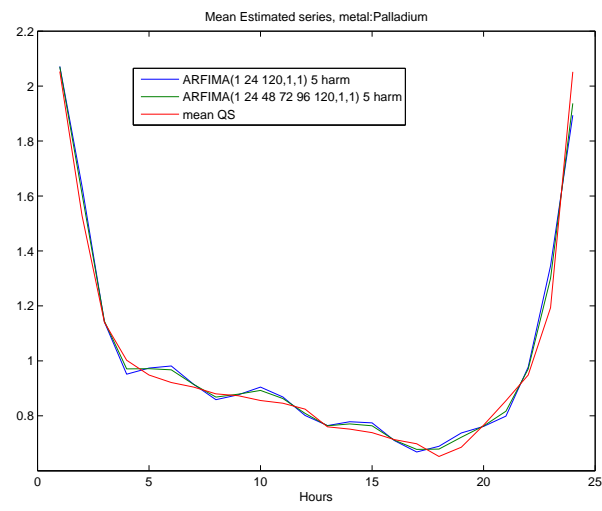

(f) XPD

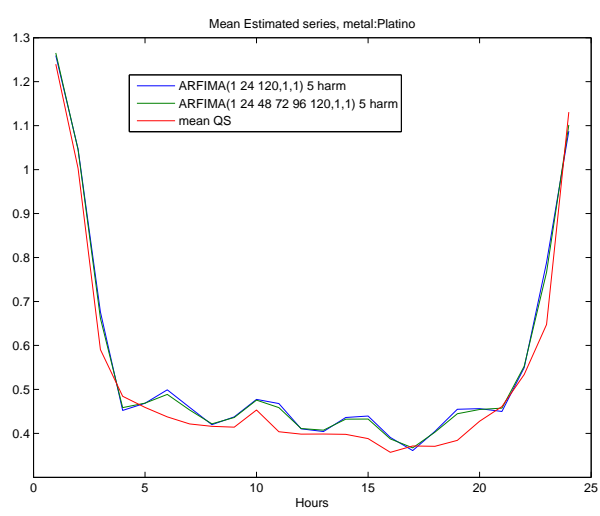

(h) XPT

Figure A.15: ACF standardized squared residuals $Q S$ and mean estimated series 